Universidade de São Paulo-USP

Escola de Engenharia de São Carlos

Departamento de Engenharia Elétrica e de Computação Programa de Pós-Graduação em Engenharia Elétrica

Willian Martins Leão

\title{
Análise Comparativa de Controladores Robustos Aplicados em Robôs Móvel e Aéreo
}





\section{Willian Martins Leão}

\section{Análise Comparativa de Controladores Robustos Aplicados em Robôs Móvel e Aéreo}

Dissertação de mestrado apresentada ao Programa de Engenharia Elétrica da Escola de Engenharia de São Carlos como parte dos requisitos para a obtenção do título de Mestre em Ciências.

Área de concentração: Sistemas Dinâmicos

Orientador: Prof. Dr. Marco Henrique Terra

\section{São Carlos} EESC/USP que aloja o Programa de Pós-Graduação de Engenharia Elétrica. 
AUTORIZO A REPRODUÇÃO TOTAL OU PARCIAL DESTE TRABALHO, POR QUALQUER MEIO CONVENCIONAL OU ELETRÔNICO, PARA FINS DE ESTUDO E PESQUISA, DESDE QUE CITADA A FONTE.

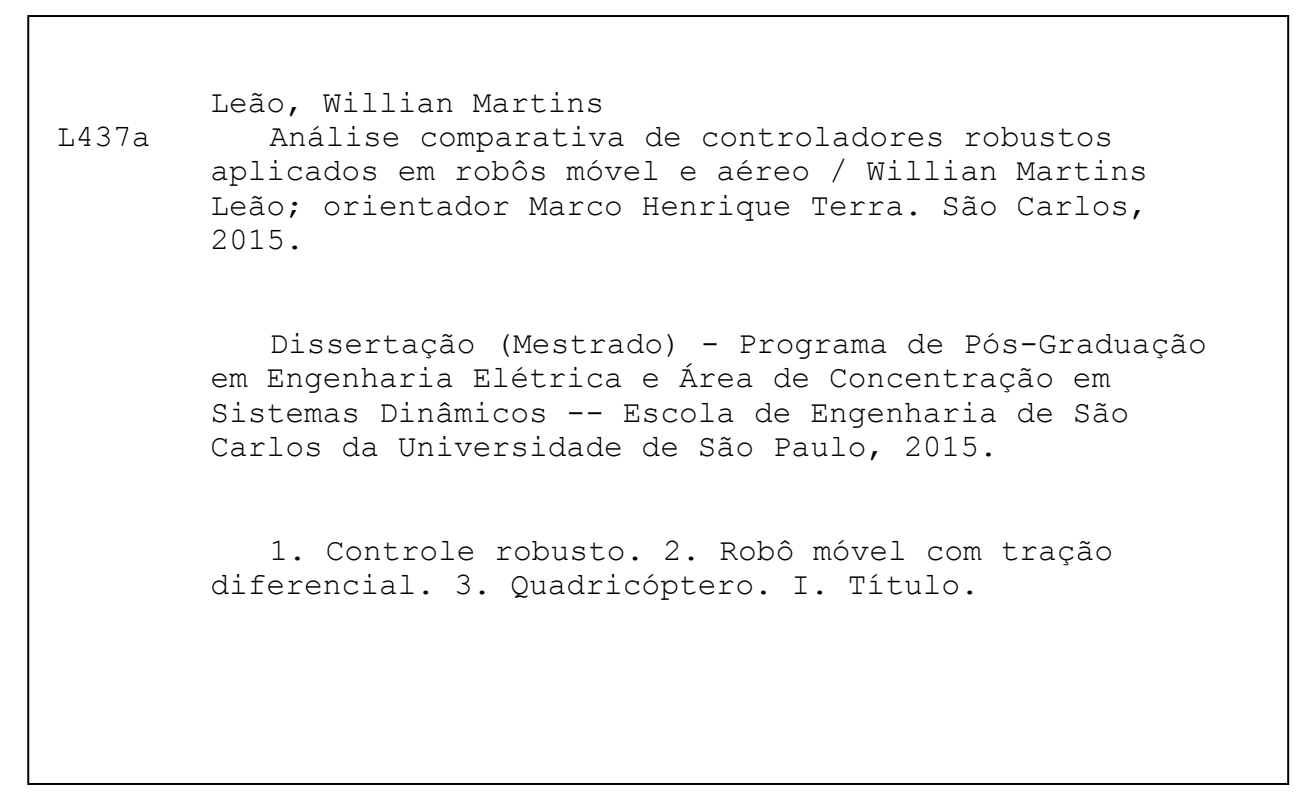




\section{FOLHA DE JULGAMENTO}

Candidato: Engenheiro WILLIAN MARTINS LEĀO.

Título da dissertação: "Análise comparativa de controladores robustos aplicados em robôs móvel e aéreo".

Data da defesa: 09/09/2015

\section{Comissão Julgadora:}

Prof. Associado Marco Henrique Terra (Orientador) (Escola de Engenharia de São Carlos/EESC)

\section{Prof. Dr. José Paulo Vilela Soares da Cunha}

APROVADP

Resultado:

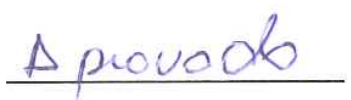

(Universidade do Estado do Rio de Janeiro/UERJ)

Prof. Associado Adriano Almeida Gonçalves Siqueira (Escola de Engenharia de São Carlos/EESC)

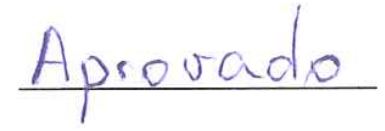

Coordenador do Programa de Pós-Graduação em Engenharia Elétrica: Prof. Associado Luis Fernando Costa Alberto

Presidente da Comissão de Pós-Graduação:

Prof. Associado Paulo César Lima Segantine 

Este trabalho é dedicado aos meus pais, José e Helena, e ao meu primo Wilson, pelo incentivo e apoio em todas as minhas escolhas e decisões. 



\section{Agradecimentos}

A Deus pela benção da oportunidade e o privilégio de realizar mais esse sonho. Além disso, por ter colocado pessoas tão especiais ao meu lado, com as quais foi possível realizar esse trabalho.

À minha família, pelo carinho, pelo incentivo e, principalmente, pela compreensão da minha ausência em vários momentos.

Ao meu orientador, Prof. Dr. Marco Henrique Terra, meus sinceros agradecimentos pela competência e simpatia nas valiosas discussões durante o andamento da pesquisa, que contribuíram no desenvolvimento desta dissertação.

Ao Prof. Dr. Roberto Santos Inoue pela atenção, incentivo e disposição em contribuir para a realização do meu mestrado.

Aos professores e funcionários do Departamento de Engenharia Elétrica da Escola de Engenharia de São Carlos, pelas contribuições durante o mestrado.

Aos amigos do LASI e demais laboratórios da Engenharia Elétrica, pela paciência, companheirismo e colaborações durante a realização das disciplinas e deste trabalho.

Ao Conselho Nacional de Desenvolvimento Científico e Tecnológico (CNPq) pela concessão da bolsa de mestrado.

À Fundação de Amparo à Pesquisa do Estado de São Paulo (FAPESP) pelo financiamento dos equipamentos e materiais utilizados neste projeto. 

"A coisa mais indispensável a um homem é reconhecer o uso que deve fazer do seu próprio conhecimento." 



\section{Resumo}

Leão, W.M. Análise Comparativa de Controladores Robustos Aplicados em Robôs Móvel e Aéreo. 78 p. Dissertação de mestrado - Escola de Engenharia de São Carlos, Universidade de São Paulo, 2015.

Nesta dissertação é realizado um estudo comparativo entre controladores robustos projetados para sistemas lineares em espaço de estado sujeitos a incertezas paramétricas. O objetivo é resolver problemas de acompanhamento de trajetória de robôs. O estudo é realizado em um robô móvel com tração diferencial e em um quadricóptero. Para tal, é aplicado um Regulador Linear Quadrático Robusto no qual engloba em uma estrutura unificada todos os parâmetros de incerteza de entrada e saída de maneira recursiva, útil em aplicações em tempo real. A fim de demonstrar a eficiência do Regulador Robusto, resultados de simulações e de experimentos são empregados comparando-o com controle $\mathcal{H}_{\infty}$ não linear via teoria dos jogos e com um controle Proporcional-Derivativo mais torque calculado.

Palavras-chave: Controle robusto. Robô móvel com tração diferencial. Quadricóptero. 



\section{Abstract}

Leão, W.M. Comparative Analysis of Robust Controllers Applied in Mobile and Aerial Robots. 78 p. Master Thesis - São Carlos School of Engineering, University of São Paulo, 2015.

This work provides a comparative study between robust controllers for linear statespace systems subject to parametric uncertainties to solve trajectory tracking problems. The study is developed in a mobile robot with differential traction and in a quadricopter. A Robust Linear Quadratic Regulator is applied, which encompasses in a unified framework all input and output uncertain parameters, useful in online applications. In order to show the effectiveness of the robust regulator, simulations and experiments results allow the comparison with nonlinear $\mathcal{H}_{\infty}$ control via game theory and with a ProportionalDerivative control plus computed torque.

Keywords: Robust control. Differential drive mobile robot. Quadricopter. 



\section{Lista de ilustrações}

Figura 1 Esquemático do robô móvel. . . . . . . . . . . . . . . . . . . . . . 27

Figura 2 Sistema de coordenadas inercial e do corpo de um quadricóptero . . . . 35

Figura 3 Resultados de simulação com Regulador Linear Quadrático Robusto (RLQ-R) no robô móvel com tração diferencial (RMTD). . . . . . . . . 51

Figura 4 Resultados de simulação com controlador $\mathcal{H}_{\infty}$-TJ no RMTD. . . . . . . 51

Figura 5 Resultados de simulação com controlador PD no RMTD. . . . . . . . . 52

Figura 6 Simulador do quadricóptero. . . . . . . . . . . . . . . . . . . . . 52

Figura 7 Diagrama de blocos da simulação. . . . . . . . . . . . . . . 53

Figura 8 Curva em escala logarítmica da média do erros quadráticos da posição. 55

Figura 9 Curva em escala logarítmica da média do erros quadráticos da atitude. 55

Figura 10 Posição do quadricóptero com o controlador RLQ-R. . . . . . . . . . . . 55

Figura 11 Atitude do quadricóptero com o controlador RLQ-R. . . . . . . . . . . 56

Figura 12 Posicionamento das câmeras T40S no laboratório. . . . . . . . . . . . 57

Figura 13 Marcador reflexivo. . . . . . . . . . . . . . . . . . . 58

Figura 14 Câmera Vicon ${ }^{\circledR}$ modelo T-series T40S. . . . . . . . . . . . . . . . . . . 58

Figura 15 Computador das câmeras e o software Tracker. . . . . . . . . . . . . . 59

Figura 16 Robô móvel com tração diferencial construído. . . . . . . . . . . . . . . 60

Figura 17 Modelo do robô móvel no software Inventor. . . . . . . . . . . . . . . . 60

Figura 18 Infraestrutura de comunicação para o controle do RMTD. . . . . . . . . 61

Figura 19 Diagrama de blocos do controle de acompanhamento de trajetória do RMTD. . . . . . . . . . . . . . . . . . 6 6

Figura 20 Trajetória do robô móvel. . . . . . . . . . . . . . . . . . 63

Figura 21 Resultados experimentais com RLQ-R no RMTD. . . . . . . . . . . . . 63

Figura 22 Resultados experimentais com $\mathcal{H}_{\infty}$-Teoria dos Jogos (TJ) no RMTD. . 64

Figura 23 Resultados experimentais com controlador Proporcional-Derivativo (PD) no RMTD. . . . . . . . . . . . . . . . . . . . . . . . . . 64 
Figura 24 Interface PCTx. . . . . . . . . . . . . . . . . . . 66

Figura 25 Layout da placa da interface PC-rádio. . . . . . . . . . . . . . . 67

Figura 26 Esquemático da interface PC-rádio. . . . . . . . . . . . . . . . . 68

Figura 27 Interface PC-rádio construída. . . . . . . . . . . . . . . . 68

Figura 28 Sinal PPM para 9 canais. . . . . . . . . . . . . . . . . . . 69

Figura 29 Rádio DX7s da Spectrum. . . . . . . . . . . . . . . . 69 


\section{Lista de tabelas}

Tabela 1 Regulador Linear Quadrático Robusto . . . . . . . . . . . . 43

Tabela 2 Parâmetros do RMTD. . . . . . . . . . . . . . . . . . 61

Tabela 3 Comparativo entre os controladores. . . . . . . . . . . 65

Tabela 4 Lista de materiais do circuito eletrônico . . . . . . . . . . . . . 67 



\section{Lista de siglas}

CC Corrente Contínua

CDC Communication Device Class

HID Human Interface Device

LASI Laboratório de Sistemas Inteligentes

quase-LPV quase linear com parâmetros variantes

PD Proporcional-Derivativo

PPM Pulse Position Modulation

PWM Pulse Width Modulation

RLQ-R Regulador Linear Quadrático Robusto

RMTD robô móvel com tração diferencial

TJ Teoria dos Jogos

VANTs Veículos Aéreos Não-Tripulados 



\section{Sumário}

1 Introdução 23

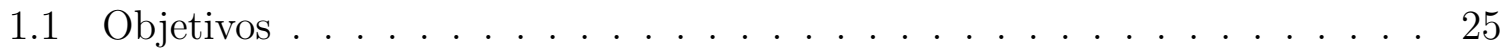

1.2 Disposição dos capítulos . . . . . . . . . . . . . . . . . . . 25

2 Robô móvel com tração diferencial $\quad 27$

2.1 Modelo Cinemático . . . . . . . . . . . . . . . . . . . . . . . . . . 28

2.2 Modelo Dinâmico . . . . . . . . . . . . . . . . . . . . . . . 29

2.3 Modelo do Motor de Corrente Contínua . . . . . . . . . . . . . . . . . . 30

2.4 Formulação do problema para o RMTD . . . . . . . . . . . . . . . . . 31

2.5 Trajetória de Referência para o RMTD . . . . . . . . . . . . . . . . . 33

3 Quadricóptero $\quad 35$

3.1 Modelo Dinâmico . . . . . . . . . . . . . . . . . . . . . . . 36

3.2 Formulação do problema para o Quadricóptero . . . . . . . . . . . . . . 37

3.3 Trajetória de Referência para o quadricóptero . . . . . . . . . . . . . . . 38

4 Controladores $\quad 41$

4.1 Regulador Linear Quadrático Robusto . . . . . . . . . . . . . . . . . 41

4.2 Controlador $\mathcal{H}_{\infty}$ via teoria dos jogos . . . . . . . . . . . . . . . . . 43

4.3 Controlador Proporcional-Derivativo . . . . . . . . . . . . . . . . . 46

4.4 Controlador Cinemático . . . . . . . . . . . . . . . . . . . . . . . 47

4.5 Determinação dos ângulos de referência . . . . . . . . . . . . . . . . . 47

5 Simulações $\quad 49$

5.1 Simulações para o RMTD . . . . . . . . . . . . . . . . . . . . . . . . . 49

5.1 .1 Parâmetros do Controlador Cinemático . . . . . . . . . . . . . 50

5.1 .2 Parâmetros do RLQ-R . . . . . . . . . . . . . . . . . . . . 50

5.1.3 Parâmetros do controlador $\mathcal{H}_{\infty}$-TJ . . . . . . . . . . . . . . . . . 50

5.1.4 Parâmetros do controlador PD . . . . . . . . . . . . . . . 50 
5.1.5 Resultados de Simulação . . . . . . . . . . . . . . . . . . 50

5.2 Simulações para o quadricóptero . . . . . . . . . . . . . . . . . . 52

5.2.1 Parâmetros Determinação de Trajetória . . . . . . . . . . . . . . 53

5.2 .2 Parâmetros do RLQ-R . . . . . . . . . . . . . . . 54

5.2.3 Parâmetros do controlador $\mathcal{H}_{\infty}$-TJ . . . . . . . . . . . . . . . . . 54

5.2.4 Parâmetros do controlador PD . . . . . . . . . . . . . . . . . 54

5.2.5 Resultados de Simulação . . . . . . . . . . . . . . 54

$6 \quad$ Resultados Experimentais $\quad 57$

6.1 Resultados Experimentais do RMTD . . . . . . . . . . . . . . 57

6.1 .1 Câmeras da Vicon . . . . . . . . . . . . . . . . . . 57

6.1.2 Projeto do robô móvel . . . . . . . . . . . . . . . . . . . . . 59

6.1.3 Organização dos Experimentos . . . . . . . . . . . . . . . . . . . 61

6.1.4 Análise dos Experimentos . . . . . . . . . . . . . . 65

6.2 Interface de comunicação para VANTs . . . . . . . . . . . . . . . 66

6.2.1 Circuito Eletrônico . . . . . . . . . . . . . . . . . . 67

6.2.2 Comunicação do Rádio . . . . . . . . . . . . . . . . . 68

$\begin{array}{ll}\text { Conclusão } & 71\end{array}$

$\begin{array}{ll}\text { Referências } & 73\end{array}$ 


\section{Introdução}

Este trabalho compara técnicas para o acompanhamento de trajetória de um robô móvel com tração diferencial (RMTD) e um quadricóptero. Esses sistemas estão sujeitos a incertezas paramétricas, as quais exigem que o controle possua robustez suficiente para desempenhar uma tarefa pré-determinada.

O termo robô móvel ao longo do texto será utilizado sempre fazendo referência ao robô móvel com tração diferencial (RMTD).

Os modelos matemáticos utilizados para representar os robôs móveis são diversos, podendo ser baseados na cinemática (CAMPION; BASTIN; DANDREA-NOVEL, 1996; COELHO; NUNES, 2003) ou na dinâmica (COELHO; NUNES, 2003) . O modelo cinemático considera a posição e suas derivadas sem considerar as forças que causam o movimento. Já o modelo dinâmico considera as forças envolvidas, o que é interessante em situações de elevada velocidade, em transportes de cargas e em aplicações que demandam maior precisão. Todo modelo tem sua peculiaridade, o que o torna mais importante de acordo com o propósito ou com as informações que o usuário deseja observar.

Diversos métodos de controle têm sido utilizados em robôs móveis como: backstepping (CHWA, 2010; ANEESH, 2012), preditivo (BREZAK; PETROVIC; PERIC, 2009; MAUROVIC; BAOTIC; PETROVIC, 2011), $\mathcal{H}_{\infty}$ (REIS; SIQUEIRA; TERRA, 2005; RIGATOS; SIANO, 2014), fuzzy (RASHID et al., 2010) e controladores adaptativos (FENG; KOREN; BORENSTEIN, 1994; DONG; SUN; TSO, 2002).

Atualmente, os Veículos Aéreos Não-Tripulados (VANTs) são utilizados por diversos setores da economia, tais como agricultura, indústria, comercial e predial. Isso ocorreu principalmente devido à crescente disponibilidade de recursos computacionais de alto desempenho, avanços em tecnologias de transmissão de dados e de posicionamento global, o que permitiu o desenvolvimento de aeronaves mais confiáveis e versáteis e a diminuição dos custos de construção desses veículos (INOUE, 2011).

A popularidade de pesquisas com VANTs se deve à sua simplicidade de construção e manutenção, habilidade de pairar e capacidade de decolagem e pouso vertical (HOFFMANN et al., 2007). Em Bills, Chen e Saxena (2011), experimentos com quadricópteros foram re- 
alizados para navegação autônoma visual em ambientes estruturados. Em Bills e Yosinski (2010), abordagens de aprendizado de máquinas foram aplicadas para predizer erros de posição de acompanhamento de trajetória do voo de um quadricóptero. Além disso, esse tipo de aeronave tem sido utilizado em aplicações de vigilância autônoma (FAIGL et al., 2010), interação homem-máquina (NG; SHARLIN, 2011), e até mesmo como assistente de esporte (HIGUCHI; SHIMADA; REKIMOTO, 2011).

Entretanto, para realizar o controle, sem a presença de um operador, desse tipo de veículo é interessante conhecer o seu modelo matemático (LUUKKONEN, 2011). Assim, em Hoffmann et al. (2007) e Huang et al. (2009) foi estudado o modelo dinâmico do quadricóptero com adição de propriedades aerodinâmicas mais complexas. Já em relação ao controle, diferentes estratégias vêm sendo utilizadas: controladores PID (ZUO, 2010; BOUABDALLAH; NOTH; SIEGWART, 2004), controle backstepping (ZEMALACHE; BEJI; MARREF, 2005), controle $\mathcal{H}_{\infty}$ (RAFFO; ORTEGA; RUBIO, 2010), RLQ (BOUABDALLAH; NOTH; SIEGWART, 2004), e controladores não lineares com saturações (CASTILLO; LOZANO; DZUL, 2005; ESCARENO; SALAZAR-CRUZ; LOZANO, 2006).

Nos sistemas mecânicos caracterizados por restrições cinemáticas não holonômicas, como é o caso do RMTD e do quadricóptero, não há garantia de que um ponto de equilíbrio seja assintoticamente estável através de uma lei de realimentação de estados suave e invariante no tempo, conforme em Bloch e McClamroch (1989), Bloch e Reyhanoglu (1990), Oriolo, Luca e Vendittelli (2002) baseados nos resultados de Brockett (1983). Essa limitação não é superada com a teoria de controle linear clássica, por isso é necessária a pesquisa com outros métodos como os exemplos e referências citados em Kolmanovsky e McClamroch (1995), onde abordagens como: estabilização descontínua invariante no tempo, estabilização variante no tempo e métodos híbridos estão sendo utilizados para superar esse problema.

Além disso, incertezas nos modelos dos robôs são comuns e responsáveis em degradar os resultados de controle. As fontes de incertezas podem ser provenientes de: mudanças das características dos robôs; incertezas e imprecisões nas medições dos parâmetros; nãolinearidades; simplificações do modelo e desconhecimento de determinados parâmetros. Estudos envolvendo incertezas no sistema de controle têm sido relevantes nas últimas décadas, ao ponto de surgir a área de teoria de controle conhecida como Controle Robusto. Trabalhos de controle envolvendo incertezas podem ser vistos em Park et al. (2009), Hwang e Wu (2013), Martins et al. (2008), Hu, Ge e Su (2004) e Khalaji e Moosavian (2014).

Em Terra, Cerri e Ishihara (2014) foi desenvolvido um regulador robusto recursivo baseado em função penalidade (LUENBERGER, 2003) e mínimos quadrados regularizados robustos (SAYED; NASCIMENTO, 1999). A principal característica do controlador ótimo robusto é a independência de parâmetros de ajuste em aplicações de tempo real. Sua implementação computacional depende somente de ponderações e matrizes de parâmetros 
conhecidas a priori.

Outro inconveniente, em geral, é a negligência da dinâmica do atuador no modelo dos robôs móveis, o que se torna mais uma fonte de incerteza. Trabalhos como os apresentados em Park et al. (2010), Hou et al. (2009) e Shojaei e Shahri (2012) incorporam no desenvolvimento de seus controladores a dinâmica do motor. Essa abordagem emprega a tensão elétrica como entrada de controle ao invés do torque, obtendo uma melhor aproximação da implementação prática.

Uma inovação na aplicação com robôs é o uso de sistemas óticos de captura de movimento. Esses sistemas são baseados na coleta de sequências de imagens as quais são analisadas para rastrear e localizar um dado objeto no espaço. Além disso, eles são imunes a distúrbios como vibração, mudança de temperatura e interferências eletromagnéticas, como é o caso de unidades de medida inercial e podem fornecer medidas com alta precisão. O emprego desses sistemas está presente em aplicações tais como: reabilitação (LI et al., 2012; METCALF et al., 2013; ZONG; CLADY; CHETOUANI, 2011); robôs humanoides (AZAD et al., 2007; KANG et al., 2012); robôs manipuladores (DUBE, 2013); robôs cirúrgicos (LARIBI et al., 2012; LARIBI et al., 2013); robôs móveis (ZARROUK; SHARF; SHOHAM, 2012; SHAN; WANG, 2013); VANTs (DAVIS; NIZETTE; YU, 2013; ABEYWARDENA et al., 2014; CUI; INANC, 2012).

\subsection{Objetivos}

Levando-se em conta o cenário exposto, o objetivo deste trabalho é a comparação entre controladores em sistemas lineares em espaço de estados sujeitos a incertezas paramétricas. Essa pesquisa lida com problemas de acompanhamento de trajetória em um RMTD e em um quadricóptero. Os controladores abordados são o Regulador Linear Quadrático Robusto (RLQ-R), o $\mathcal{H}_{\infty}$ via teoria dos jogos e o controlador Proporcional-Derivativo (PD). No modelo dinâmico do RMTD será incluído a dinâmica do motor a fim de obter melhores resultados e aproximar análise do problema real.

Para isso, experimentos foram conduzidos através de um sistema comercial de captura de movimento da fabricante Vicon ${ }^{\circledR}$, o qual é baseado em rastreio de objetos por marcadores infravermelhos, o que garante robustez na detecção.

Outra contribuição almejada foi o desenvolvimento de uma interface de comunicação com VANTs no Laboratório de Sistemas Inteligentes (LASI).

\subsection{Disposição dos capítulos}

No Capítulo 2, são descritos os modelos envolvidos no RMTD e no quadricóptero. No modelo dinâmico do robô móvel é incluído o atuador.

No Capítulo 3, é realizada uma descrição sobre os controladores utilizados. 
No Capítulo 4, é abordado o desenvolvimento das trajetórias para o RMTD e o quadricóptero.

No Capítulo 5, é exposta a simulação de controle de acompanhamento de trajetória do RMTD e do quadricóptero.

No Capítulo 6, são apresentados os detalhes dos experimentos no RMTD através do sistema de captura de movimento. Além disso, a interface desenvolvida de comunicação entre o computador e o rádio do quadricóptero é mostrada.

No Capítulo 7, as conclusões e propostas de trabalhos futuros são apontadas. 


\section{Robô móvel com tração diferencial}

O robô móvel com tração diferencial (RMTD) é um robô composto de duas acionadas por motores e uma roda passiva. O movimento do robô é gerado através da diferença de velocidade entre as rodas motorizadas da direita e esquerda. No entanto, não é possível realizar deslocamento no sentido lateral, o que leva esse robô a ser considerado um sistema não-holonômico, ou seja, um sistema com dimensão finita onde é imposto uma ou mais restrições nos seus estados (FIGUEIREDO; JOTA, 2004).

O esquemático do robô é dado na Figura 1, sendo: (X,Y) os eixos do sistema de coordenada inercial; $\left(\mathrm{X}_{c}, \mathrm{Y}_{c}\right)$ os eixos do sistema de coordenada local fixados no centro de massa $P_{c} ; d$ a distância entre o centro de massa $P_{c}$ e o ponto médio $P_{0}$ entre os eixos das rodas acionadas; $b$ a distância entre as rodas acionadas e o eixo de simetria do robô; $r$ o raio das rodas acionadas; $\alpha$ a orientação do robô, correspondendo ao ângulo entre o eixo de $\mathrm{X}_{c}$ do sistema de coordenada local e o eixo $X$ do sistema de coordenada inercial; $\theta_{d}$ e $\theta_{e}$ os deslocamentos angulares da roda da direita e esquerda, respectivamente.

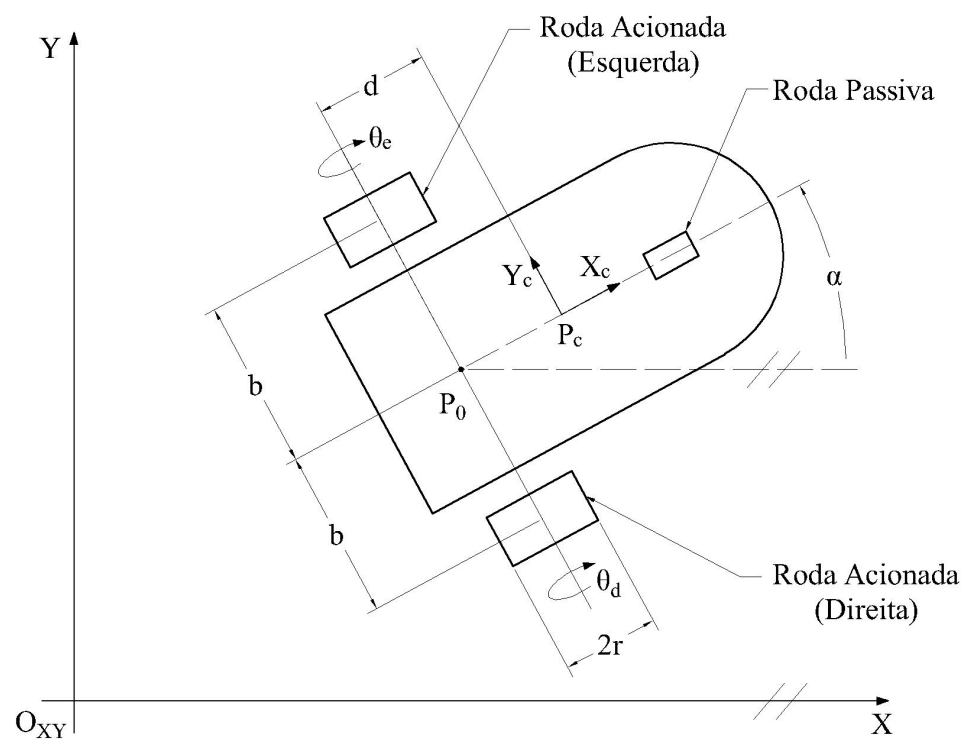

Figura 1 - Esquemático do robô móvel. 
Este capítulo é dividido em cinco seções. A primeira apresenta o modelo cinemático do RMTD baseado em restrições impostas no robô. Na segunda seção é exposto o modelo dinâmico do robô. Na terceira seção é demonstrado o modelo do motor de corrente contínua a ser incorporado ao modelo dinâmico do robô. Na quarta seção é mostrado o modelo dinâmico modificado e a formulação do problema de seguimento de trajetória na forma de espaço de estados a qual será usada para os cálculos dos ganhos dos controladores. E por fim, na quinta seção é dado as equações da trajetória circular de referência utilizada na avaliação do controle para o seguimento de trajetória.

\subsection{Modelo Cinemático}

Segundo Coelho e Nunes (2003), o modelo apresentado na Figura 1 possui três restrições cinemáticas. A primeira restrição é a velocidade em $P_{0}$ está na direção do eixo de simetria (no eixo $X_{c}$ ), logo temos em relação à $P_{c}$ a equação dada por

$$
\dot{y}_{c} \cos \alpha-\dot{x}_{c} \operatorname{sen} \alpha-d \dot{\alpha}=0
$$

sendo $\left(x_{c}, y_{c}\right)$ as coordenadas do centro de massa $P_{c}$ no sistema de coordenada inercial, e $\alpha$ o ângulo entre o eixo simetria do robô e o eixo $X$.

A segunda e a terceira restrições são definidas a partir do pressuposto de que as rodas do robô não deslizam, ou seja, não giram em falso, assim temos as equações dadas como

$$
\begin{aligned}
& \dot{x}_{c} \cos \alpha+\dot{y}_{c} \operatorname{sen} \alpha+b \dot{\alpha}-r \dot{\theta}_{d}=0, \\
& \dot{x}_{c} \cos \alpha+\dot{y}_{c} \operatorname{sen} \alpha-b \dot{\alpha}-r \dot{\theta}_{e}=0 .
\end{aligned}
$$

Definindo o vetor $q_{1}=\left[x_{c} y_{c} \alpha \theta_{d} \theta_{e}\right]$, as restrições podem ser expressadas na forma

$$
A\left(q_{1}\right) \dot{q}_{1}=\left[\begin{array}{ccccc}
-\operatorname{sen} \alpha & \cos \alpha & -d & 0 & 0 \\
-\cos \alpha & -\operatorname{sen} \alpha & -b & r & 0 \\
-\cos \alpha & -\operatorname{sen} \alpha & b & 0 & r
\end{array}\right] \dot{q}_{1}=0
$$

A matriz $A_{c}\left(q_{1}\right)$ tem posto completo e pode ser particionada em duas matrizes na forma $A_{c}\left(q_{1}\right)=\left[A_{1}\left(q_{1}\right)_{(3 \times 3)} A_{2(3 \times 2)}\right]$. Como $A_{1}\left(q_{1}\right)$ é não singular, logo é possível encontrar uma matriz $S_{c}\left(q_{1}\right)$, dada na Equação 2, cujas colunas são o espaço nulo de $A_{c}\left(q_{1}\right)$, ou seja, $A_{c}\left(q_{1}\right) S\left(q_{1}\right)=0$.

$$
S_{c}\left(q_{1}\right)=\left[\begin{array}{cc}
\frac{r}{2 b}(b \cos \alpha-d \operatorname{sen} \alpha) & \frac{r}{2 b}(b \cos \alpha+d \operatorname{sen} \alpha) \\
\frac{r}{2 b}(b \operatorname{sen} \alpha+d \cos \alpha) & \frac{r}{2 b}(b \operatorname{sen} \alpha-d \cos \alpha) \\
\frac{r}{2 b} & -\frac{r}{2 b} \\
1 & 0 \\
0 & 1
\end{array}\right]
$$


Essa matriz $S_{c}\left(q_{1}\right)$ permite transformar as velocidades angulares das rodas atuadas nas velocidades do ponto $P_{c}$ no sistema de coordenadas inercial, e portanto a equação cinemática do robô móvel será dada por

$$
\dot{q}_{1}(t)=S_{c}\left(q_{1}\right) \dot{q}_{2}(t)
$$

sendo $\dot{q}_{2}=\left[\dot{\theta}_{d} \dot{\theta}_{e}\right]^{T}$ o vetor de velocidades angulares das rodas.

Para maiores detalhes do modelo cinemático veja Coelho e Nunes (2003).

\subsection{Modelo Dinâmico}

A equação dinâmica do RMTD foi elaborada a partir da teoria de Lagrange conforme em Coelho e Nunes (2003) como

$$
M\left(q_{1}\right) \ddot{q}_{1}+C\left(q_{1}, \dot{q}_{1}\right) \dot{q}_{1}=E \tau-A^{T}\left(q_{1}\right) \lambda
$$

sendo: $\lambda=\left[\begin{array}{lll}\lambda_{1} & \lambda_{2} & \lambda_{3}\end{array}\right]^{T}$ o vetor de forças de restrições; $E=\left[\begin{array}{ll}0_{(2 \times 3)} & I_{(2 \times 2)}\end{array}\right]^{T}$ a matriz de entrada; $\tau=\left[\begin{array}{ll}\tau_{d} & \tau_{e}\end{array}\right]^{T}$ o vetor de entrada (torque nas rodas);

$$
C\left(q_{1}, \dot{q}_{1}\right)=\left[\begin{array}{ccccc}
0 & 0 & 2 m d \dot{\alpha} \cos \alpha & 0 & 0 \\
0 & 0 & 2 m d \dot{\alpha} \operatorname{sen} \alpha & 0 & 0 \\
& 0_{(3 \times 5)} & &
\end{array}\right]
$$

é a matriz de forças de Coriolis e centrípeta; e

$$
M\left(q_{1}\right)=\left[\begin{array}{ccccc}
m & 0 & 2 m d \operatorname{sen} \alpha & 0 & 0 \\
0 & m & -2 m d \cos \alpha & 0 & 0 \\
2 m d \operatorname{sen} \alpha & -2 m d \cos \alpha & I & 0 & 0 \\
0 & 0 & 0 & I_{r} & 0 \\
0 & 0 & 0 & 0 & I_{r}
\end{array}\right]
$$

é a matriz de inércia. Os parâmetros $m$ e $I$ são dados por

$$
\begin{gathered}
m=m_{p}+2 m_{r} \mathrm{e} \\
I=I_{c}+2 m_{r}\left(d^{2}+b^{2}\right)+2 I_{m},
\end{gathered}
$$

sendo: $m_{r}$ a massa de cada roda acionada mais a massa do rotor do motor; $m_{p}$ a massa da plataforma do robô; $I_{c}$ o momento de inércia da plataforma do robô em relação ao eixo vertical em $P_{c} ; I_{r}$ o momento de inércia de cada roda com o rotor do motor em relação ao eixo da roda; $I_{m}$ o momento de inércia em relação ao eixo definido no plano da roda (perpendicular ao eixo da roda).

Entretanto, é interessante alterar o modelo dinâmico do robô, exposto na Seção 2.2, para um sistema em função do vetor de velocidades angulares das rodas. Assim, conforme (COELHO; NUNES, 2003), deriva-se a Equação (3) em relação ao tempo, depois substitui-se 
o resultado na Equação (4) e em seguida multiplica-se à esquerda pela matriz $S^{T}$, obtendo

$$
M_{2} \ddot{q}_{2}+C_{2}\left(\dot{q}_{1}\right) \dot{q}_{2}=S^{T} E \tau=\tau
$$

sendo $M_{2}$ uma matriz simétrica e não-singular, dada por $S^{T}\left(q_{1}\right) M\left(q_{1}\right) S\left(q_{1}\right)$ e $C_{2}\left(\dot{q}_{1}\right)=$ $C_{2}(\dot{\alpha})=S^{T}\left(q_{1}\right) C\left(q_{1}, \dot{q}_{1}\right) S\left(q_{1}\right)+S^{T}\left(q_{1}\right) M\left(q_{1}\right) \dot{S}\left(q_{1}\right)$.

Logo depois, pré-multiplica-se por $M_{2}^{-1}$ a Equação (5) e tem-se

$$
\ddot{q}_{2}=A_{2}\left(\dot{q}_{2}\right) \dot{q}_{2}+B \tau
$$

sendo $A_{2}\left(\dot{q}_{2}\right)=-M_{2}^{-1} C_{2}\left(\dot{q}_{2}\right)$ e $B=M_{2}^{-1}$.

O modelo dinâmico apresentado na Equação (6) relaciona o vetor de velocidades angulares das rodas $\dot{q}_{2}=\left[\dot{\theta}_{d} \dot{\theta}_{e}\right]^{T}$ em função do vetor de torque aplicado nas rodas $\tau=\left[\begin{array}{ll}\tau_{d} & \tau_{e}\end{array}\right]^{T}$.

\subsection{Modelo do Motor de Corrente Contínua}

Neste trabalho, pretendeu-se englobar o modelo do motor de Corrente Contínua (CC) no modelo dinâmico do RMTD. Essa incorporação muda a variável de controle de torque para tensão elétrica, promovendo melhor aproximação da implementação prática. Além disso, no caso do motor de CC, outra vantagem é a realimentação de velocidade intrínseca no modelo do motor quando o controle é realizado por tensão.

A dinâmica do motor de CC é modelada através das equações elétrica e de torque do motor (KRISHNAN, 2001) dadas por

$$
\begin{gathered}
L \frac{d i}{d t}+R i+k_{w} \dot{\theta}_{m}=e, \\
I_{s} \ddot{\theta}_{m}+\tau_{\text {carga }}+\nu \dot{\theta}_{m}=k_{t} i,
\end{gathered}
$$

sendo $L$ a indutância da armadura; $R$ a resistência da armadura; $k_{w}$ a constante de tensão; $i$ a corrente da armadura; $\dot{\theta}_{m}$ a velocidade angular no eixo do motor; $e$ a tensão aplicada da armadura do motor; $\nu$ o coeficiente de fricção viscosa ; $k_{t}$ a constante do torque do motor; $I_{s}$ é o momento de inércia no eixo do motor. O parâmetro $I_{s}$, que pode ser calculado através da Equação (9), consiste na soma dos momentos de inércia do rotor $I_{\text {rotor }}$, do redutor $I_{\text {redutor }}$ e da roda $I_{\text {roda }}$ refletido no eixo do motor através da relação de redução do redutor $\left(n_{r}>1\right)$.

$$
I_{s}=I_{\text {rotor }}+I_{\text {redutor }}+\frac{I_{\text {roda }}}{n_{r}^{2}}
$$

Nesse trabalho, a variável $\tau_{\text {carga }}$ da Equação (8) corresponde ao torque $\tau$ na Equação (4). Agora, dividindo a Equação 7 por $R$ e isolando o termo da corrente temos:

$$
i=\frac{e-k_{w} \dot{\theta}_{m}}{R}-\frac{L}{R} \frac{d i}{d t}
$$


Em seguida, a constante de tempo elétrica $L / R$ é considerada desprezível e a Equação (10) é substituída na Equação (8), obtendo assim o modelo reduzido do motor como

$$
\tau=-I_{s} \ddot{\theta}_{m}-\left(\frac{k_{w} k_{t}}{R}+\nu\right) \dot{\theta}_{m}+\frac{k_{t}}{R} e_{a} .
$$

Mudando a variável de velocidade no eixo do motor $\dot{\theta}$ para a velocidade na roda através da relação de redução, temos as equações dos motores da direita e esquerda, respectivamente

$$
\begin{gathered}
\tau_{d}=-n_{r} I_{s} \ddot{\theta}_{d}-n_{r}\left(\frac{k_{w} k_{t}}{R}+\nu\right) \dot{\theta}_{d}+\frac{k_{t}}{R} e_{d}, \\
\tau_{e}=-n_{r} I_{s} \ddot{\theta}_{e}-n_{r}\left(\frac{k_{w} k_{t}}{R}+\nu\right) \dot{\theta}_{e}+\frac{k_{t}}{R} e_{e},
\end{gathered}
$$

sendo $e_{d}$ e $e_{e}$ as tensões elétricas aplicados nos motores da roda direita e esquerda, respectivamente, e $\tau_{d}$ e $\tau_{e}$ os torques aplicados nas rodas direita e esquerda, respectivamente.

A partir das equações (12) e (13) é elaborado o modelo do motor em espaço de estados como

$$
\tau=P \ddot{q}_{2}+Q \dot{q}_{2}+\beta e,
$$

sendo

$$
\begin{aligned}
& \tau=\left[\begin{array}{c}
\tau_{d} \\
\tau_{e}
\end{array}\right], \quad e=\left[\begin{array}{c}
e_{d} \\
e_{e}
\end{array}\right], \quad \dot{q}_{2}=\left[\begin{array}{c}
\dot{\theta}_{d} \\
\dot{\theta}_{e}
\end{array}\right], \quad P=n_{r}\left[\begin{array}{cc}
-I_{s} & 0 \\
0 & -I_{s}
\end{array}\right], \\
& Q=n_{r}\left[\begin{array}{cc}
-\left(\frac{k_{w} k_{t}}{R}+\nu\right) & 0 \\
0 & -\left(\frac{k_{w} k_{t}}{R}+\nu\right)
\end{array}\right] \quad \text { e } \quad \beta=\left[\begin{array}{cc}
\frac{k_{t}}{R} & 0 \\
0 & \frac{k_{t}}{R}
\end{array}\right] \text {. }
\end{aligned}
$$

Note que foi considerado que os parâmetros dos motores da direita e da esquerda são similares. A Equação (14) pode ser reescrita como

$$
e=\beta^{-1}\left(\tau-P \ddot{q}_{2}-Q \dot{q}_{2}\right)
$$

a qual será utilizada na Seção 4.2 para calcular a tensão a partir do torque calculado para o controlador $\mathcal{H}_{\infty}$-TJ.

\subsection{Formulação do problema para o RMTD}

Neste trabalho, para o propósito de implementar o controle para o problema de seguimento de trajetória é desenvolvido o modelo na forma de espaço de estados. Assim, primeiramente, seja $\dot{q}_{2}^{d}=\left[\begin{array}{ll}\dot{\theta}_{d}^{d} & \dot{\theta}_{e}^{d}\end{array}\right]^{T}$ o vetor das velocidades angulares desejadas nas rodas da direita e da esquerda, respectivamente, os quais são calculados pelo controlador cinemático a ser apresentado na Seção 4.4. Em seguida, adiciona-se e subtrai-se $\ddot{q}_{2}^{d}$ e $A_{2}\left(\dot{q}_{2}\right) \dot{q}_{2}^{d}$ 
na Equação (6) e define-se o estado como

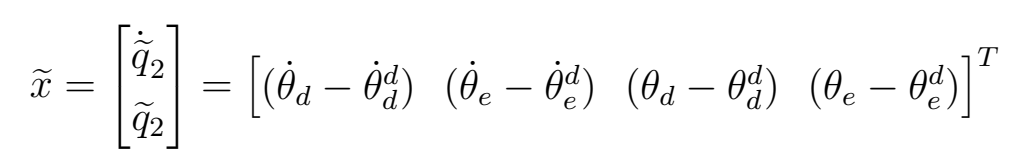

a representação quase linear com parâmetros variantes (quase-LPV) ${ }^{1}$ para o controle de acompanhamento da trajetória do RMTD é encontrada na forma de espaço de estados por

$$
\dot{\widetilde{x}}=\left[\begin{array}{cc}
A_{2}\left(\dot{q}_{2}\right) & 0 \\
I & 0
\end{array}\right] \widetilde{x}+\left[\begin{array}{l}
I \\
0
\end{array}\right] u
$$

sendo

$$
u=-\ddot{q}_{2}^{d}+A_{2} \dot{q}_{2}^{d}+B \tau
$$

que pode ser reescrita como

$$
\tau=B^{-1}\left(\ddot{q}_{2}^{d}-A_{2} \dot{q}_{2}^{d}+u\right)
$$

sendo $I=\left[\begin{array}{ll}1 & 0 \\ 0 & 1\end{array}\right], A_{2}\left(\dot{q}_{2}\right)=-M_{2}^{-1} C_{2}\left(\dot{q}_{2}\right)$ e $B=M_{2}^{-1}$.

O sistema na forma de espaço de estados na Equação (16) relaciona o erro das velocidades e dos deslocamentos angulares das rodas em função do torque aplicado nas rodas.

A substituição da Equação (14) nas equações (6), (16), (17) e (18) muda a variável de entrada do sistema em função do torque para a tensão, assim, como é apresenta nas equações

$$
\begin{gathered}
\ddot{q}_{2}=A_{3}\left(\dot{q}_{2}\right) \dot{q}_{2}+B_{2} e+B_{3} w, \\
\dot{\widetilde{x}}=\left[\begin{array}{cc}
A_{3}\left(\dot{q}_{2}\right) & 0 \\
I & 0
\end{array}\right] \widetilde{x}+\left[\begin{array}{l}
I \\
0
\end{array}\right] u, \\
u=-\ddot{q}_{2}^{d}+A_{3} \dot{q}_{2}^{d}+B_{2} e, \\
e=B_{2}^{-1}\left(\ddot{q}_{2}^{d}-A_{3} \dot{q}_{2}^{d}+u\right) .
\end{gathered}
$$

sendo $I=\left[\begin{array}{ll}1 & 0 \\ 0 & 1\end{array}\right], A_{3}=(I-B P)^{-1}\left(A_{2}+B Q\right)$ e $B_{2}=(I-B P)^{-1} B \beta$.

A representação do modelo em função da tensão elétrica, aplicada aos motores, permite analisar problemas de saturação no comando devido às limitações de fornecimento da fonte de tensão, que nesse trabalho serão as baterias.

Observe que apesar dos vetores de entrada nas equações (16) e (20) estarem representados por $u$, estes vetores não são correspondentes. A notação foi mantida em ambas no intuito de facilitar a compreensão quando essas individualmente são utilizadas nos controladores propostos.

\footnotetext{
${ }^{1}$ Definição: Sistemas não lineares em que os parâmetros correspondem aos estados ou parte deles.
} 


\subsection{Trajetória de Referência para o RMTD}

A referência do modelo de espaço de estados do RMTD, apresentado na seção anterior, é definida em duas etapas: a primeira é a geração da trajetória de referência circular dada nesta seção 2.5 e a segunda parte é o cálculo das velocidades desejadas para as rodas a partir de um controlador cinemático, a ser apresentado na Seção 4.4.

A trajetória de referência utilizada no RMTD é uma curva circular baseada em um ciclo-limite apresentado em Khalil (1996) e descrito pelas equações

$$
\begin{array}{r}
\dot{r}=\rho r-r^{2}, \\
\dot{\psi}=\omega_{s},
\end{array}
$$

sendo: $r$ o raio da trajetória de referência em relação a origem do sistema de coordenada inercial; $\dot{\psi}_{r}$ a velocidade angular da trajetória de referência; $\rho$ uma constante correspondente ao raio escolhido para o círculo; $\omega_{s}$ uma constante correspondente a velocidade angular definida como $\omega_{s}=\bar{v} / \rho$, onde $\bar{v}$ a velocidade linear de referência.

Esse ciclo-limite corresponde uma solução com órbita estável periódica de raio $\rho$ para qualquer posição inicial diferente da origem, devido essa ser um ponto de equilíbrio instável deste sistema. Em outras palavras, para qualquer posição no espaço diferente da origem, seja fora ou dentro da região do círculo, a trajetória gerada converge para uma órbita circular de período $\omega_{s}$.

A postura $P_{r}=\left(x_{r}, y_{r}, \alpha_{r}\right)$ é obtida pela integração das variáveis $\dot{r}$ e $\dot{\psi}_{r}$ e pela relação trigonométrica $x_{r}=r \cos \psi$ e $y_{r}=r \operatorname{sen} \psi$. Já a orientação de referência do RMTD é calculada como $\alpha_{r}=\arctan (\dot{y} / \dot{x})$. 


\section{Quadricóptero}

O quadricóptero consiste de uma aeronave com quatro motores conectados cada um na extremidade do corpo. Para cada motor há uma rotor formado por uma hélice que gira de forma independente as demais. A combinação dos movimentos rotativos das hélices formam um força de impulso e um momento angular que determina a translação e a rotação do aeromodelo. Apesar disso, no quadricóptero há restrições cinemáticas, por exemplo, não é possível mudar a orientação dos ângulos de arfagem e rolagem sem mudar a velocidade linear em alguma direção, que o caracteriza como um sistema não-holonômico.

A Figura 2 representa a estrutura do quadricóptero, com as velocidades angulares, torques e forças criadas por cada um dos rotores. Sendo $i \in\{1,2,3,4\}, \omega_{i}$ a velocidade angular em cada rotor, $f_{i}$ a força em cada rotor, $\tau_{M_{i}}$ o torque em cada rotor, $\phi$ o ângulo de rolagem dado pela rotação em torno do eixo $x, \theta$ o ângulo arfagem dado pela rotação em torno do eixo $y$, e $\psi$ o ângulo de guinada dado pela rotação em torno do eixo $z$ no sistema de coordenada inercial.
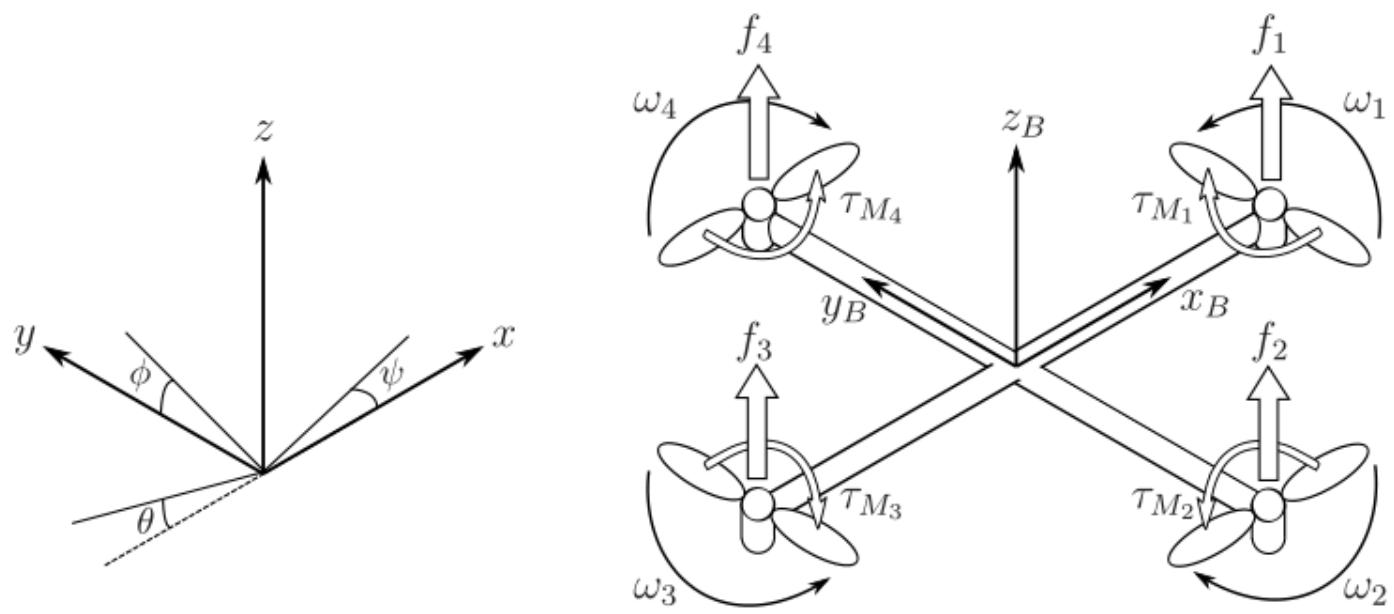

Figura 2 - Sistema de coordenadas inercial e do corpo de um quadricóptero 
A combinação das forças $f_{i}$ geradas por cada rotor formam a força de impulso que sempre aponta na direção $z_{B}$ no sistema de coordenadas do corpo e é dada por

$$
T=\sum_{1}^{4} f_{i}=k \sum_{1}^{4} \omega_{i}^{2}
$$

sendo $k_{i}$ a constante de sustentação ${ }^{1}$ que está relacionada com a densidade do ar, a forma das pás da hélice e o número de pás.

Além disso, há os torques $\tau_{\phi}, \tau_{\theta}$ e $\tau_{\psi}$ em relação aos ângulos no sistema de coordenadas do corpo que são dados por

$$
\tau=\left[\begin{array}{c}
\tau_{\phi} \\
\tau_{\theta} \\
\tau_{\psi}
\end{array}\right]=\left[\begin{array}{c}
l k\left(-\omega_{2}^{2}+\omega_{4}^{2}\right) \\
l k\left(-\omega_{1}^{2}+\omega_{3}^{2}\right) \\
\sum_{1}^{4} \tau_{M_{i}}
\end{array}\right]
$$

sendo $l$ a distância entre o rotor e o centro de massa do quadricóptero.

Este capítulo está dividido em três seções. A primeira seção apresenta o modelo dinâmico do quadricóptero com as condições em que esse é válido. A segunda seção mostra a formulação do problema de seguimento de trajetória na forma de espaço de estados a qual será usada para os cálculos dos ganhos dos controladores. E por fim, na terceira seção são dadas as equações da trajetória baseadas em um polinômio de $5^{\circ}$ grau que determina a curva através de pontos de passagem desejados.

\subsection{Modelo Dinâmico}

Conforme mostrado em Garcia, Lozano e Dzul (2006), através da teoria de Lagrange a equação dinâmica do quadricóptero para acelerações rotacionais é dada por

$$
\mathcal{M}(\eta) \ddot{\eta}+\mathcal{C}(\eta, \dot{\eta}) \dot{\eta}=\tau
$$

sendo $\eta=\left[\begin{array}{lll}\phi & \theta & \psi\end{array}\right]^{T}$ o vetor dos ângulos de Euler da aeronave, $\tau=\left[\begin{array}{lll}\tau_{\phi} & \tau_{\theta} \tau_{\psi}\end{array}\right]$ o vetor dos torques em relação aos ângulos de Euler, $\mathcal{M}$ a matriz Jacobiana igual a

$\mathcal{M}=\left[\begin{array}{ccc}I_{x x} & 0 & -I_{x x} \operatorname{sen} \theta \\ 0 & I_{y y} \cos ^{2} \phi+I_{z z} \operatorname{sen}^{2} \phi & \left(I_{y y}-I_{z z}\right) \cos \phi \operatorname{sen} \phi \cos \theta \\ -I_{x x} \operatorname{sen} \theta & \left(I_{y y}-I_{z z}\right) \cos \phi \operatorname{sen} \phi \cos \theta & I_{x x} \operatorname{sen}^{2} \theta+I_{y y} \operatorname{sen}^{2} \phi \cos ^{2} \theta+I_{z z} \cos ^{2} \phi \cos ^{2} \theta\end{array}\right]$

e $\mathcal{C}$ a matriz de Coriolis dada por

$$
\mathcal{C}=\left[\begin{array}{lll}
C_{11} & C_{12} & C_{13} \\
C_{21} & C_{22} & C_{23} \\
C_{31} & C_{32} & C_{33}
\end{array}\right]
$$

\footnotetext{
${ }^{1}$ Em inglês: lift constant
} 
sendo

$$
\begin{aligned}
C_{11} & =0, \\
C_{12} & =\left(I_{y y}-I_{z z}\right)\left(\dot{\theta} \cos \phi \operatorname{sen} \phi+\dot{\psi} \operatorname{sen} \phi^{2} \cos \theta\right)+\left(I_{z z}-I_{y y}\right) \dot{\psi} \cos \phi^{2} \cos \theta-I_{x x} \dot{\psi} \cos \theta, \\
C_{13} & =\left(I_{z z}-I_{y y}\right) \dot{\psi} \cos \phi \operatorname{sen} \phi \cos \theta^{2}, \\
C_{21} & \left.=\left(I_{z z}-I_{y y}\right) \dot{\theta} \cos \phi \operatorname{sen} \phi+\dot{\psi} \operatorname{sen} \phi \cos \theta\right)+\left(I_{y y}-I_{z z}\right) \dot{\psi} \cos \phi^{2} \cos \theta+I_{x x} \dot{\psi} \cos \theta, \\
C_{22} & =\left(I_{z z}-I_{y y}\right) \dot{\phi} \cos \phi \operatorname{sen} \phi, \\
C_{23} & =-I_{x x} \dot{\psi} \operatorname{sen} \theta \cos \theta+I_{y y} \dot{\psi} \operatorname{sen} \phi^{2} \operatorname{sen} \theta \cos \theta+I_{z z} \dot{\psi} \cos \phi^{2} \operatorname{sen} \theta \cos \theta, \\
C_{31} & =\left(I_{y y}-I_{z z}\right) \dot{\psi} \cos \theta^{2} \operatorname{sen} \phi \cos \phi-I_{x x} d \theta \cos \theta, \\
C_{32} & =\left(I_{z z}-I_{y y}\right)\left(\dot{\theta} \cos \phi \operatorname{sen} \phi \operatorname{sen} \theta+\dot{\phi} \operatorname{sen} \phi^{2} \cos \theta\right)+\left(I_{y y}-I_{z z}\right) \dot{\phi} \cos \phi^{2} \cos \theta \\
& +I_{x x} \dot{\psi} \operatorname{sen} \theta \cos \theta-I_{y y} \dot{\psi} \operatorname{sen} \phi^{2} \operatorname{sen} \theta \cos \theta-I_{z z} \dot{\psi} \cos \phi^{2} \operatorname{sen} \theta \cos \theta, \\
C_{33} & =\left(I_{y y}-I_{z z}\right) \dot{\phi} \cos \phi \operatorname{sen} \phi \cos \theta^{2}-I_{y y} \dot{\theta} \operatorname{sen} \phi^{2} \cos \theta \operatorname{sen} \theta-I_{z z} \dot{\theta} \cos \phi^{2} \cos \theta \operatorname{sen} \theta \\
& +I_{x x} \dot{\theta} \cos \theta \operatorname{sen} \theta
\end{aligned}
$$

Já acelerações lineares da aeronave (BOUADI; BOUCHOUCHA; TADJINE, 2007) são baseadas nas equações de Newton-Euler e são dadas por

$$
\ddot{\xi}=-g\left[\begin{array}{l}
0 \\
0 \\
1
\end{array}\right]+\frac{T}{m}\left[\begin{array}{c}
\cos \psi \operatorname{sen} \theta \cos \phi+\operatorname{sen} \psi \operatorname{sen} \phi \\
\operatorname{sen} \psi \operatorname{sen} \theta \cos \phi-\cos \psi \operatorname{sen} \phi \\
\cos \theta \cos \phi
\end{array}\right]-\frac{1}{m}\left[\begin{array}{ccc}
A_{x} & 0 & 0 \\
0 & A_{y} & 0 \\
0 & 0 & A_{z}
\end{array}\right] \dot{\xi},
$$

sendo: $\xi=\left[\begin{array}{lll}x & y & z\end{array}\right]^{T}$ o vetor de posição da aeronave do referencial inercial; $A_{x}, A_{y}$ e $A_{z}$ os coeficientes da força de arraste gerada pela resistência do ar nas correspondentes direções do referencial inercial; $T$ a força de impulso; $g$ a aceleração da gravidade; $m$ a massa da aeronave.

Os dois modelos dinâmicos são uma simplificação da dinâmica a partir do pressuposto de que o quadricóptero é um corpo rígido, simétrico em relação os eixo $x_{B}, y_{B}$ e $z_{B}$ no sistema de coordenadas do corpo, com centro de massa e centro de gravidade coincidentes e que alguns efeitos na aerodinâmica em baixas velocidades podem ser desconsiderados.

\subsection{Formulação do problema para o Quadricóptero}

Neste trabalho, para a aplicação no quadricóptero no seguimento de trajetória dois controles são aplicados: controle de posição e controle de atitude. O controle de posição é realizado no modelo da Equação (28) através do controlador apresentado na Seção (4.5) o qual determina os ângulos referência para o controle de atitude. Já para o controle de atitude serão utilizados os controladores apresentados nas seções 4.1 à 4.3, os quais são os objetos de comparação neste trabalho. 
Assim, para o controle de atitude, o modelo na Equação (27) é representado na forma de espaço de estados como

$$
\ddot{\eta}=A(\dot{\eta}) \dot{\eta}+B \tau
$$

sendo $A(\dot{\eta})=-\mathcal{M}^{-1} \mathcal{C}(\dot{\eta})$ e $B=\mathcal{M}^{-1}$.

Agora, no intuito de utilizar os controladores aqui propostos, o sistema quase-LPV terá seu estado modificado para o erro de velocidade angular. Assim, seja $\dot{\eta}_{r}=\left[\begin{array}{lll}\dot{\phi}_{r} & \dot{\theta}_{r} & \dot{\psi}_{r}\end{array}\right]^{T}$ o vetor de velocidades angulares de referência em relação ao sistema de coordenada inercial. Em seguida, soma-se e subtrai-se os termos $\ddot{\eta}_{r}$ e $A(\dot{\eta}) \dot{\eta}_{r}$ na Equação (29), e define-se o estado como

$$
\widetilde{x}=\left[\begin{array}{l}
\dot{\tilde{\eta}} \\
\widetilde{\eta}
\end{array}\right]=\left[\begin{array}{l}
\dot{\eta}-\dot{\eta}_{r} \\
\eta-\eta_{r}
\end{array}\right],
$$

tem-se a representação em espaço de estado para o controle de atitude dado por

$$
\dot{\widetilde{x}}=\left[\begin{array}{cc}
A(\dot{\eta}) & 0 \\
I & 0
\end{array}\right] \widetilde{x}+\left[\begin{array}{l}
I \\
0
\end{array}\right] u
$$

sendo

$$
u=-\ddot{\eta}_{r}+A \dot{\eta}_{r}+B \tau
$$

$\mathrm{ou}$

$$
\tau=B^{-1}\left(\ddot{\eta}_{r}-A \dot{\eta}_{r}+u\right) .
$$

O vetor $\dot{\eta}_{r}=\left[\begin{array}{lll}\dot{\phi}_{r} & \dot{\theta}_{r} & \dot{\psi}_{r}\end{array}\right]^{T}$ é calculado através do exposto Seção (4.5) através da trajetória de referência obtida na Seção 3.3 .

\subsection{Trajetória de Referência para o quadricóptero}

A trajetória de referência a qual se deseja que quadricóptero siga, é definida através de dois pontos de passagem pré-definidos. A partir da trajetória de referência é encontrado os ângulos de referência de arfagem e rolagem, a serem mostrados na Seção 4.5.

A otimização da trajetória do quadricóptero é uma tarefa complexa, visto que deve ser suave para que a aeronave mova-se de uma posição inicial para uma final desejada, por meio do controle da velocidade dos quatro motores da mesma.

$\mathrm{Na}$ concepção da trajetória de referência do quadricóptero, foi utilizado o polinômio do quinto grau desenvolvido para manipuladores em Craig (2005), mas adaptado para o robô móvel na geração de trajetória em relação ao sistemas de coordenada inercial com os eixos $x, y$ e $z$.

O método referido é interessante, pois permite calcular a posição $x, y$ e $z$ na trajetória de forma independente entre eles. Para isso, é necessário definir seis restrições, as quais 
são a posição inicial e final e suas derivadas até a segunda ordem, conforme a Equação 34 .

$$
\begin{array}{ll}
q_{i}^{d}\left(t_{0}\right)=q_{i 0}, & q_{i}^{d}\left(t_{f}\right)=q_{i f}, \\
\dot{q}_{i}^{d}\left(t_{0}\right)=\dot{q}_{i 0}, & \dot{q}_{i}^{d}\left(t_{f}\right)=\dot{q}_{i f}, \\
\ddot{q}_{i}^{d}\left(t_{0}\right)=\ddot{q}_{i 0}, & \ddot{q}_{i}^{d}\left(t_{f}\right)=\ddot{q}_{i f} .
\end{array}
$$

Assim, para cada variável de posição, os parâmetros $\mathbf{a}_{i}=\left[\begin{array}{llllll}a_{i 0} & a_{i 1} & a_{i 2} & a_{i 3} & a_{i 4} & a_{i 5}\end{array}\right]^{T}$ são calculados a partir do vetor de restrições $\mathbf{q}_{i}=\left[\begin{array}{llllll}q_{i 0} & \dot{q}_{i 0} & \ddot{q}_{i 0} & q_{i f} & \dot{q}_{i f} & \ddot{q}_{i f}\end{array}\right]^{T}$ e as seguintes equações:

$$
\begin{aligned}
& q_{i}^{d}(t)=a_{i 0}+a_{i 1} \Delta t+a_{i 2} \Delta t^{2}+a_{i 3} \Delta t^{3}+a_{i 4} \Delta t^{4}+a_{i 5} \Delta t^{5} \\
& \dot{q}_{i}^{d}(t)=a_{i 1}+2 a_{i 2} \Delta t+3 a_{i 3} \Delta t^{2}+4 a_{i 4} \Delta t^{3}+5 a_{i 5} \Delta t^{4} \\
& \ddot{q}_{i}^{d}(t)=2 a_{i 2}+6 a_{i 3} \Delta t+12 a_{i 4} \Delta t^{2}+20 a_{i 5} \Delta t^{3}
\end{aligned}
$$

sendo $\Delta t=t-t_{0}$ a diferença entre o tempo atual e inicial da trajetória.

Finalmente, obtém-se os parâmetros do polinômio do quinto grau através do cálculo de

$$
\mathbf{a}_{i}=\left[\begin{array}{cccccc}
1 & 0 & 0 & 0 & 0 & 0 \\
0 & 1 & 0 & 0 & 0 & 0 \\
0 & 0 & 2 & 0 & 0 & 0 \\
1 & \left(t_{f}-t_{i}\right) & \left(t_{f}-t_{i}\right)^{2} & \left(t_{f}-t_{i}\right)^{3} & \left(t_{f}-t_{i}\right)^{4} & \left(t_{f}-t_{i}\right)^{5} \\
0 & 1 & 2\left(t_{f}-t_{i}\right) & 3\left(t_{f}-t_{i}\right)^{2} & 4\left(t_{f}-t_{i}\right)^{3} & 5\left(t_{f}-t_{i}\right)^{4} \\
0 & 0 & 2 & 6\left(t_{f}-t_{i}\right) & 12\left(t_{f}-t_{i}\right)^{2} & 20\left(t_{f}-t_{i}\right)^{3}
\end{array}\right]^{-1} \mathbf{q}_{i}
$$

sendo $t_{f}$ o tempo final da trajetória.

Nesta seção, foi apresentado o cálculo da posição na trajetória do quadricóptero. Na Seção 4.5 será exposto o controle de posição que é utilizado para determinar os ângulos de referência de arfagem e rolagem do quadricóptero. 


\section{Controladores}

\subsection{Regulador Linear Quadrático Robusto}

O Regulador Linear Quadrático Robusto (RLQ-R) apresentado em Terra, Cerri e Ishihara (2014), trata do problema de controle recursivo robusto em sistemas lineares variantes no tempo sujeito a incertezas paramétricas. Para tanto, essa abordagem transforma um controle sujeito a incertezas restrito em um não-restrito. Isso fornece uma lei de controle robusta que recupera a simplicidade do controle ótimo padrão.

O problema acima citado é modelado através do seguinte sistema linear discreto no tempo sujeito a incertezas paramétricas

$$
x_{i+1}=\left(F_{i}+\delta F_{i}\right) x_{i}+\left(G_{i}+\delta G_{i}\right) u_{i}, \quad i=0, \ldots, N,
$$

sendo $F_{i} \in \mathbb{R}^{n \times n}$ e $G_{i} \in \mathbb{R}^{n \times m}$ matrizes discretas do modelo em espaço de estado, $x_{i} \in \mathbb{R}^{n}$ o vetor de estado, $u_{i} \in \mathbb{R}^{m}$ o vetor de entrada de controle e o estado inicial $x_{0}$ é assumido ser conhecido. Seja $\delta F_{i} \in \mathbb{R}^{n \times n}$ e $\delta G_{i} \in \mathbb{R}^{n \times m}$ matrizes de incerteza modeladas como

$$
\left[\begin{array}{ll}
\delta F_{i} & \delta G_{i}
\end{array}\right]=H_{i} \Delta_{i}\left[\begin{array}{ll}
E_{F_{i}} & E_{G_{i}}
\end{array}\right] ; \quad i=0, \ldots, N
$$

sendo $H_{i} \in \mathbb{R}^{n \times p}, E_{F_{i}} \in \mathbb{R}^{l \times n}, E_{G_{i}} \in \mathbb{R}^{l \times m}$ matrizes conhecidas, e $\Delta_{i} \in \mathbb{R}^{p \times l}$ uma matriz de contração $\left\|\Delta_{i}\right\| \leq 1$. Além do mais, a matriz $H_{i}$ é considerada não nula para todo $i$.

O RLQ-R é baseado na solução $\left(x_{i+1}^{*}(\mu), u_{i}^{*}(\mu)\right)$ de um problema de jogos do tipo min-max, onde se leva em conta dois objetivos contraditórios que são minimizar o estado para o máximo de incerteza. Em outras palavras, obter uma solução de realimentação de estado para o controle no pior caso de incerteza. Esse problema de otimização é dado por

$$
\min _{x_{i+1}, u_{i}} \max _{\delta F_{i}, \delta G_{i}}\left\{\tilde{J}_{i}^{\mu}\left(x_{i+1}, u_{i}, \delta F_{i}, \delta G_{i}\right)\right\}
$$

sendo $\mu>0$ um parâmetro de penalidade, $\tilde{J}_{i}^{\mu}$ uma função de custo quadrática regularizada dada pela Equação (40) com as matrizes de ponderação $P_{i+1} \succ 0, Q_{i} \succ 0$ e $R_{i} \succ 0$. A 
função de custo $\widetilde{J}_{i}^{\mu}$ é definida por

$$
\begin{gathered}
\tilde{J}_{i}^{\mu}\left(x_{i+1}, u_{i}, \delta F_{i}, \delta G_{i}\right)=\left[\begin{array}{c}
x_{i+1} \\
u_{i}
\end{array}\right]^{T}\left[\begin{array}{cc}
P_{i+1} & 0 \\
0 & R_{i}
\end{array}\right]\left[\begin{array}{c}
x_{i+1} \\
u_{i}
\end{array}\right]+ \\
+\left\{\left(\left[\begin{array}{cc}
0 & 0 \\
I & -G_{i}
\end{array}\right]+\left[\begin{array}{cc}
0 & 0 \\
0 & -\delta G_{i}
\end{array}\right]\right)\left[\begin{array}{c}
x_{i+1} \\
u_{i}
\end{array}\right]-\left(\left[\begin{array}{c}
-I \\
F_{i}
\end{array}\right] x_{i}+\left[\begin{array}{c}
0 \\
\delta F_{i}
\end{array}\right] x_{i}\right)\right\}^{T}\left[\begin{array}{cc}
Q_{i} & 0 \\
0 & \mu I
\end{array}\right]\{\bullet\} .
\end{gathered}
$$

A solução ótima para cada $\mu>0$ é dada pelas equações (41) e (42).

$$
\begin{aligned}
& {\left[\begin{array}{c}
x_{i+1}^{*}(\mu) \\
u_{i}^{*}(\mu) \\
\tilde{J}_{i}^{\mu}\left(x_{i+1}^{*}(\mu), u_{i}^{*}(\mu)\right)
\end{array}\right]=\left[\begin{array}{ccc}
I & 0 & 0 \\
0 & I & 0 \\
0 & 0 & x_{i}^{*}(\mu)^{T}
\end{array}\right]\left[\begin{array}{c}
L_{i, \mu} \\
K_{i, \mu} \\
P_{i, \mu}
\end{array}\right] x_{i}^{*}(\mu),} \\
& {\left[\begin{array}{c}
L_{i, \mu} \\
K_{i, \mu} \\
P_{i, \mu}
\end{array}\right]=\left[\begin{array}{ccc}
0 & 0 & 0 \\
0 & 0 & 0 \\
0 & 0 & -I \\
0 & 0 & \mathcal{F}_{i} \\
I & 0 & 0 \\
0 & I & 0
\end{array}\right]^{T}\left[\begin{array}{cccccc}
P_{i+1}^{-1} & 0 & 0 & 0 & I & 0 \\
0 & R_{i}^{-1} & 0 & 0 & 0 & I \\
0 & 0 & Q_{i}^{-1} & 0 & 0 & 0 \\
0 & 0 & 0 & \Sigma_{i}\left(\mu, \lambda_{i}\right) & \mathcal{I} & -\mathcal{G}_{i} \\
I & 0 & 0 & \mathcal{I}^{T} & 0 & 0 \\
0 & I & 0 & -\mathcal{G}_{i}^{T} & 0 & 0
\end{array}\right]^{-1}\left[\begin{array}{c}
0 \\
0 \\
-I \\
\mathcal{F}_{i} \\
0 \\
0
\end{array}\right]}
\end{aligned}
$$

sendo

$$
\Sigma_{i}\left(\mu, \lambda_{i}\right)=\left[\begin{array}{cc}
\mu^{-1} I-\hat{\lambda}_{i}^{-1} H_{i} H_{i}^{T} & 0 \\
0 & \hat{\lambda}_{i}^{-1} I
\end{array}\right], \quad \mathcal{I}=\left[\begin{array}{l}
I \\
0
\end{array}\right], \mathcal{G}_{i}=\left[\begin{array}{c}
G_{i} \\
E_{G_{i}}
\end{array}\right], \quad \mathcal{F}_{i}=\left[\begin{array}{c}
F_{i} \\
E_{F_{i}}
\end{array}\right]
$$

e

$$
\lambda_{i}>\left\|\mu H_{i}^{T} H_{i}\right\|
$$

de acordo com Sayed e Nascimento (1999).

Conforme Terra, Cerri e Ishihara (2014), o método da função de penalidade impõe que $\mu \rightarrow+\infty$, o que tem como consequência

$$
\lim _{\mu \rightarrow+\infty} \Sigma_{i}\left(\mu, \lambda_{i}\right)=0
$$

$\lambda_{i}$ desaparece e o regulador quadrático linear robusto mostrado na Tabela 1 é obtido.

Note que o algoritmo recursivo depende somente das matrizes de ponderação e do modelo nominal, os quais são conhecidos a priori (TERRA; CERRI; ISHIHARA, 2014). O aumento da incerteza no modelo implica em perda de desempenho nos resultados do RLQ-R, porém há a garantia de que o controlador estabilize o sistema.

No caso do RMTD, após calculada a entrada de controle $u$, a tensão elétrica a ser aplicada nos motores das rodas é calculada pela Equação (22). Já para o quadricóptero, a partir do cálculo da entrada $u$ o torque para o controle de atitude é encontrado através da Equação (33). 
Tabela 1 - Regulador Linear Quadrático Robusto

Modelo Incerto: Considere as equações (37), (38) e (40) com $F_{i}, G_{i}, E_{F_{i}}, E_{G_{i}}$, $Q_{i} \succ 0$ e $R_{i} \succ 0$ conhecidos para todo $i$.

Condições Iniciais: Definem-se $x_{0}$ e $P_{N+1} \succ 0$.

Passo 1: (Sentido Inverso)

Calcula-se para todo $i=N, \ldots 0$ :

$$
\left[\begin{array}{c}
L_{i} \\
K_{i} \\
P_{i}
\end{array}\right]=\left[\begin{array}{ccc}
0 & 0 & 0 \\
0 & 0 & 0 \\
0 & 0 & -I \\
0 & 0 & F_{i} \\
0 & 0 & E_{F_{i}} \\
I & 0 & 0 \\
0 & I & 0
\end{array}\right]^{T}\left[\begin{array}{ccccccc}
P_{i+1}^{-1} & 0 & 0 & 0 & 0 & I & 0 \\
0 & R_{i}^{-1} & 0 & 0 & 0 & 0 & I \\
0 & 0 & Q_{i}^{-1} & 0 & 0 & 0 & 0 \\
0 & 0 & 0 & 0 & 0 & I & -G_{i} \\
0 & 0 & 0 & 0 & 0 & 0 & -E_{G_{i}} \\
I & 0 & 0 & I & 0 & 0 & 0 \\
0 & I & 0 & -G_{i}^{T} & -E_{G_{i}}^{T} & 0 & 0
\end{array}\right]^{-1}\left[\begin{array}{c}
0 \\
0 \\
-I \\
F_{i} \\
E_{F_{i}} \\
0 \\
0
\end{array}\right]
$$

Passo 2: (Sentido Direto)

Obter para cada $i=0, \ldots N$ :

$$
\left[\begin{array}{c}
x_{i+1}^{*} \\
u_{i}^{*}
\end{array}\right]=\left[\begin{array}{c}
L_{i} \\
K_{i}
\end{array}\right] x_{i}^{*},
$$

com o custo total dado por $J_{r}^{*}=x_{0}^{T} P_{0} x_{0}$.

\subsection{Controlador $\mathcal{H}_{\infty}$ via teoria dos jogos}

Nesta seção, o controlador $\mathcal{H}_{\infty}$ via teoria do jogos $\left(\mathcal{H}_{\infty}\right.$-TJ $)$ proposto em Chen, Lee e Feng (1994) é aplicado no RMTD e no quadricóptero a partir dos seus modelos dinâmicos do erro dado nas equações (16) e (31), respectivamente. A escolha do modelo foi definida para que a diferença $C(q, \dot{q})-\frac{1}{2} \dot{M}(q, \dot{q})$ seja uma matriz antissimétrica conforme diretrizes definidas em Chen, Lee e Feng (1994).

O controle $\mathcal{H}_{\infty}$-TJ é uma abordagem baseada em um critério de desempenho que inclui um nível de atenuação de distúrbio desejado $\gamma$ para um erro dinâmico de acompanhamento de trajetória, dado por

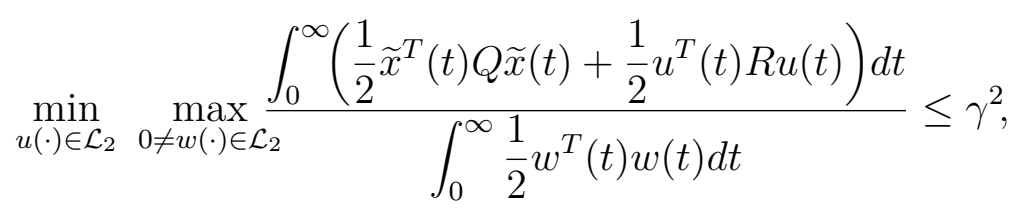

sendo $Q$ e $R$ matrizes de ponderação simétricas e definidas positivas, e $\widetilde{x}(0)=0$.

A solução para a Equação (43) para o problema de acompanhamento de trajetória é encontrada através de teoria diferencial dos jogos em Basar e Bernhard (1991), Basar e Olsder (1998) para tratar problemas min-max e uma escolha adequada de função Lyapunov $\tilde{V}(\tilde{x}, t)$ (CHEN; LEE; FENG, 1994) combinada com o trabalho de Johansson (1990). 
A seguir, será demonstrado um resumo do desenvolvimento do controle para RMTD, sendo que as passagens podem ser generalizadas ao modelo do quadricóptero apresentado na Equação (31) com as respectivas adequações das dimensões e mudando o estado $\tilde{x}$ em relação $q_{2}$ para $\eta$.

Seja $n$ a dimensão do número de estados do modelo tratado ( $n=2$ para o RMTD e $\mathrm{n}=3$ para o quadricóptero), e estabelecida a seguinte transformação de variáveis

$$
\widetilde{z}=\left[\begin{array}{c}
\widetilde{z}_{1} \\
\widetilde{z}_{2}
\end{array}\right]=T_{0} \widetilde{x}=\left[\begin{array}{cc}
T_{11} & T_{12} \\
0 & I
\end{array}\right]\left[\begin{array}{c}
\dot{\tilde{x}} \\
\widetilde{x}
\end{array}\right]
$$

sendo $T_{11}, T_{12} \in \Re^{n \times n}$ matrizes constantes a serem determinadas e $T_{11}$ é assumida ser diagonal.

Na prática, os parâmetros do sistema não podem ser conhecidos precisamente, por isso nesse controle as incertezas paramétricas e não-linearidades negligenciadas (folga, histerese) aparecem como distúrbio do sistema. Assim, sendo $w$ um distúrbio de torque, acrescenta-se o termo Bw na Equação (16), obtendo

$$
\dot{\widetilde{x}}=\left[\begin{array}{cc}
A_{2}\left(\dot{q}_{2}\right) & 0 \\
I & 0
\end{array}\right] \widetilde{x}+\left[\begin{array}{l}
I \\
0
\end{array}\right] u+\left[\begin{array}{c}
B \\
0
\end{array}\right] w
$$

Agora, conforme em Chen, Lee e Feng (1994), aplica-se a transformação da Equação (44) na Equação (45) e tem-se

$$
\dot{\tilde{x}}=A_{T}\left(\dot{q}_{2}\right) \widetilde{x}+B_{T} u+B_{T} T_{11} w
$$

sendo

$$
\begin{gathered}
A_{T}=T_{0}^{-1}\left[\begin{array}{cc}
A\left(\dot{q}_{2}\right) & 0 \\
T_{11}^{-1} & -T_{11}^{-1} T_{12}
\end{array}\right] T_{0}, \quad B_{T}=T_{0}^{-1}\left[\begin{array}{c}
B \\
0
\end{array}\right], \\
u=T_{11}\left(-M\left({\ddot{q_{2}}}^{d}-T_{11}^{-1} T_{12} \dot{\dot{q}_{2}}\right)-C\left({\dot{q_{2}}}^{d}-T_{11}^{-1} T_{12} \widetilde{q_{2}}\right)+\tau\right)
\end{gathered}
$$

$\mathrm{Ou}$

$$
\tau=M\left(\ddot{q}_{2}{ }^{d}-T_{11}^{-1} T_{12} \dot{\tilde{q_{2}}}\right)+C\left(\dot{q}_{2}{ }^{d}-T_{11}^{-1} T_{12} \widetilde{q_{2}}\right)+T_{11}^{-1} u
$$

Agora, escolhendo um função de Lyapunov na forma

$$
V(\widetilde{x}, t)=\frac{1}{2} \widetilde{x}^{T} P(\widetilde{x}, t) \widetilde{x}
$$

sendo $P(\widetilde{x}, t)$ uma matriz definida positiva e simétrica para todos os valores para todo tempo, a teoria dos jogos fornece a seguinte equação de Riccati (CHEN; LEE; FENG, 1994)

$$
\dot{P}(\widetilde{x}, t)+P(\widetilde{x}, t) A_{T}(\widetilde{x}, t)+A_{T}^{T}(\widetilde{x}, t) P(\widetilde{x}, t)-P(\widetilde{x}, t) B_{T}(\widetilde{x}, t)\left(R^{-1}-\frac{1}{\gamma^{2}} I\right) B_{T}^{T}(\widetilde{x}, t) P(\widetilde{x}, t)+Q=0 .
$$


Assim, escolhendo uma matriz apropriada $P(\widetilde{x}, t)$ e desde que a matriz $\left(C_{2}\left(q_{1}, \dot{q}_{1}\right)-\right.$ $\frac{1}{2} \dot{M}_{2}$ ) seja antissimétrica (CHEN; LEE; FENG, 1994), a equação de Riccati pode ser simplificada para uma equação algébrica. A matriz $P(\widetilde{x}, t)$ é definida por Chen, Lee e Feng (1994) e Johansson (1990) como

$$
P(\widetilde{x}, t)=T_{0}^{T}\left[\begin{array}{cc}
M_{2} & 0 \\
0 & K
\end{array}\right] T_{0},
$$

sendo $K$ uma matriz simétrica e definida positiva.

A equação algébrica simplificada é dada por

$$
\left[\begin{array}{cc}
0 & K \\
K & 0
\end{array}\right]-T_{0}^{T}\left[\begin{array}{ll}
I & 0
\end{array}\right]^{T}\left(R^{-1}-\frac{1}{\gamma^{2}} I\right)\left[\begin{array}{ll}
I & 0
\end{array}\right] T_{0}+Q=0 .
$$

O problema de controle $\mathcal{H}_{\infty}$ dado na Equação (43) possui solução se $\gamma^{2} I>R$ e a equação algébrica (48) tem as matrizes $K>0$ e a matriz $T_{0}$ não-singular. Satisfeitas as condições anteriores, o controle ótimo pode ser escrito como

$$
u^{*}=-R^{-1}\left[\begin{array}{ll}
I & 0
\end{array}\right] T_{0} \widetilde{x} .
$$

Agora, dado a matriz $Q$ simétrica e definida positiva, sendo fatorada como

$$
Q=\left[\begin{array}{cc}
Q_{1}^{T} Q_{1} & Q_{12} \\
Q_{12}^{T} & Q_{2}^{T} Q_{2}
\end{array}\right]
$$

as seguintes equações em (48) são retiradas.

$$
\begin{gathered}
Q_{1}^{T} Q_{1}-T_{11}^{T}\left(R^{-1}-\frac{1}{\gamma^{2}} I\right) T_{11}=0 \\
K+Q_{12}^{T}-T_{12}^{T}\left(R^{-1}-\frac{1}{\gamma^{2}} I\right) T_{11}=0 \\
K+Q_{12}-T_{11}^{T}\left(R^{-1}-\frac{1}{\gamma^{2}} I\right) T_{12}=0 \\
Q_{2}^{T} Q_{2}-T_{12}^{T}\left(R^{-1}-\frac{1}{\gamma^{2}} I\right) T_{12}=0 .
\end{gathered}
$$

A partir das equações (51) a (54), temos que a matriz $\left(R^{-1}-\left(1 / \gamma^{2}\right) I\right)$ deve ser definida positiva, pois as matrizes $Q_{1}^{T} Q_{1}$ e $Q_{2}^{T} Q_{2}$ são definidas positivas. Agora, seja

$$
R_{1}^{T} R_{1}=\left(R^{-1}-\frac{1}{\gamma^{2}} I\right)^{-1}
$$

e substituindo-a nas (51) e (54), encontramos as submatrizes $T_{11}=R_{1}^{T} Q_{1}$ e $T_{12}=R_{1}^{T} Q_{2}$, e obtemos a matriz $T_{0}$ dada como

$$
T_{0}=\left[\begin{array}{cc}
R_{1}^{T} Q_{1} & R_{1}^{T} Q_{2} \\
0 & I
\end{array}\right]
$$


Por fim, substituindo os valores de $T_{11}$ e $T_{12}$ nas equações (52) e (53), encontramos a matriz $K$ como

$$
K=\frac{1}{2}\left(Q_{1}^{T} Q_{2}+Q_{2}^{T} Q_{1}\right)-\frac{1}{2}\left(Q_{12}^{T}+Q_{12}\right) .
$$

Devido a matriz $\left(C(\dot{\eta})-\frac{1}{2} \dot{M}\right)$ ser necessariamente antissimétrica pelo controlador $\mathcal{H}_{\infty^{-}}$ TJ, o modelo utilizado para o RMTD é o mostrado na Equação (16) que está em função do torque. Isso é necessário devido ao fato de que o modelo em relação a tensão, dado na Equação (20), tem a propriedade de antissimétria perdida devido à inclusão do modelo do motor CC.

Assim, para controlar o robô móvel, primeiramente, é calculado a entrada $u$ através da Equação (49). Depois, o torque é obtido a partir da Equação (47). E por fim, é determinada a tensão elétrica a ser aplicada nos motores das rodas através da Equação (15).

Em relação ao quadricóptero, a entrada $u$ é calculada pela Equação (49) e o modelo apresentado na Equação 31. Após isso, calcula-se o torque através da Equação (18).

Para maiores detalhes veja Chen, Lee e Feng (1994), onde é exposto um algoritmo para busca dos valores ótimos do parâmetro $\gamma$ e das matrizes de ponderação.

\subsection{Controlador Proporcional-Derivativo}

O controlador PD é uma técnica amplamente conhecida em diversas aplicações. Neste trabalho, são utilizados controladores PD com uma única entrada e única saída, de tal forma, que cada um controle uma variável de forma independente do outro.

Nesse trabalho, o controlador PD será implementado para calcular a tensão elétrica no motor de cada roda do RMTD e para calcular os torques a serem aplicados no quadricóptero.

Equação geral deste controlador é dada por

$$
u=-K_{P D} \tilde{x}
$$

sendo para o RMTD

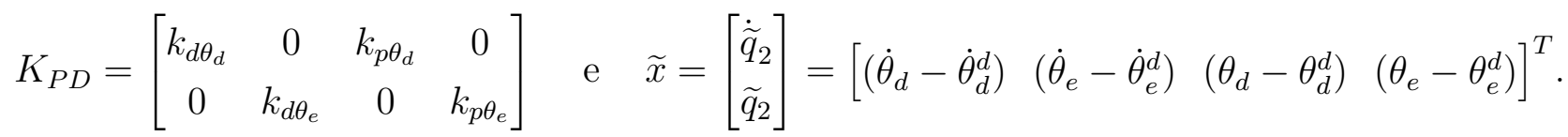

e para o quadricóptero

$$
K_{P D}=\left[\begin{array}{cccccc}
k_{d \phi} & 0 & 0 & k_{p \phi} & 0 & 0 \\
0 & k_{d \theta} & 0 & 0 & k_{p \theta} & 0 \\
0 & 0 & k_{d \psi} & 0 & 0 & k_{p \psi}
\end{array}\right] \quad \text { e } \quad \widetilde{x}=\left[\begin{array}{c}
\dot{\tilde{\eta}} \\
\widetilde{\eta}
\end{array}\right]=\left[\begin{array}{c}
\dot{\eta}-\dot{\eta}_{r} \\
\eta-\eta_{r}
\end{array}\right] .
$$

Uma vez calculada a entrada $u$, as tensões do RMTD e os torques do quadricóptero são calculados pelas equações (22) e (18), respectivamente. 


\subsection{Controlador Cinemático}

A fim de que o RMTD acompanhe uma trajetória factível, é utilizado o controlador baseado na cinemática proposto por Kanayama et al. (1990) para veículos não-holonômicos. Esse determina as velocidades desejadas linear e angular para o controle de locomoção do robô.

Nesse controle há duas variáveis de entrada: a postura de referência $P_{r}=\left(x_{r}, y_{r}, \alpha_{r}\right)$ definida pela trajetória vista na Seção 2.5 e a postura atual do robô móvel $P_{c}=\left(x_{c}, y_{c}, \alpha_{c}\right)$ que é postura real no momento. A partir destas variáveis é calculado o erro de postura dado por:

$$
\begin{aligned}
& x_{e}=\cos \alpha_{c}\left(x_{r}-x_{c}\right)+\operatorname{sen} \alpha_{c}\left(y_{r}-y_{c}\right), \\
& y_{e}=-\operatorname{sen} \alpha_{c}\left(x_{r}-x_{c}\right)+\cos \alpha_{c}\left(y_{r}-y_{c}\right), \\
& \alpha_{e}=\alpha_{r}-\alpha_{c},
\end{aligned}
$$

sendo $\alpha_{r}$ a orientação calculada como $\alpha_{r}=\operatorname{tg}^{-1}\left(\dot{y}_{r} / \dot{x}_{r}\right)$.

As velocidades linear $\left(v^{d}\right)$ e angular $\left(\omega^{d}\right)$ desejadas são dadas por:

$$
\begin{aligned}
v_{d} & =v_{r} \cos \alpha_{e}+k_{x} x_{e}, \\
\omega_{d} & =\omega_{r}+v_{r}\left(k_{y} y_{e}+k_{\alpha} \operatorname{sen} \alpha_{e}\right),
\end{aligned}
$$

sendo $k_{x}, k_{y}, k_{\alpha}$ constantes positivas e

$$
v_{r}=\sqrt{\left(\dot{x}_{r}\right)^{2}+\left(\dot{y}_{r}\right)^{2}} \quad \text { e } \quad \omega_{r}=\dot{\alpha}_{r} .
$$

Por fim as velocidades angulares desejadas das rodas são calculadas por:

$$
\dot{q}_{2}^{d}=\left[\begin{array}{c}
\dot{\theta}_{d}^{d} \\
\dot{\theta}_{e}^{d}
\end{array}\right]=\left[\begin{array}{cc}
1 / r & b / r \\
1 / r & -b / r
\end{array}\right]\left[\begin{array}{c}
v_{d} \\
\omega_{d}
\end{array}\right],
$$

sendo $\dot{\theta}_{d}^{d}$ e $\dot{\theta}_{e}^{d}$ as velocidades angulares desejadas da roda direita e esquerda, respectivamente.

\subsection{Determinação dos ângulos de referência}

A abordagem em Zuo (2010) para a determinação da trajetória é empregada para o cálculo dos ângulos de referência de rolagem $\left(\phi_{r}\right)$ e arfagem $\left(\theta_{r}\right)$, e para o cálculo do comando de impulso do quadricóptero.

Esse método baseia-se em um controlador proporcional-derivativo atuando como malha externa de controle de posição do quadricóptero, o qual tem como resultado o vetor de controle virtual $U$, dado por

$$
\left[\begin{array}{l}
U_{1} \\
U_{2} \\
U_{3}
\end{array}\right]=\left[\begin{array}{l}
\ddot{x}_{r} \\
\ddot{y}_{r} \\
\ddot{z}_{r}
\end{array}\right]+\left[\begin{array}{ccc}
k_{d x} & 0 & 0 \\
0 & k_{d y} & 0 \\
0 & 0 & k_{d z}
\end{array}\right]\left[\begin{array}{l}
\dot{x}_{r}-\dot{x}_{c} \\
\dot{y}_{r}-\dot{y}_{c} \\
\dot{z}_{r}-\dot{z}_{c}
\end{array}\right]+\left[\begin{array}{ccc}
k_{p x} & 0 & 0 \\
0 & k_{p y} & 0 \\
0 & 0 & k_{p z}
\end{array}\right]\left[\begin{array}{l}
x_{r}-x_{c} \\
y_{r}-y_{c} \\
z_{r}-z_{c}
\end{array}\right] .
$$


Em seguida, os ângulos de referência são obtidos por

$$
\begin{gathered}
\phi_{r}=\arcsin \left(\frac{U_{1} \operatorname{sen} \psi_{r}-U_{2} \cos \psi_{r}}{\sqrt{U_{1}^{2}+U_{2}^{2}+\left(U_{3}+g\right)^{2}}}\right), \\
\theta_{r}=\arctan \left(\frac{U_{1} \cos \psi_{r}+U_{2} \operatorname{sen} \psi_{r}}{U_{3}+g}\right) .
\end{gathered}
$$

E por fim, o comando de impulso é calculado por

$$
\begin{aligned}
T= & m\left[U_{1}\left(\operatorname{sen} \theta_{c} \cos \psi_{c} \cos \phi_{c}+\operatorname{sen} \psi_{c} \operatorname{sen} \phi_{c}\right)+\right. \\
& \left.U_{2}\left(\operatorname{sen} \theta_{c} \operatorname{sen} \psi_{c} \cos \phi_{c}-\cos \psi_{c} \operatorname{sen} \phi_{c}\right)+\left(U_{3}+g\right) \cos \theta_{c} \cos \phi_{c}\right] .
\end{aligned}
$$

Quanto ao ângulo de referência de guinada do quadricóptero, foi afixado em zero para todos os trajetos. 


\section{Simulações}

\subsection{Simulações para o RMTD}

O ambiente de simulação para o RMTD foi desenvolvido em MATLAB. Os controladores foram simulados para o modelo apresentado no Capítulo 2. Incertezas na massa e no momento de inércia foram atribuídas como $m_{\text {real }}=(1+\Delta) \cdot m_{\text {modelo }}$ e $I_{\text {real }}=(1+\Delta) \cdot I_{\text {modelo }}$, respectivamente. A saturação de tensão em $8 \mathrm{~V}$ foi definida para a fonte de tensão que alimenta os motores das rodas do robô, simulando as limitações da bateria.

Os testes foram simulados com tempo de amostragem e ciclo de controle, $T_{s}=100 \mathrm{~ms}$. O tempo de simulação foi de 100s por cada teste, ou seja, com duração de $N=1000$ amostragens. O tempo de passo de integração do simulador foi de 10ms. O tempo de amostragem foi definido baseado nas limitações no ciclo de execução do controle nos testes experimentais a serem apresentados na Seção 6.1.

De acordo com o modelo no espaço de estado apresentado na seção 2.4, o estado $\tilde{x}$ é composto do erro entre as velocidades angulares da rodas e o erro de deslocamento angular da roda. Esse último é estimado pela pseudo-inversa das três primeiras linhas de $S_{c}\left(q_{1}\right)$ dada na Equação (2), conforme a fórmula apresentada por Inoue et al. (2013) como

$$
\delta_{e}=\left[\begin{array}{c}
\theta_{d}-\theta_{d}^{d} \\
\theta_{e}-\theta_{e}^{d}
\end{array}\right] \approx S^{+}\left[\begin{array}{c}
x-x_{d} \\
y-y_{d} \\
\alpha-\alpha_{d}
\end{array}\right]
$$

Os testes desenvolvidos consistem em simulações sem incerteza e com incerteza no modelo. O percurso do robô móvel consiste do movimento a partir de um ponto próximo da origem para uma trajetória que converge em um curva periódica, circular com raio $\rho$ de um metro e velocidade linear de referência $\bar{v}=0,1 \mathrm{~m} / \mathrm{s}$. A escolha dos parâmetros dos controladores são apresentados nas subseções 5.1.1 à 5.1.4 mostradas a seguir. 


\subsubsection{Parâmetros do Controlador Cinemático}

Os ganhos do controlador foram escolhidos baseados nas recomendações propostas por Kanayama et al. (1990), de tal forma que a dimensão da constante de tempo $1 / k_{x}$ seja suficientemente maior que o tempo de amostragem $T_{s}$, garantindo convergência rápida, mas que não haja oscilações. Além disso, os valores de $k_{y}$ e $k_{\alpha}$ foram escolhidos de tal forma que não exigem excessivas velocidades de rotação. Os ganhos do controlador cinemático são

$$
k_{x}=1, \quad k_{y}=75 \text { e } k_{\alpha}=5 .
$$

\subsubsection{Parâmetros do RLQ-R}

Os parâmetros do controlador RLQ-R foram escolhidos heuristicamente, de tal forma que o sinal de tensão não saturasse, como

$$
\begin{aligned}
P=10^{5} \cdot I_{4 \times 4}, \quad Q & =\left[\begin{array}{cc}
1000 \cdot I_{2 \times 2} & 0_{2 \times 2} \\
0_{2 \times 2} & I_{2 \times 2}
\end{array}\right], R=10 \cdot I_{2 \times 2}, \\
E_{F} & =\left[\begin{array}{llll}
0,1 & 0,1 & 0 & 0
\end{array}\right], \quad E_{G}=\left[\begin{array}{ll}
0,1 & 0,1
\end{array}\right] .
\end{aligned}
$$

Os resultados da simulação são apresentados na Figura 3.

\subsubsection{Parâmetros do controlador $\mathcal{H}_{\infty}$-TJ}

Os parâmetros do controlador $\mathcal{H}_{\infty}$-TJ foram definidos, através do algoritmo apresentado em Chen, Lee e Feng $(1994)$, como $\gamma=10^{8}, Q_{1}=10 \cdot I_{(2 \times 2)}, Q_{2}=1000 \cdot I_{(2 \times 2)}, Q_{12}=0$ e $R=8 \cdot 10^{4} \cdot I_{(2 \times 2)}$, de modo que o sinal de tensão enviado não sature. Já as matrizes $R_{1}$ e $T_{0}$ foram encontradas pela solução das equações (55) e (56), respectivamente.

Os resultados são apresentados na Figura 4.

\subsubsection{Parâmetros do controlador PD}

Os ganhos do controlador PD foram definidos como $k_{p 1}=k_{p 2}=0.01$ e $k_{d 1}=k_{d 2}=1$. A escolha dos parâmetros visa que o sinal de comando do motor não sature.

Os resultados da simulação são apresentados na Figura 5.

\subsubsection{Resultados de Simulação}

Os resultados de simulação com incerteza com incerteza de mais $40 \%$ na massa e no momentos de inércia $(\Delta=0,4)$ são apresentados nas figuras a seguir. 


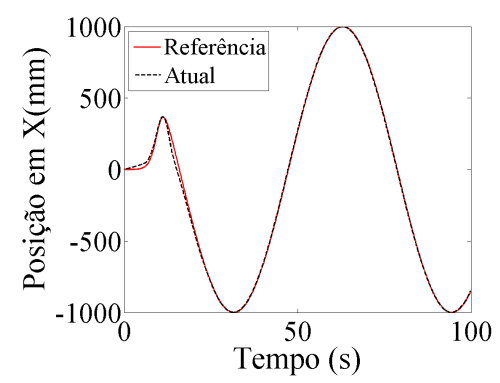

(a) Trajetória em $X$.

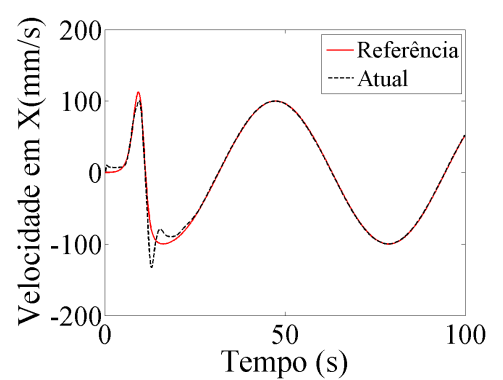

(d) Velocidade em $X$.

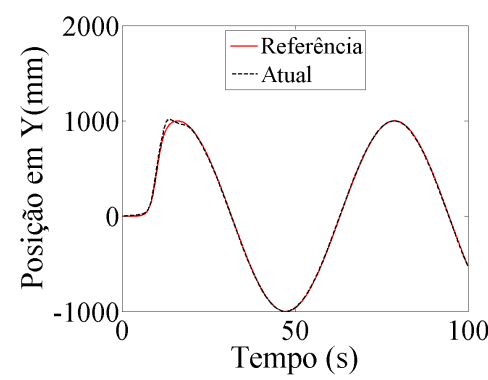

(b) Trajetória em $Y$.

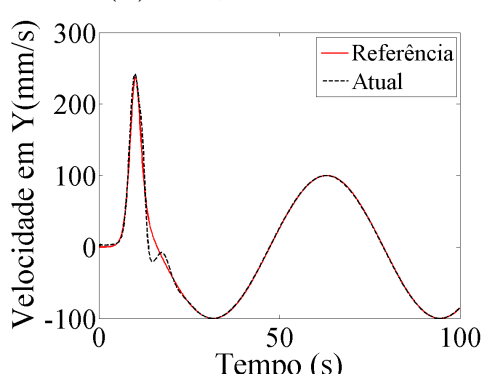

(e) Velocidade em $Y$.

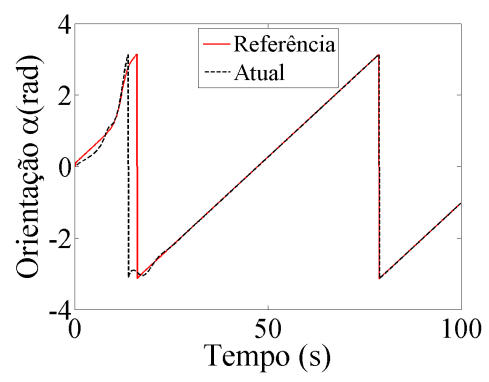

(c) Orientação.

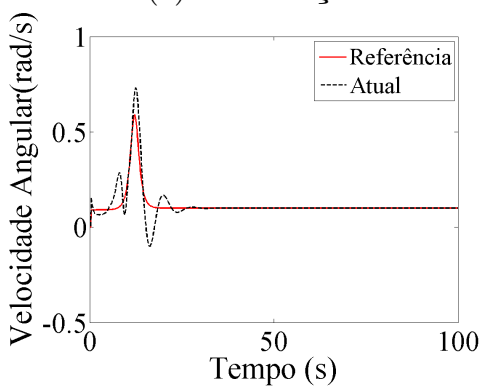

(f) Velocidade angular.

Figura 3 - Resultados de simulação com RLQ-R no RMTD.

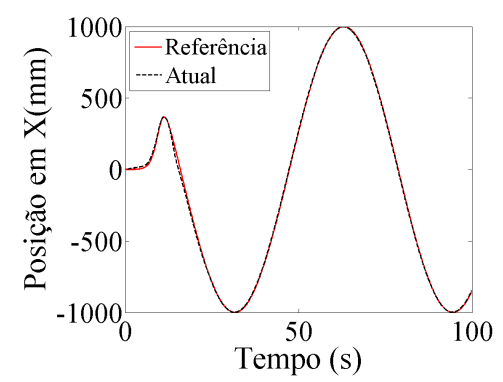

(a) Trajetória em $X$.

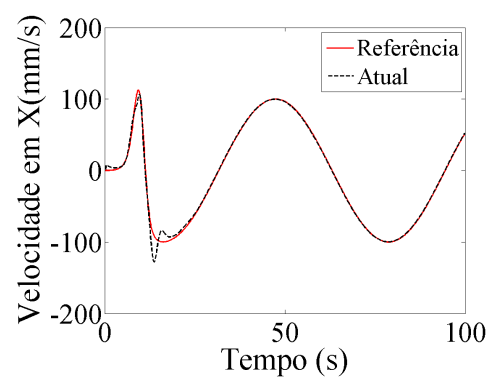

(d) Velocidade em $X$.

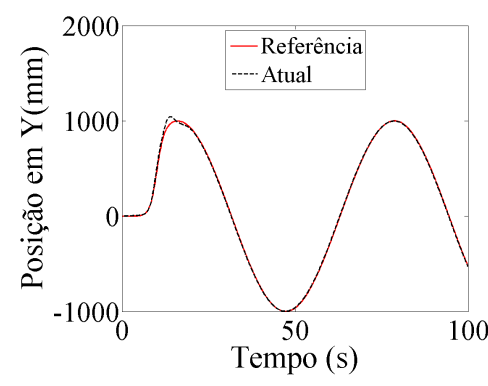

(b) Trajetória em $Y$.

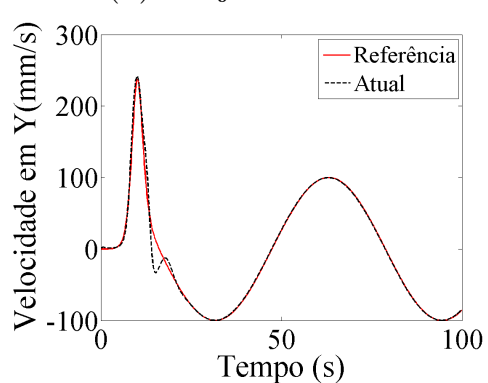

(e) Velocidade em $Y$.

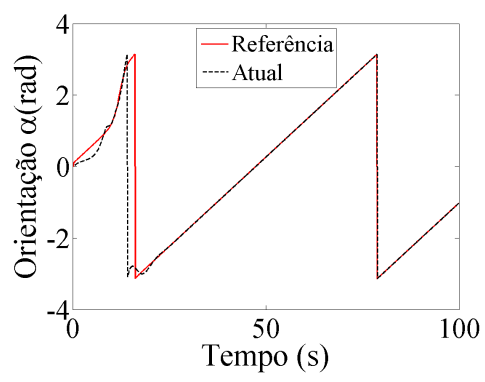

(c) Orientação.

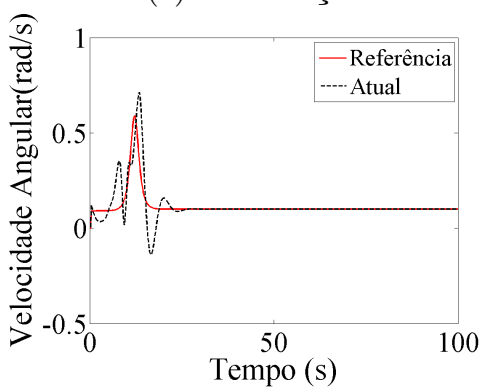

(f) Velocidade angular.

Figura 4 - Resultados de simulação com controlador $\mathcal{H}_{\infty}$-TJ no RMTD. 


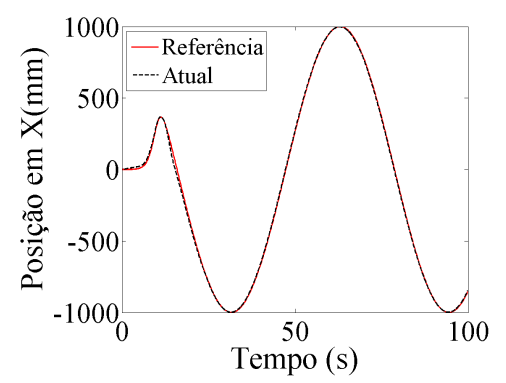

(a) Trajetória em $X$.

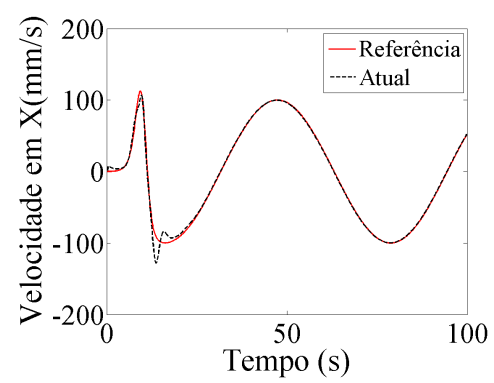

(d) Velocidade em $X$.

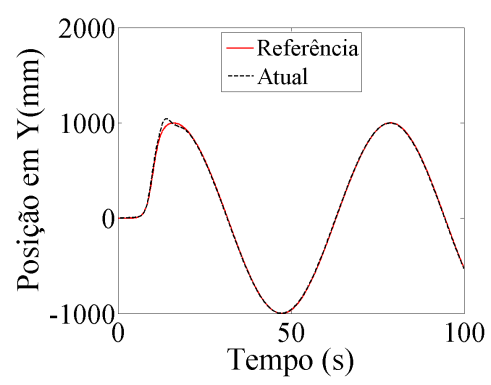

(b) Trajetória em $Y$.

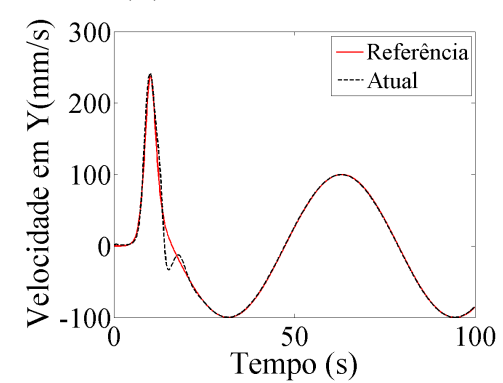

(e) Velocidade em $Y$.

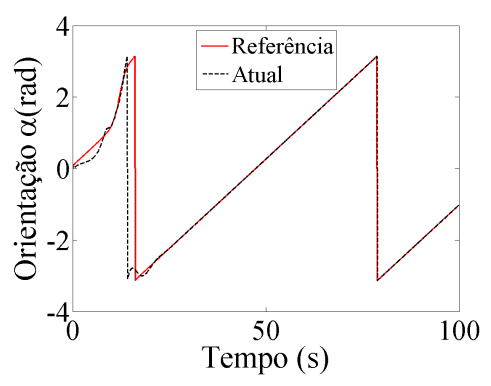

(c) Orientação.

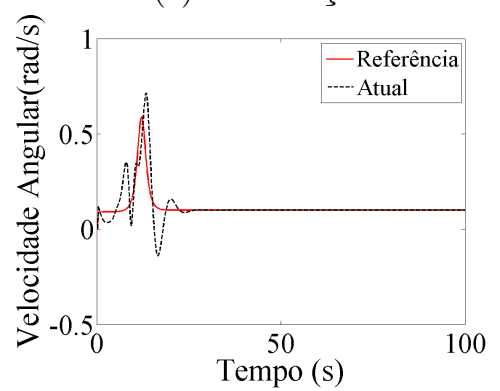

(f) Velocidade angular.

Figura 5 - Resultados de simulação com controlador PD no RMTD.

\subsection{Simulações para o quadricóptero}

Nesta seção é apresentada uma simulação de controle de acompanhamento de trajetória de um quadricóptero em MATLAB ${ }^{\circledR}$, conforme a Figura 6. O modelo do quadricóptero utilizado foi baseado na Seção 3, cujos parâmetros do modelo dinâmico foram obtidos do trabalho de Luukkonen (2011).

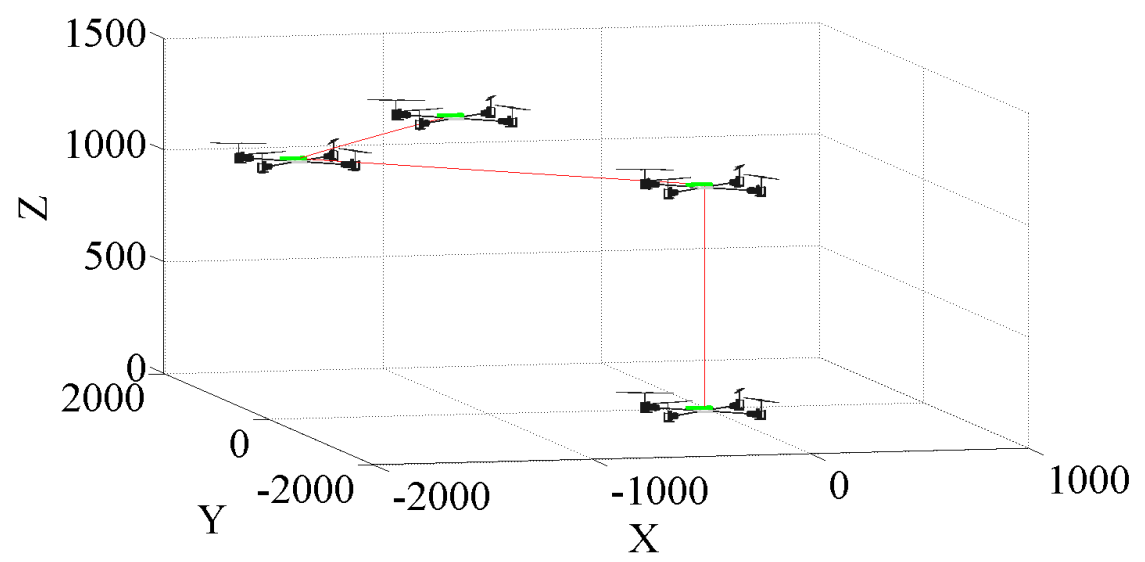

Figura 6 - Simulador do quadricóptero.

O cálculo da trajetória é realizado a partir do tempo estimado entre etapas e as posições atuais e final desejada para a aeronave. O tempo estimado é calculado através da distância da posição atual à final desejada e dividido-a pela velocidade média estipulada 
de $100 \mathrm{~mm} / \mathrm{s}$. Um tempo de cinco segundos é acrescido ao tempo estimado para que o quadricóptero alcance o ponto desejado e haja a transição entre etapas.

Os testes foram simulados com tempo de amostragem e ciclo de controle, $T_{s}$, de $100 \mathrm{~ms}$. O tempo de simulação foi de 200s por cada teste, ou seja, com duração de $N=2000$ amostragens. O tempo de passo de integração do simulador foi de $10 \mathrm{~ms}$.

O voo foi organizado em cinco etapas: inicialmente a aeronave se encontra na posição $x_{0}=0 \mathrm{~mm}, y_{0}=0 \mathrm{~mm}, z_{0}=0 \mathrm{~mm}$ e orientação $\psi_{0}=0$ rad e decola para o ponto de passagem $x_{f}=0, y_{f}=0$ e $z_{f}=1000 \mathrm{~mm}$, e em seguida segue os pontos de passagem $x_{f}$ $=-1500 \mathrm{~mm}, y_{f}=1500 \mathrm{~mm} \mathrm{e} z_{f}=1000 \mathrm{~mm}$ e $x_{f}=-1500 \mathrm{~mm}, y_{f}=-1500 \mathrm{~mm} \mathrm{e} z_{f}=$ $1500 \mathrm{~mm}, x_{f}=1500 \mathrm{~mm}, y_{f}=1500 \mathrm{~mm} z_{f}=1000 \mathrm{~mm}$ e finalmente $x_{f}=0 \mathrm{~mm}, y_{f}=$ $0 \mathrm{~mm} z_{f}=1000 \mathrm{~mm}$ até o resto da simulação, sempre mantendo a referência no ângulo de guinada, $\psi$, fixo em zero.

O diagrama de blocos na Figura 7 mostra uma visão geral do projeto desenvolvido.

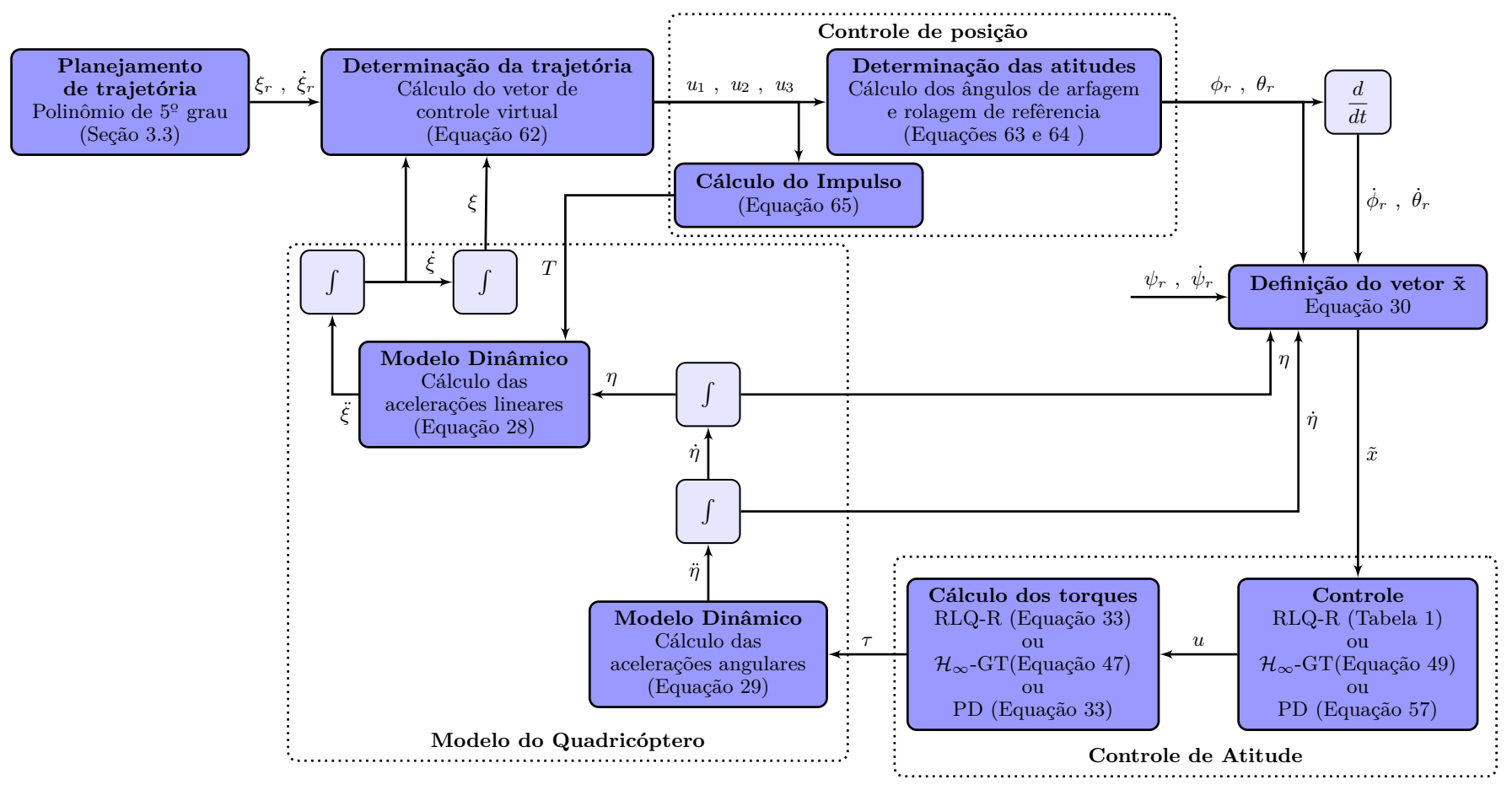

Figura 7 - Diagrama de blocos da simulação.

\subsubsection{Parâmetros Determinação de Trajetória}

Os ganhos para a determinação da trajetória foram escolhidos heuristicamente com o objetivo de garantir que o erro de regime permanente da posição seja zero. Os ganhos são

$$
\begin{gathered}
k_{p x}=k_{p y}=1,3, \quad k_{p z}=80, \\
k_{d x}=k_{d y}=0,5, \quad k_{d z}=5 .
\end{gathered}
$$




\subsubsection{Parâmetros do RLQ-R}

Os parâmetros do controlador RLQ-R foram escolhidos heuristicamente como

$$
\begin{array}{r}
P=300000 \cdot I_{6 \times 6}, \quad Q=\left[\begin{array}{cc}
1000 \cdot I_{3 \times 3} & 0 \\
0 & 0,1 \cdot I_{3 \times 3}
\end{array}\right], \quad R=50 \cdot I_{3 \times 3}, \\
E_{G}=\left[\begin{array}{lll}
0,1 & 0,1 & 0,1
\end{array}\right], \quad E_{F}=\left[\begin{array}{llllll}
0,1 & 0,1 & 0,1 & 0 & 0 & 0
\end{array}\right] .
\end{array}
$$

\subsubsection{Parâmetros do controlador $\mathcal{H}_{\infty}$-TJ}

Os parâmetros do controlador $\mathcal{H}_{\infty}$-TJ foram escolhidos, através do algoritmo apresentado em Chen, Lee e Feng (1994) como

$$
\gamma=10^{8}, \quad R=40 \cdot I_{3 \times 3}, \quad Q=\left[\begin{array}{cc}
1000 I_{3 \times 3} & 0 \\
0 & 100 I_{3 \times 3}
\end{array}\right]
$$

Já as matrizes $R_{1}$ e $T_{0}$ foram encontradas pela solução das equações (55) e (56), respectivamente.

\subsubsection{Parâmetros do controlador PD}

Os parâmetros do controlador PD foram escolhidos como

$$
\begin{aligned}
& k_{p \phi}=k_{p \theta}=2,5, k_{p \psi}=1,5, \\
& k_{d \phi}=k_{d \theta}=0,1, \quad k_{d \psi}=0,3 .
\end{aligned}
$$

\subsubsection{Resultados de Simulação}

A fim de avaliar os controladores aplicados, foi utilizada a média do erro quadrático entre a referência e os resultados obtidos para as variáveis $x, y, z, \phi, \theta$ e $\psi$, conforme

$$
E\left\|x_{r, i}-x_{i}\right\|^{2}=\frac{1}{200} \sum_{j=1}^{200}\left\|x_{r, i}-x_{i}\right\|^{2} .
$$

As figuras 8 e 9 apresentam as curvas das médias, onde cada ponto da curva é a média quadrática para 200 experimentos na simulação, em escala logarítmica, variando aleatoriamente a incerteza da massa e dos momentos de inércia entre $\pm 40 \%$. Cada curva corresponde à 200s de voo da aeronave, com tempo de 100ms para amostragem e execução de cada algoritmo de controle. 


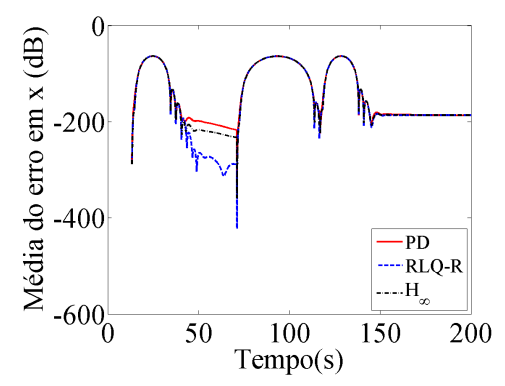

(a) $\operatorname{Em} X$.

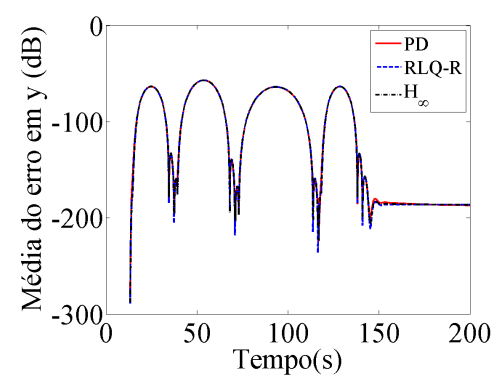

(b) $\operatorname{Em} Y$.

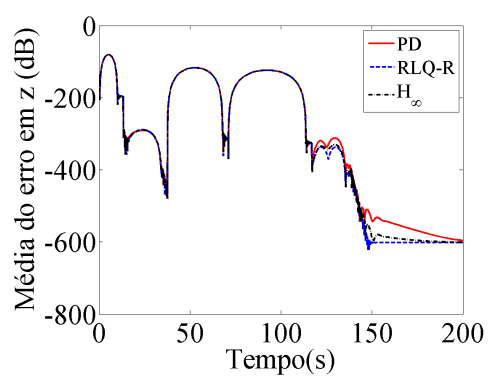

(c) $\operatorname{Em} Z$.

Figura 8 - Curva em escala logarítmica da média do erros quadráticos da posição.

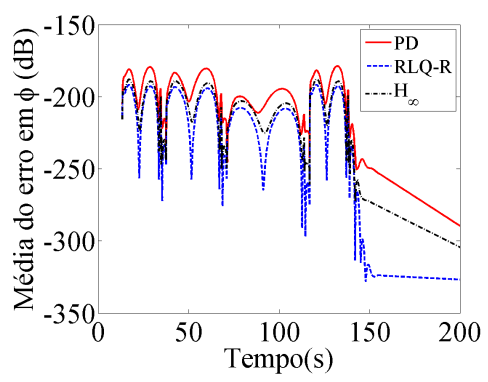

(a) $\operatorname{Em} \phi$.

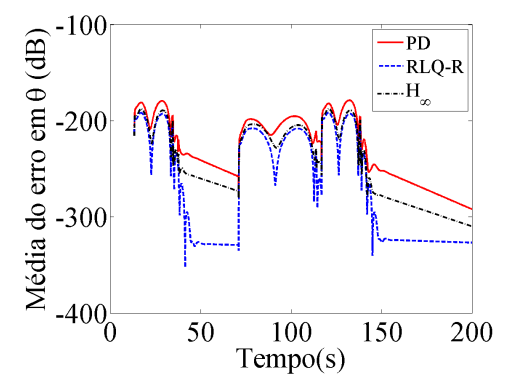

(b) $\operatorname{Em} \theta$.

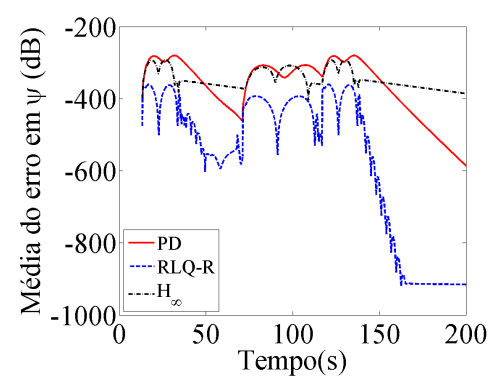

(c) $\operatorname{Em} \psi$.

Figura 9 - Curva em escala logarítmica da média do erros quadráticos da atitude.

A partir desta análise, nota-se menor erro no RLQ-R em relação aos demais controladores utilizados. Além disso, verifica-se a estabilidade e a robustez do RLQ-R sem a necessidade de ajuste de parâmetros auxiliares, o que torna interessante em aplicações online.

Os resultados de simulação apresentados nas figuras 10 e 11 utilizam o RLQ-R, sujeito a incerteza de $40 \%$ na massa e no momento de inércia.

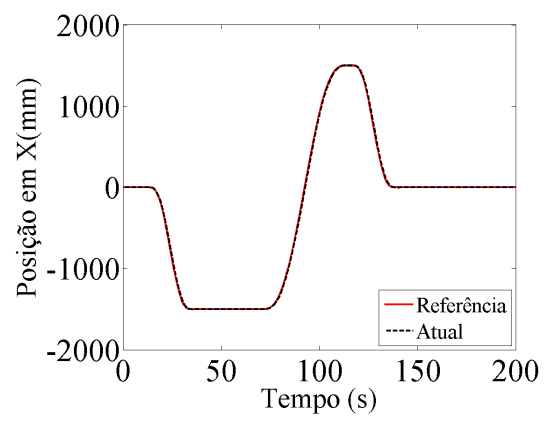

(a) Em relação o eixo $X$.

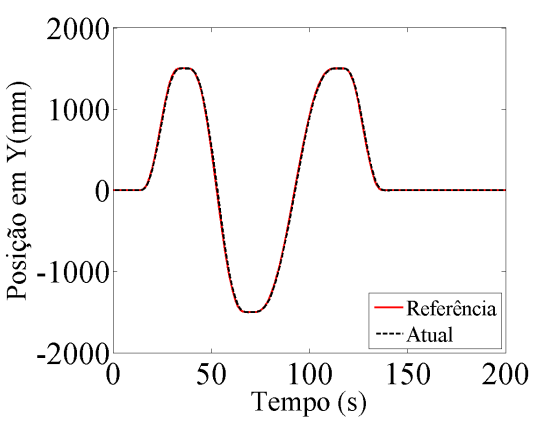

(b) Em relação o eixo $Y$.

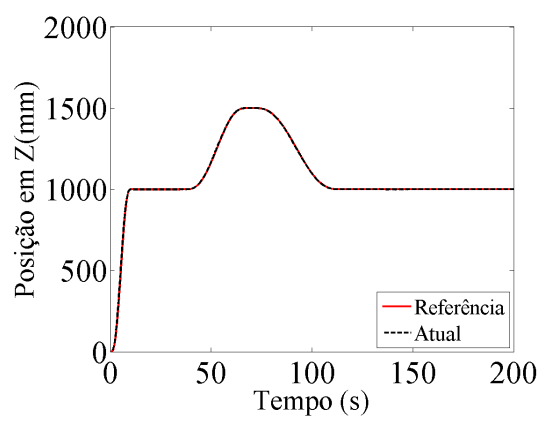

(c) Em relação o eixo $Z$

Figura 10 - Posição do quadricóptero com o controlador RLQ-R. 


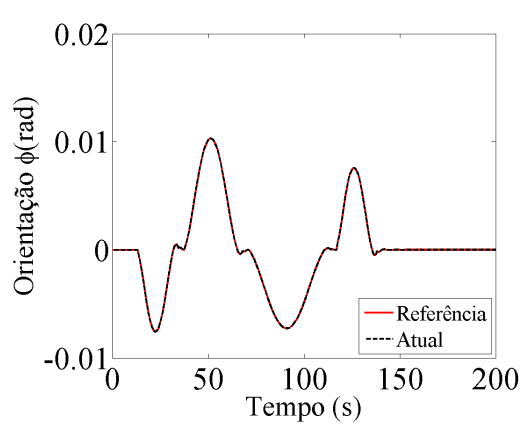

(a) Orientação no ângulo $\phi$.

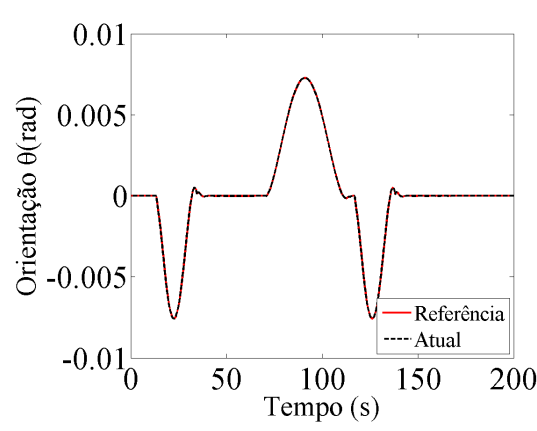

(b) Orientação no ângulo $\theta$.

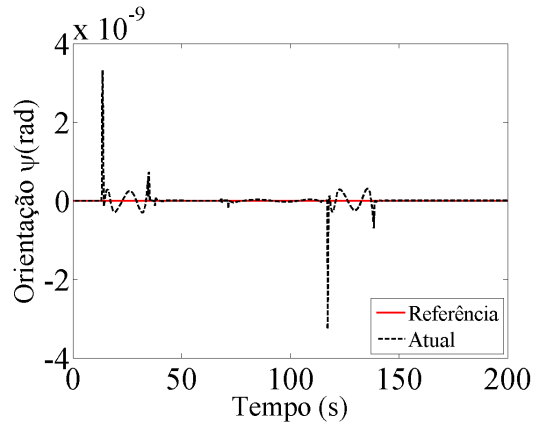

(c) Orientação no ângulo $\psi$.

Figura 11 - Atitude do quadricóptero com o controlador RLQ-R. 


\section{Resultados Experimentais}

Este capítulo está dividido em duas partes: a primeira mostra os resultados práticos com o protótipo desenvolvido utilizando um sistema de captura de movimento; a segunda parte mostra a interface desenvolvida para comunicação para VANTs utilizados em aeromodelismo.

\subsection{Resultados Experimentais do RMTD}

\subsubsection{Câmeras da Vicon}

Na localização dos robôs RMTD foi utilizado um sistema de alta precisão de captura de movimento comercializado pela Vicon ${ }^{\circledR}(\operatorname{VICON}, 2012)$. Esse sistema consiste em um conjunto de quatro câmeras instaladas nos cantos superiores no Laboratório de Sistemas Inteligentes - LASI da USP em São Carlos, conforme a Figura 12.

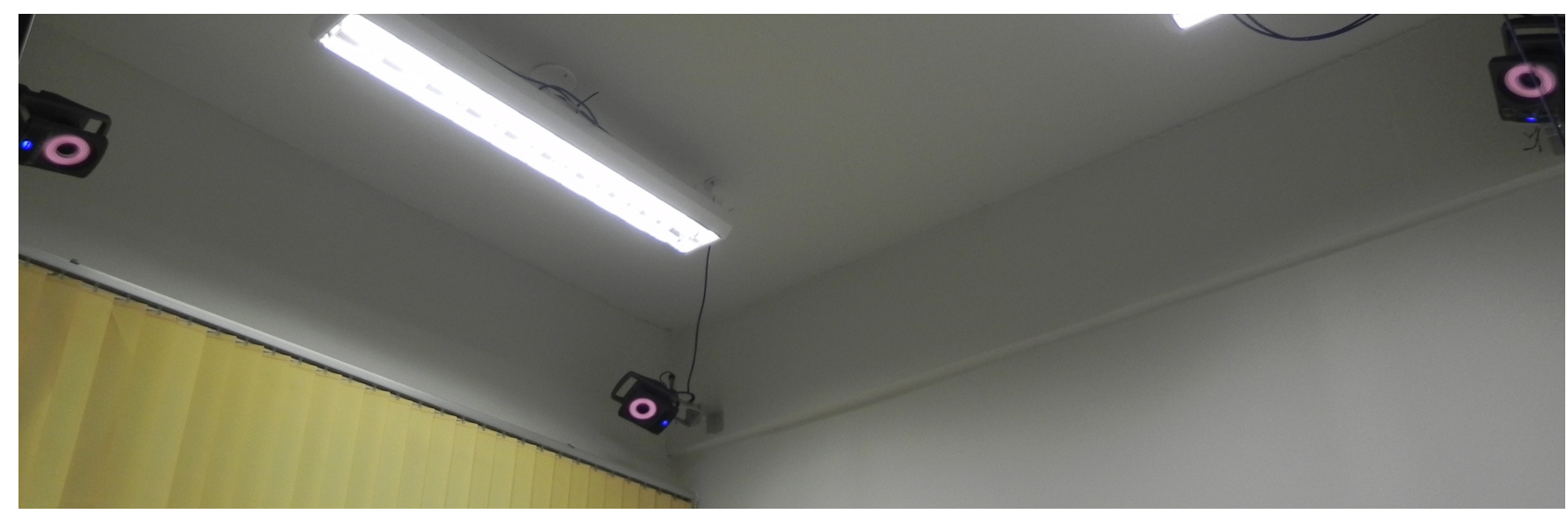

Figura 12 - Posicionamento das câmeras T40S no laboratório.

A operação desse sistema consiste na emissão de luz infravermelha por uma matriz de LEDs infravermelhos localizados na face frontal das câmeras. A luz infravermelha, por sua vez, é refletida por marcadores reflexivos (Figura 13) localizados em pontos estáticos 
no objeto a ser rastreado. Em seguida, a luz é refletida e é detectada pelas câmeras, que possuem um sistema de filtro IR óptico, para que apenas os marcadores sejam reconhecidos. Nos experimentos deste trabalho foram utilizados quatro marcadores, sendo um redundante, já que na captura são necessários apenas três marcadores por objeto.

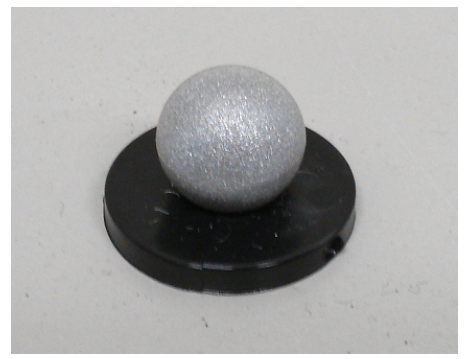

Figura 13 - Marcador reflexivo.

A Figura 14 ilustra o modelo de câmera T40S da Vicon ${ }^{\circledR}$ com resolução de 4 megapixels cada uma. Essas comunicam com um servidor dedicado via fibra óptica através do protocolo Giganet, no qual a alimentação e a comunicação das câmeras são realizadas pelo mesmo cabo. O servidor dedicado recebe as imagens das câmeras e aplica os algoritmos para determinação dos objetos no espaço. O resultado de tal processamento gera informações de posição, orientação em ângulos de Euler e rotação em quatérnios.

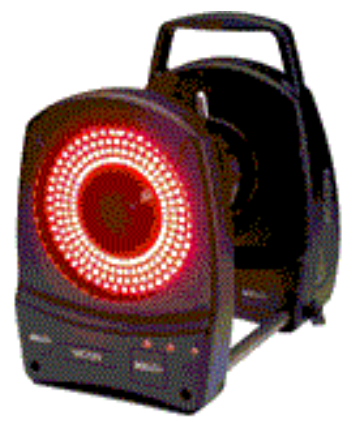

Figura 14 - Câmera Vicon ${ }^{\circledR}$ modelo T-series T40S.

Em um computador local é instalado o software Tracker da Vicon ${ }^{\circledR}$ (Figura 15), no qual configurações de operação, comunicação e o sistema de coordenada local são definidos. Além disso, por este software as informações do servidor dedicado são difundidas (broadcasting) na rede Ethernet para que qualquer computador na rede possa acessá-las.

Esse sistema possui características importantes para o projeto, tais como possibilitar a implementação de controladores em tempo real para os robôs, já que o sistema de câmeras fornece medidas das posições e orientações dos marcadores a uma frequência de até $375 \mathrm{~Hz}$. Além disso, a medida fornecida é precisa, podendo chegar a um desvio da estimativa de posição da ordem de $50 \mu \mathrm{m}$. Por fim, o sistema é robusto e mantém o rastreamento de um objeto mesmo quando ocorre oclusão dos marcadores para todas as câmeras com exceção de uma (VICON, 2013). 


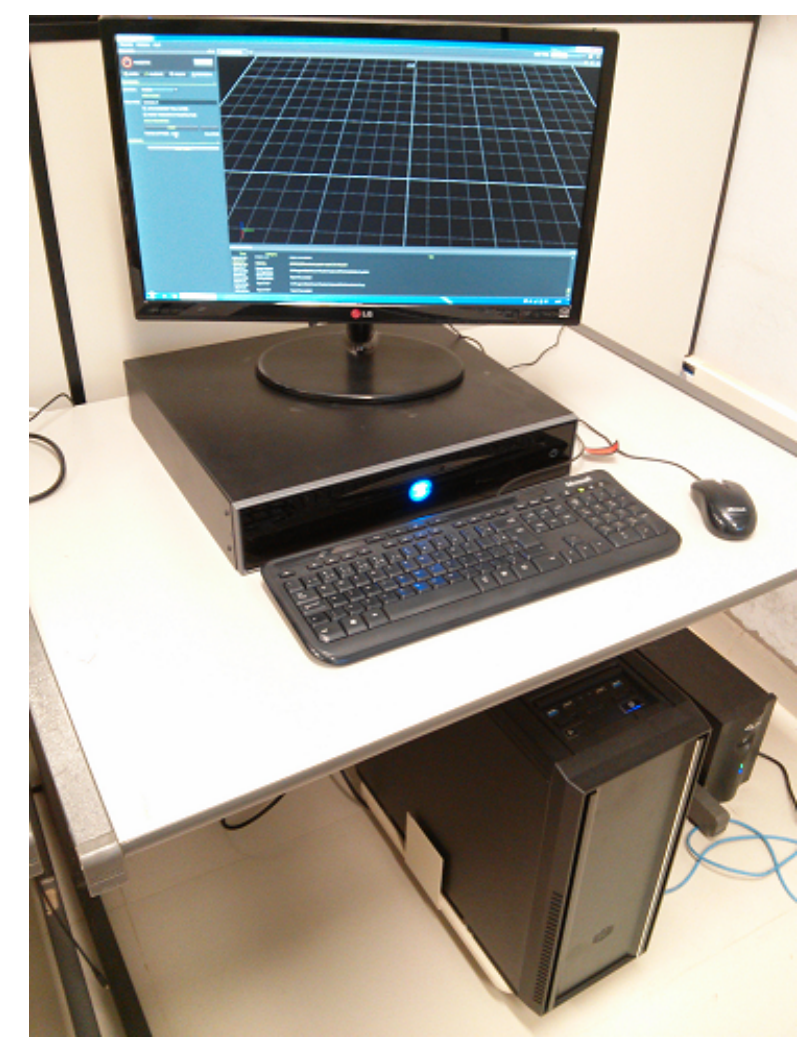

Figura 15 - Computador das câmeras e o software Tracker.

\subsubsection{Projeto do robô móvel}

Os resultados experimentais foram obtidos utilizando o RMTD descrito na Figura 16. A estrutura deste robô móvel é composta de: um chassi construído em chapa de alumínio, dois redutores de velocidade de razão 18:1 e dois motores CC com torque máximo de $0,0182 \mathrm{Nm}$.

A parte eletrônica engloba: um placa com duas pontes- $\mathrm{H}$ para acionamento de dois motores $\mathrm{CC}$, um módulo de rádio frequência Xbee do protocolo ZigBee e uma placa controladora com o microcontrolador PIC18F4520 da Microchip ${ }^{\circledR}$ operando em $20 \mathrm{MHz}$. Os comandos do computador, onde é executado os algoritmos de controle, são recebidos através do Xbee. O microcontrolador, por sua vez, gera um sinal Pulse Width Modulation $(\mathrm{PWM})^{1}$ para os transistores da ponte-H, determinando assim a tensão aplicada nos motores de cada roda.

A alimentação do robô foi realizada através de duas baterias de LiPo de 11,1V4350mAh. Uma delas tem a função de alimentar o microcontrolador e o módulo Xbee. A outra foi utilizada combinada com o regulador de tensão LM317 para alimentar a ponteH. A regulação assegura a mesma tensão de entrada para a ponte-H, desde que a tensão da bateria seja superior a um determinado limiar, o que garante maior repetibilidade dos resultados ao longo do tempo. Isso se faz necessário, pois com o consumo de energia a tensão da bateria vai diminuindo.

\footnotetext{
${ }^{1}$ Em português: Modulação por largura de pulso
} 


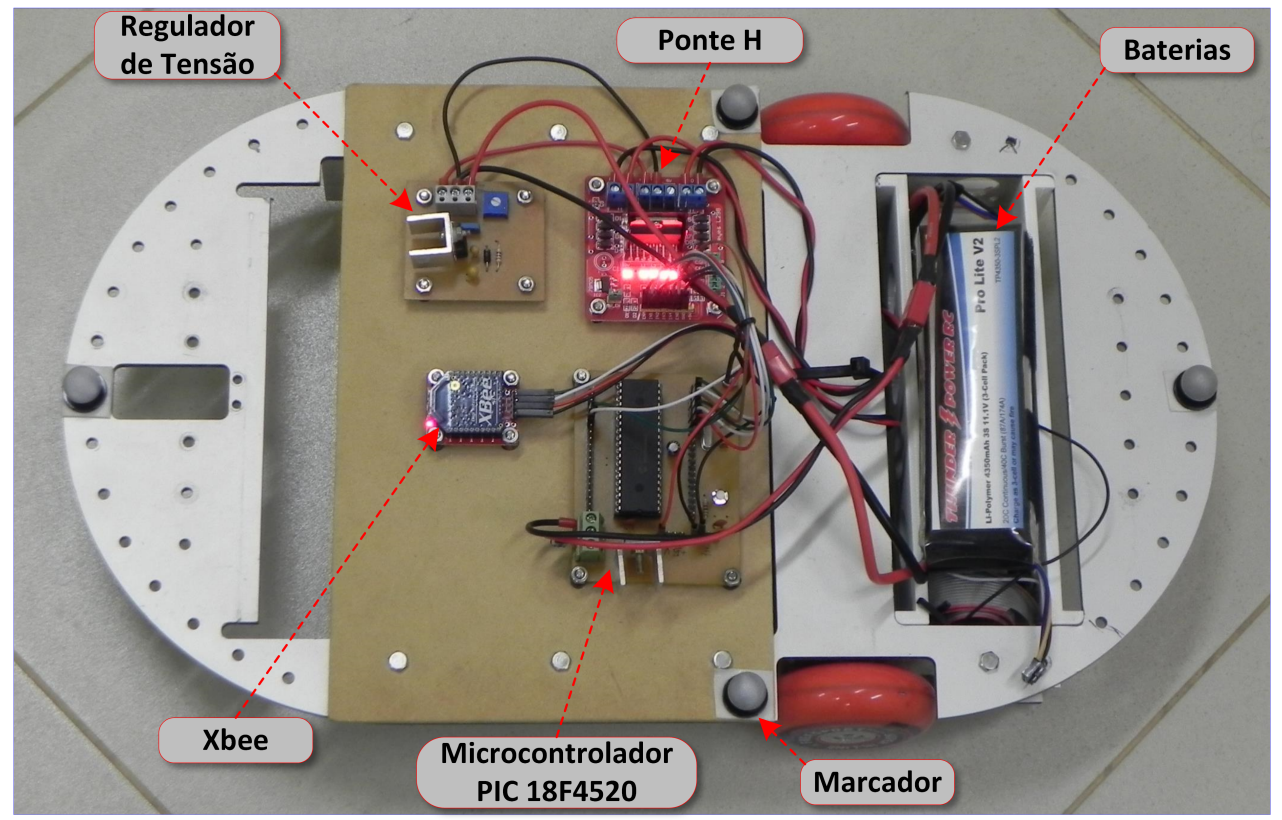

Figura 16 - Robô móvel com tração diferencial construído.

O desenvolvimento do projeto foi previamente modelado no software Inventor da Autodesk ${ }^{\circledR}$ em versão para estudantes, conforme Figura 17.

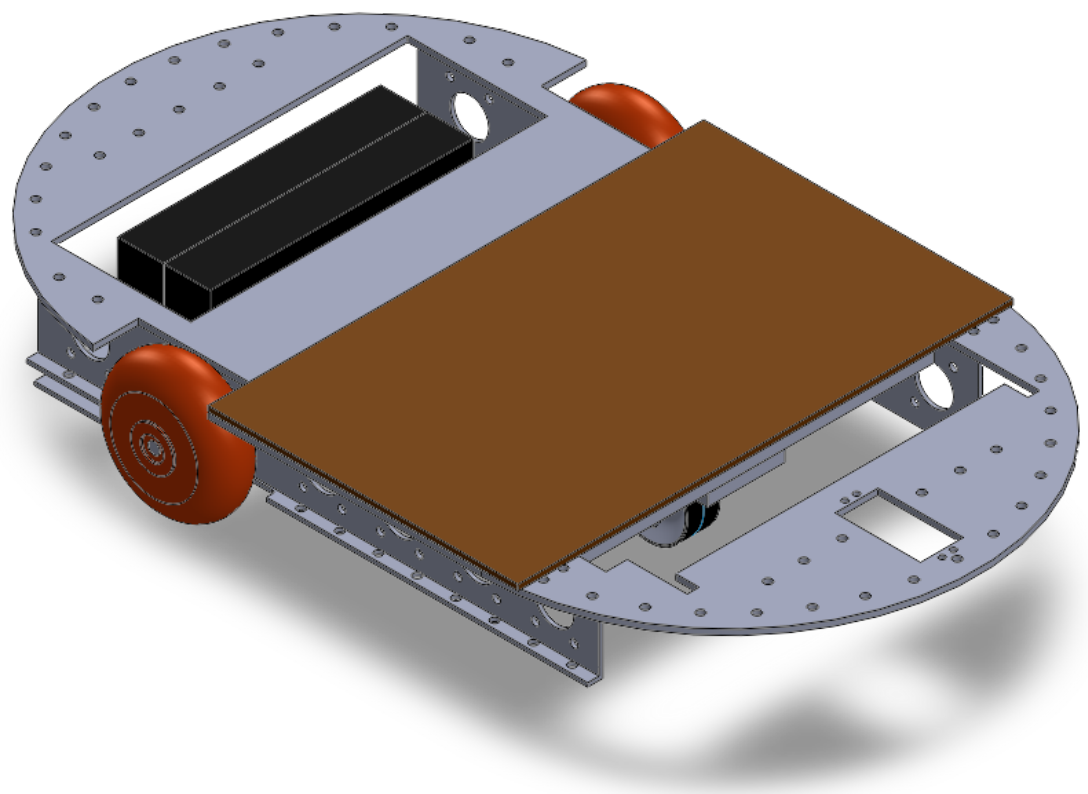

Figura 17 - Modelo do robô móvel no software Inventor.

A Tabela 2 apresenta os parâmetros do robô divididos entre os dados do motor e do corpo, os quais foram obtidos através de folha de dados do motor e do projeto executado pelo software Inventor, respectivamente. 
Tabela 2 - Parâmetros do RMTD.

\begin{tabular}{|c|c|c|c|}
\hline & Parâmetro & Valor & Unidade \\
\hline \multirow{5}{*}{ Motor } & $I_{s}$ & $2,007 \cdot 10^{-6}$ & $\mathrm{kgm}^{2}$ \\
& $k_{t}$ & 0,0230 & $\mathrm{Nm} / \mathrm{A}$ \\
& $k_{w}$ & 0,0208 & $\mathrm{Vs} / \mathrm{rad}$ \\
& $n_{r}$ & 18 & - \\
& $R$ & 5,54 & $\Omega$ \\
& $\nu$ & $5 \cdot 10^{-4}$ & $\mathrm{Nms} / \mathrm{rad}$ \\
\hline \multirow{6}{*}{ Corpo } & $I_{c}$ & 0,0062 & $\mathrm{kgm}^{2}$ \\
& $I_{m}$ & $3,038 \cdot 10^{-5}$ & $\mathrm{kgm}^{2}$ \\
& $I_{w}$ & $5,399 \cdot 10^{-5}$ & $\mathrm{kgm}^{2}$ \\
& $m_{c}$ & 1,785 & $\mathrm{~kg}$ \\
& $m_{w}$ & 0,364 & $\mathrm{~kg}$ \\
& $d$ & 0,0240 & $\mathrm{~m}$ \\
& $b$ & 0,1165 & $\mathrm{~m}$ \\
& $r$ & 0,035 & $\mathrm{~m}$ \\
\hline
\end{tabular}

\subsubsection{Organização dos Experimentos}

A Figura 18 ilustra a infraestrutura utilizada nos experimentos para o controle do RMTD.

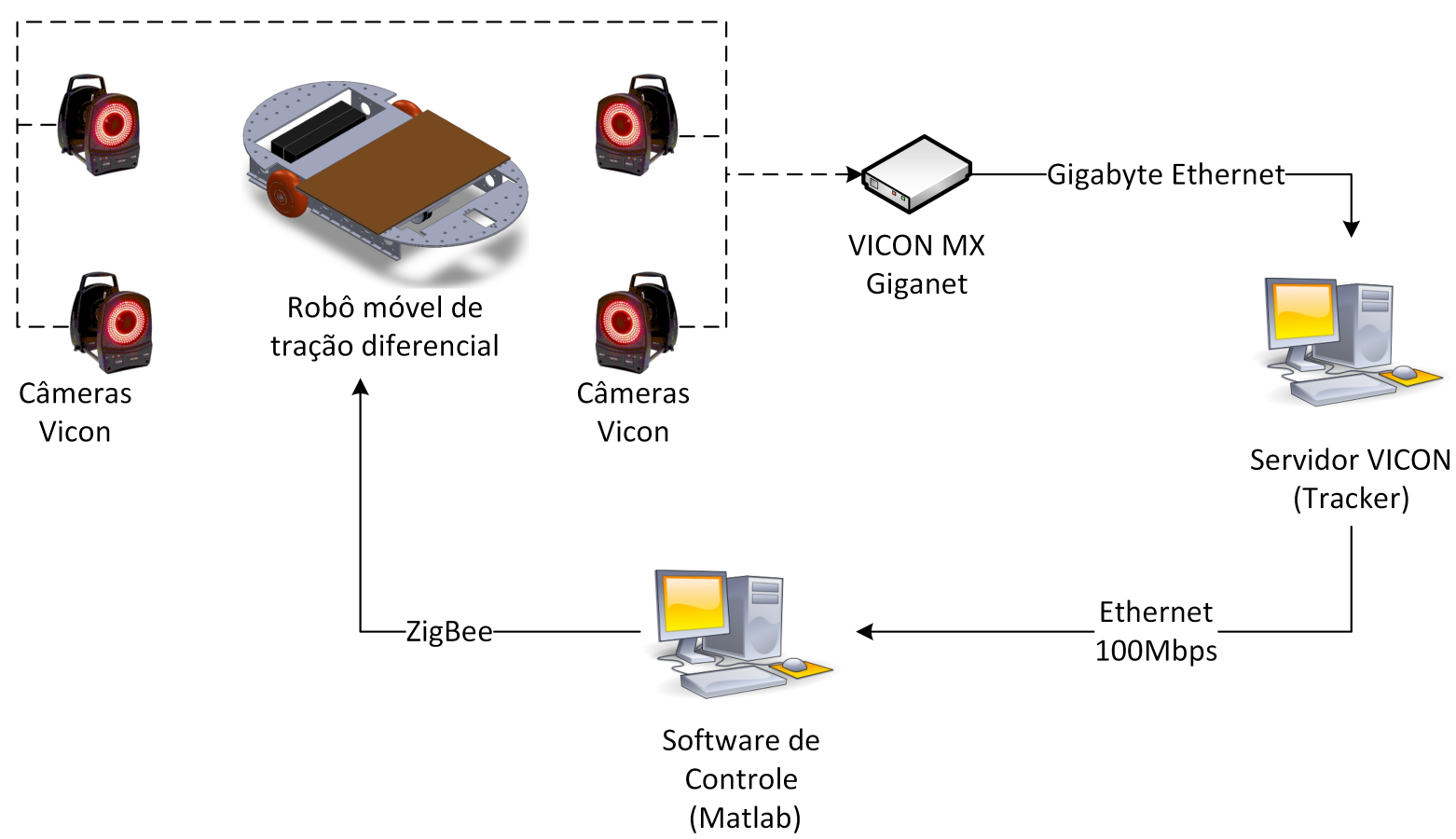

Figura 18 - Infraestrutura de comunicação para o controle do RMTD.

Primeiramente, as câmeras da Vicon recebem o reflexo do sinal de infravermelho pelos marcadores instalados no robô. As imagens coletadas são enviadas por fibra óptica para a unidade VICON MX Giganet que permite conectar e sincronizar as câmeras. Em seguida, 
o servidor da VICON, através do software Tracker, processa as imagens e difundi pacotes de dados na rede Ethernet com a posição e a orientação do robô. Um computador captura esses pacotes e executa o algoritmo de controle e envia os comandos para o robô via Zigbee. No robô, os comandos são interpretados e convertidos em sinal PWM para o chaveamento da ponte-H conectada aos motores das rodas.

O software de implementação dos algoritmos de controle no protótipo do robô móvel, apresentado na subseção anterior, foi desenvolvido em conjunto com o software elaborado para a simulação. Isso fornece a vantagem de poder simular e testar experimentalmente os algoritmos em um mesmo programa. A Figura 19 apresenta a estratégia de controle completa em diagrama de blocos.

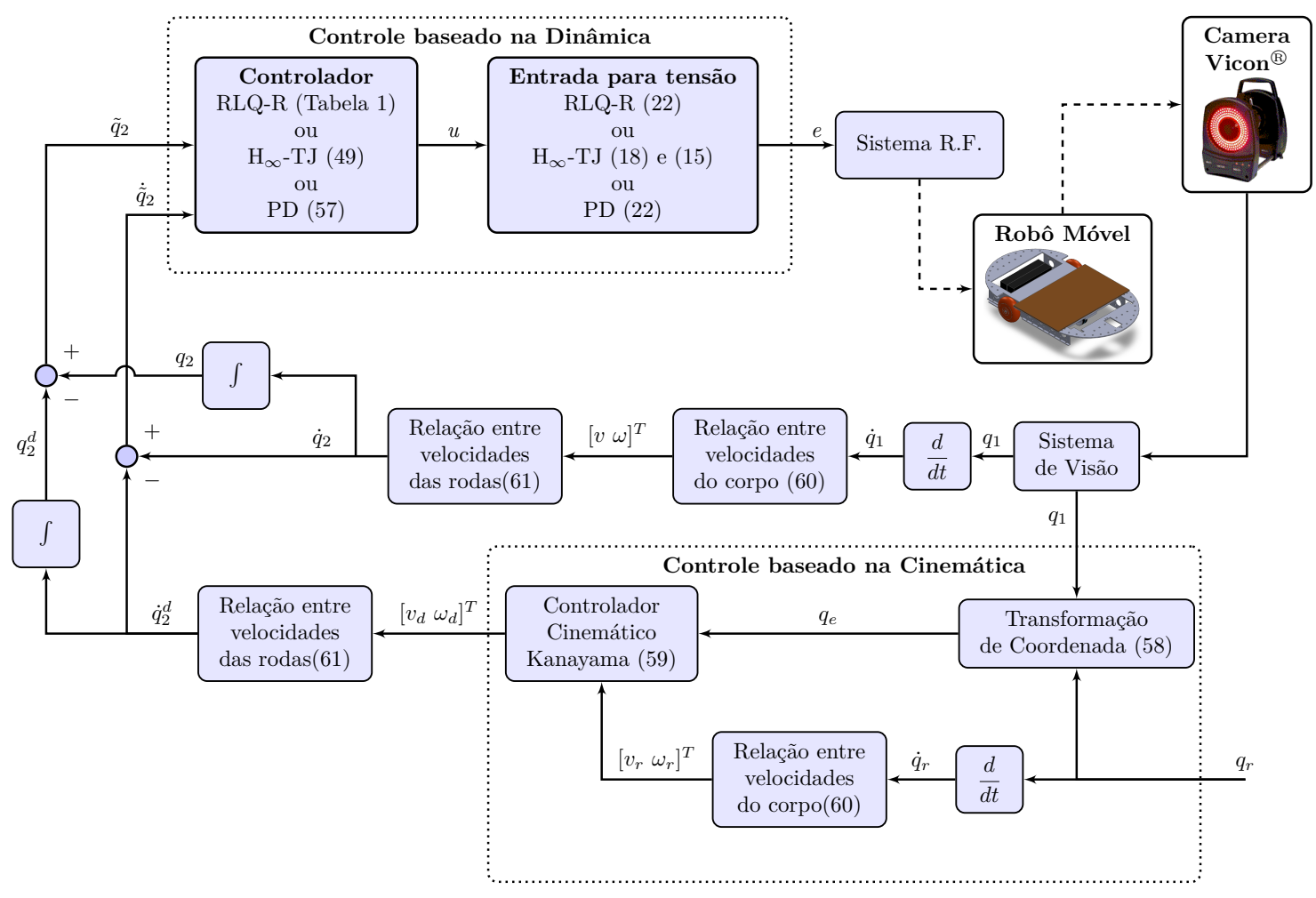

Figura 19 - Diagrama de blocos do controle de acompanhamento de trajetória do RMTD.

Os testes experimentais consistem do RMTD partir de uma posição, demarcada no espaço de trabalho, próxima a origem do sistema de coordenada inercial, no primeiro quadrante e com orientação inicial $\alpha_{0}=\frac{\pi}{6} \mathrm{rad}$. O robô desloca-se para uma trajetória circular com centro na origem e orientação definida pelo movimento, conforme a Figura 20. A trajetória de referência é gerada conforme a Seção 2.5 e em seguida as velocidades desejadas das rodas são calculadas assim como é apresentado na Seção 4.4. E em seguida é obtido, pela lei de controle utilizada, o comando de tensão a ser enviado para o robô.

O modelo usado nos experimentos foi baseado nos parâmetros do RMTD apresentados na Tabela 2. Os ganhos adotados nos controladores são mostrados nas subseções 5.1.2 à 5.1.4. 


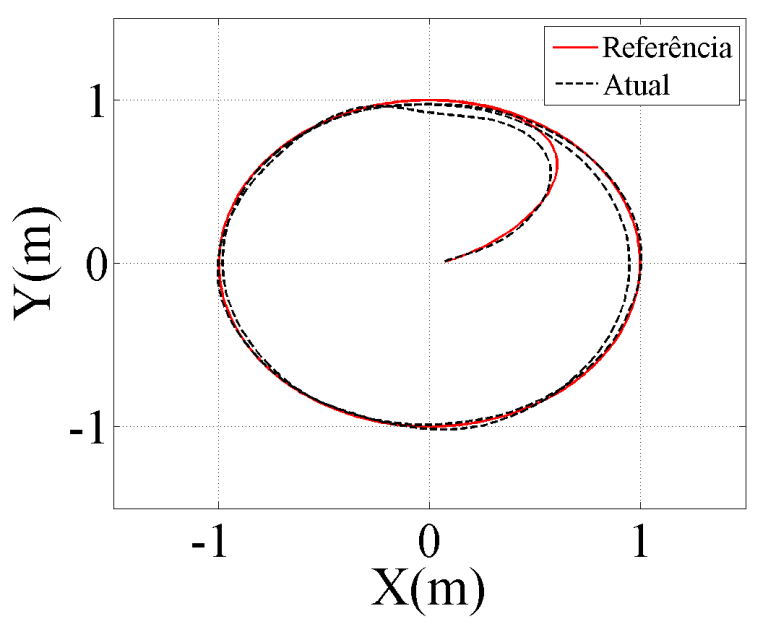

Figura 20 - Trajetória do robô móvel.

Nos experimentos com o modelo sujeito a incertezas, foi instalado um peso de $1 \mathrm{~kg}$ sobre o robô e foram definidas as mesmas condições (saturação, tempo de amostragem, ciclo de execução) determinadas na simulação.

Os resultados experimentais com incerteza gerada pelo peso de $1 \mathrm{~kg}$ são mostrados nas figuras 21 à 23.

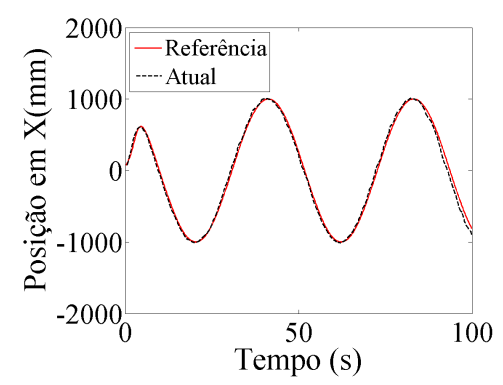

(a) Trajetória em $X$.

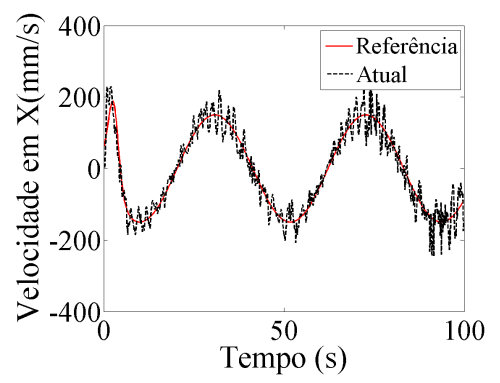

(d) Velocidade em $X$.

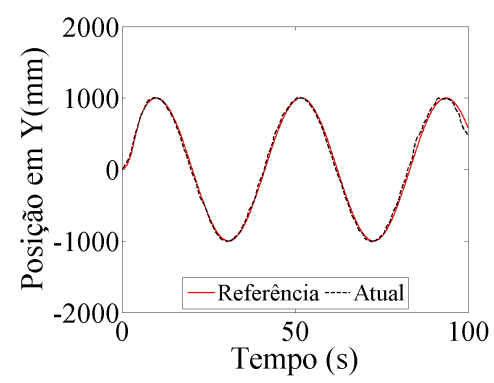

(b) Trajetória em $Y$.

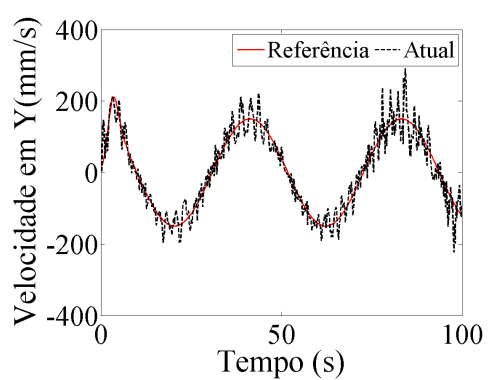

(e) Velocidade em $Y$.

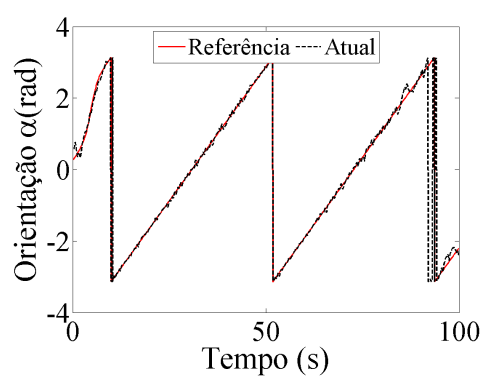

(c) Orientação.

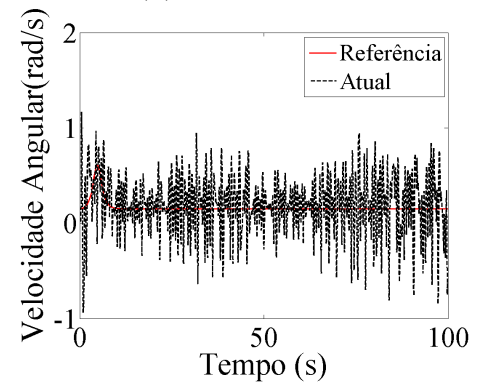

(f) Velocidade angular.

Figura 21 - Resultados experimentais com RLQ-R no RMTD. 


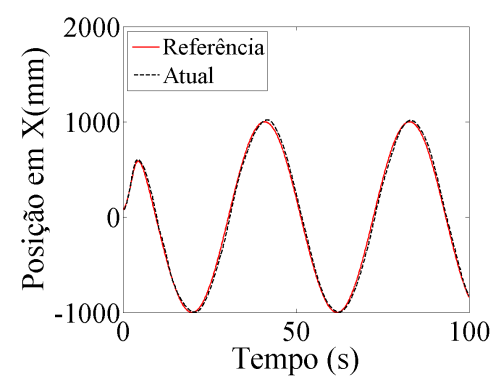

(a) Trajetória em $X$.

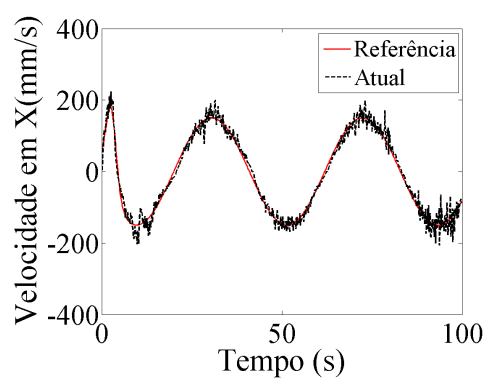

(d) Velocidade em $X$.

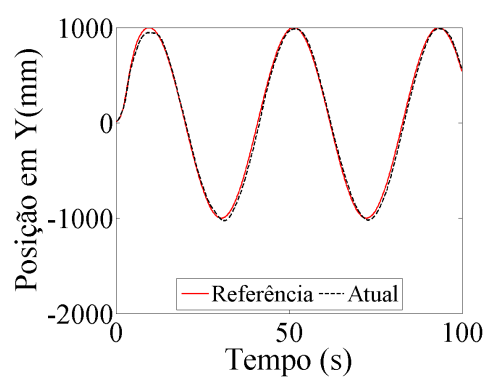

(b) Trajetória em $Y$.

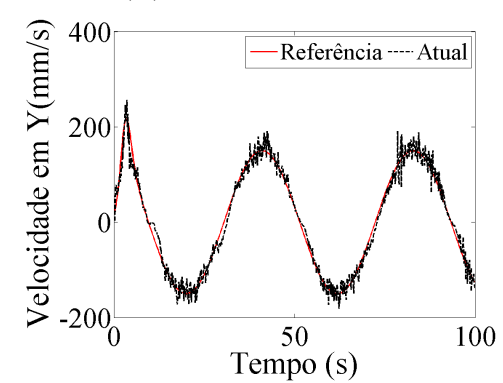

(e) Velocidade em $Y$.

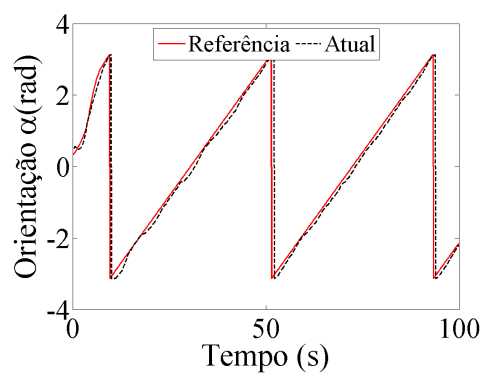

(c) Orientação.

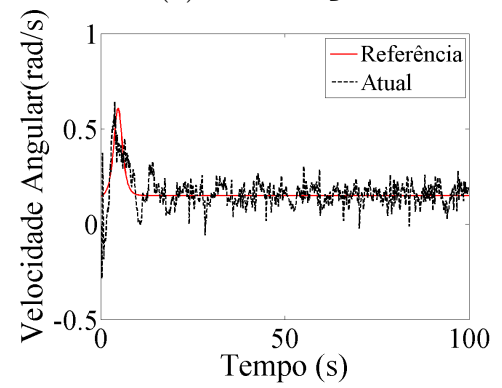

(f) Velocidade angular.

Figura 22 - Resultados experimentais com $\mathcal{H}_{\infty}$-TJ no RMTD.

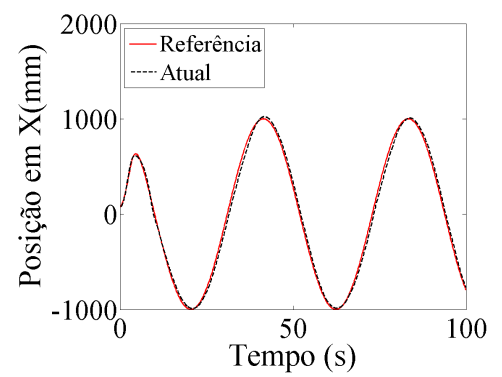

(a) Trajetória em $X$.

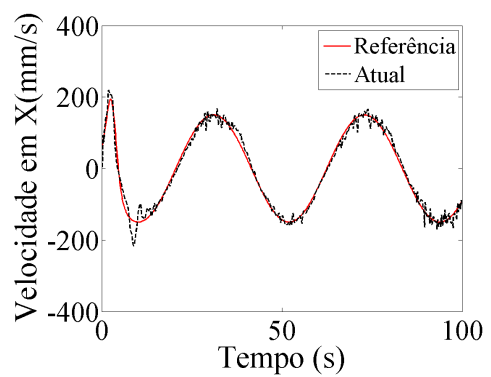

(d) Velocidade em $X$.

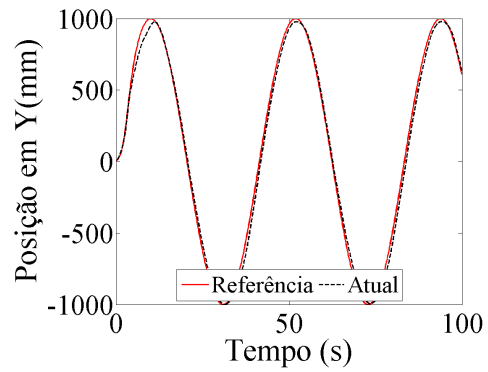

(b) Trajetória em $Y$.

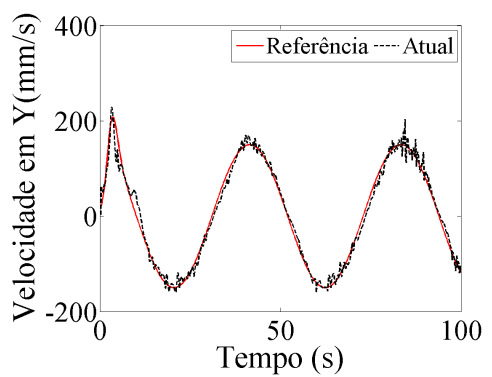

(e) Velocidade em $Y$.

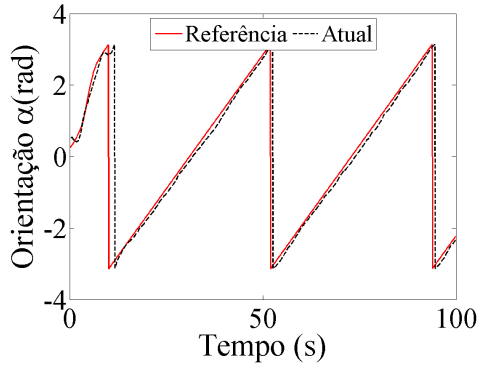

(c) Orientação.

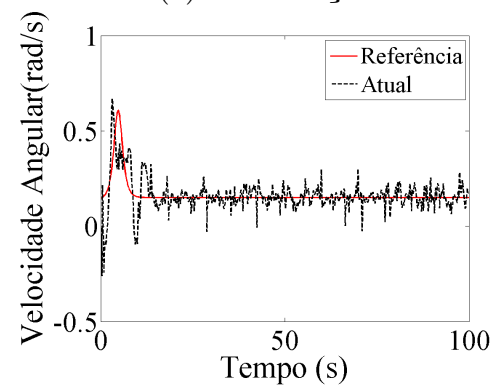

(f) Velocidade angular.

Figura 23 - Resultados experimentais com controlador PD no RMTD.

No intuito de validar as práticas foram realizados 10 testes para cada situação (sem ou com incerteza) em cada controlador, e foi considerada a média entre estes testes. A tabela 3 exibe os resultados experimentais, comparando os controladores RLQ-R, $\mathcal{H}_{\infty}$-TJ 
e PD. Na comparação, foram utilizados os seguintes índices de desempenho:

a) $\mathcal{L}_{2}$ norma do erro de posição e orientação (entre o real e a referência).

$$
\mathcal{L}_{2}(\text { erro })=\sqrt{\sum_{1}^{N} \mid \text { erro }\left._{i}\right|^{2}}
$$

b) Consumo de energia em relação à tensão

$$
E(e)=\sum_{1}^{N}\left|e_{e}\right|+\sum_{1}^{N}\left|e_{d}\right|
$$

Tabela 3 - Comparativo entre os controladores.

\begin{tabular}{|c|ccc|ccc|}
\hline & \multicolumn{4}{|c|}{ Sem incertezas } & \multicolumn{4}{c|}{ Com incerteza de 1kg } \\
Índice[Unidade] & PD & R-LQR & $\mathbf{H}_{\infty}$-TJ & PD & R-LQR & $\mathbf{H}_{\infty}$-TJ \\
\hline $\mathcal{L}_{2}\left(\right.$ erro $\left._{x}\right)[\mathrm{mm}]$ & 1,334 & 1,147 & 1,229 & 1,46 & 1,318 & 1,367 \\
$\mathcal{L}_{2}\left(\right.$ erro $\left._{y}\right)[\mathrm{mm}]$ & 1,124 & 1,086 & 1,194 & 1,541 & 1,308 & 1,445 \\
$\mathcal{L}_{2}\left(\right.$ erro $\left._{\alpha}\right)\left[^{\circ}\right]$ & 3,646 & 1,838 & 3,427 & 4,289 & 2,166 & 4,229 \\
$E(e)[\mathrm{V}]$ & 1801,856 & 1403,337 & 1826,833 & 2015,01 & 1532,153 & 2057,969 \\
\hline
\end{tabular}

\subsubsection{Análise dos Experimentos}

Mediante a Tabela 3, verifica-se que os resultados do RLQ-R são melhores que os demais controladores, tanto em relação aos erros de postura $(x, y$ e $\alpha)$ quanto no consumo de energia.

Além disso, no que diz respeito a execução, o controlador PD exibiu menor custo computacional, de rápida e fácil implementação.

O controlador $\mathcal{H}_{\infty}$-TJ apresentou maior facilidade na sintonia de seus parâmetros através do algoritmo apresentado em Chen, Lee e Feng (1994). Contudo, a necessidade da condição da matriz $\left(C_{2}\left(\dot{q}_{1}\right)-\frac{1}{2} \dot{M}_{2}\right)$ ser antissimétrica, impede a inclusão da dinâmica do atuador, neste caso o motor CC, no modelo dinâmico do robô móvel e de calcular diretamente a tensão de entrada.

Já o RLQ-R demonstrou maior peso computacional e exigiu maior experiência do usuário para sintonia dos seus parâmetros. Entretanto, devido a sua característica recursiva e por levar em conta as incertezas do modelo, este alcançou melhor resultado em relação a trajetória e a orientação. Além do mais, a aplicação RLQ-R exige menos condições do modelo dinâmico do RMTD que o controlador $\mathcal{H}_{\infty}$-TJ. 


\subsection{Interface de comunicação para VANTs}

Recentemente, o desenvolvimento de VANTs, ou popularmente conhecidos como drones, cresceu exponencialmente devido à melhoria das baterias e aumento do rendimento dos motores, ao ponto de seus preços se tornarem acessíveis à maioria da população.

Em geral, eles são fabricados por companhias privadas sem haver entres elas um padrão em comum e aberto de comunicação entre os rádios e as aeronaves. Isso dificulta embarcar ou alterar o controle destes veículos. Além do mais, desenvolver uma comunicação sem fio própria entre rádio-aeronave é uma tarefa muito complexa, pois demanda um vasto conhecimento para atender vários requisitos como: portabilidade; consumo de energia reduzido; imunidade à presença de outros comunicadores; robustez em relação às interferências elétricas externas e internas (motores); recuperação em casos de falha.

A partir dessas exigências na comunicação, é interessante utilizar os rádios existentes (hardware privado) como meios de comunicar computadores com VANTs. Dentre as soluções encontradas, tem-se a interface de comunicação PCTx do fabricante Endurance R/C LLC, que é uma interface de hardware aberto e firmware gratuito (código não livre), o que permite qualquer pessoa construir a sua. Para este trabalho foi construída essa interface conforme apresentado na Figura 24.

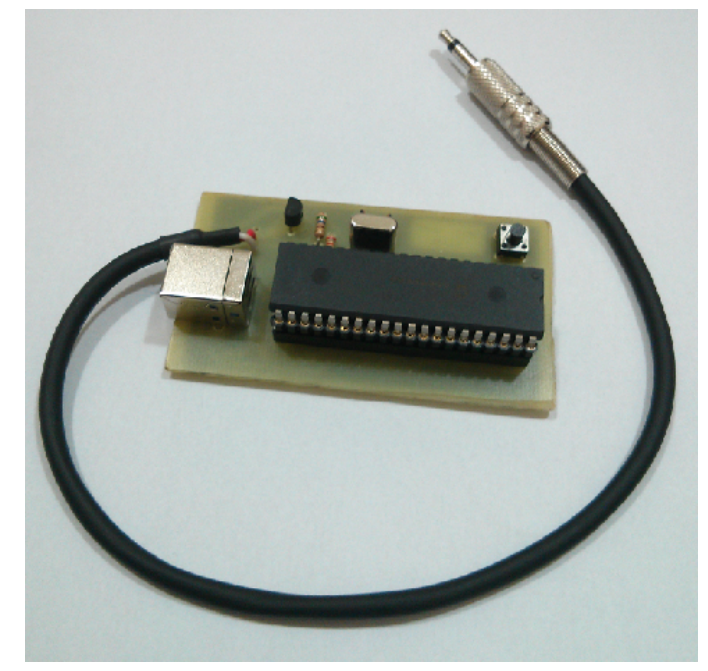

Figura 24 - Interface PCTx.

A comunicação do PCTx com o computador é via USB, sendo desenvolvida com USB class tipo Human Interface Device (HID). Essa classe de comunicação caracteriza-se por ser plug and play, o que a faz popular em todos os teclados e mouses atuais. No entanto, essa classe de comunicação tem o inconveniente de não ser difundida nas linguagens de programação, inclusive o MATLAB.

A partir disso, foi decidido desenvolver uma interface eletrônica entre o computador e o rádio, com a classe Communication Device Class (CDC) que emula uma porta serial via USB e que possui funções nativas no MATLAB. Esta interface ao ser conectada ao 
computador, via USB, permite que o rádio transmita os comandos, aos servomotores do quadricóptero, calculados pelo controle.

A seguir, é apresentado como foi desenvolvida a interface PC-rádio para este trabalho.

\subsubsection{Circuito Eletrônico}

O circuito eletrônico foi desenvolvido com um microcontrolador PIC 18F4520 da Microchip ${ }^{\circledR}$ e um módulo conversor USB-UART CP2102, de acordo com os itens especificados na Tabela 4.

Tabela 4 - Lista de materiais do circuito eletrônico

\begin{tabular}{|c|c|}
\hline Sigla & Descrição \\
\hline B1 & Chave Táctil (Push-bottom) \\
C1 & Capacitor Poliester $0,1 \mu \mathrm{F} \mathrm{x} \mathrm{50V}$ \\
C2 & Capacitor cerâmico $15 \mathrm{pF}$ \\
C3 & Capacitor cerâmico 15pF \\
C4 & Capacitor Cerâmico Multicamadas 220nF \\
D1 & Diodo de proteção (gravação) \\
J1 & Plug mono P2 \\
J3 & Conector para gravação do PIC \\
J2 & Conector fêmea USB tipo B \\
R1 & Resistência $1 \mathrm{k} \Omega$ \\
R2 & Resistência 2,2k $\Omega$ \\
R3 & Resistência $560 \Omega$ \\
T1 & Transistor bipolar $2 \mathrm{~N} 4401-\mathrm{k} 40$ \\
U1 & Microcontrador PIC18F4520 \\
U2 & Módulo conversor Serial-UART CP2102 \\
X1 & Cristal oscilador $20 \mathrm{MHz}$ \\
\hline
\end{tabular}

As Figuras 25, 26 e 27 mostram o layout da placa, o esquema de montagem e a placa construída, respectivamente.

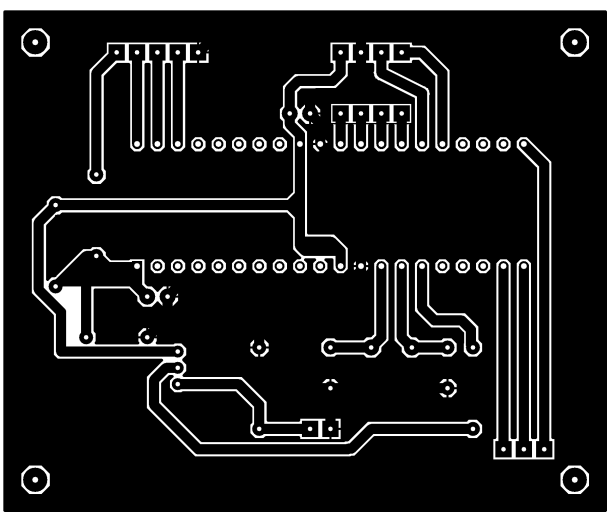

Figura 25 - Layout da placa da interface PC-rádio. 


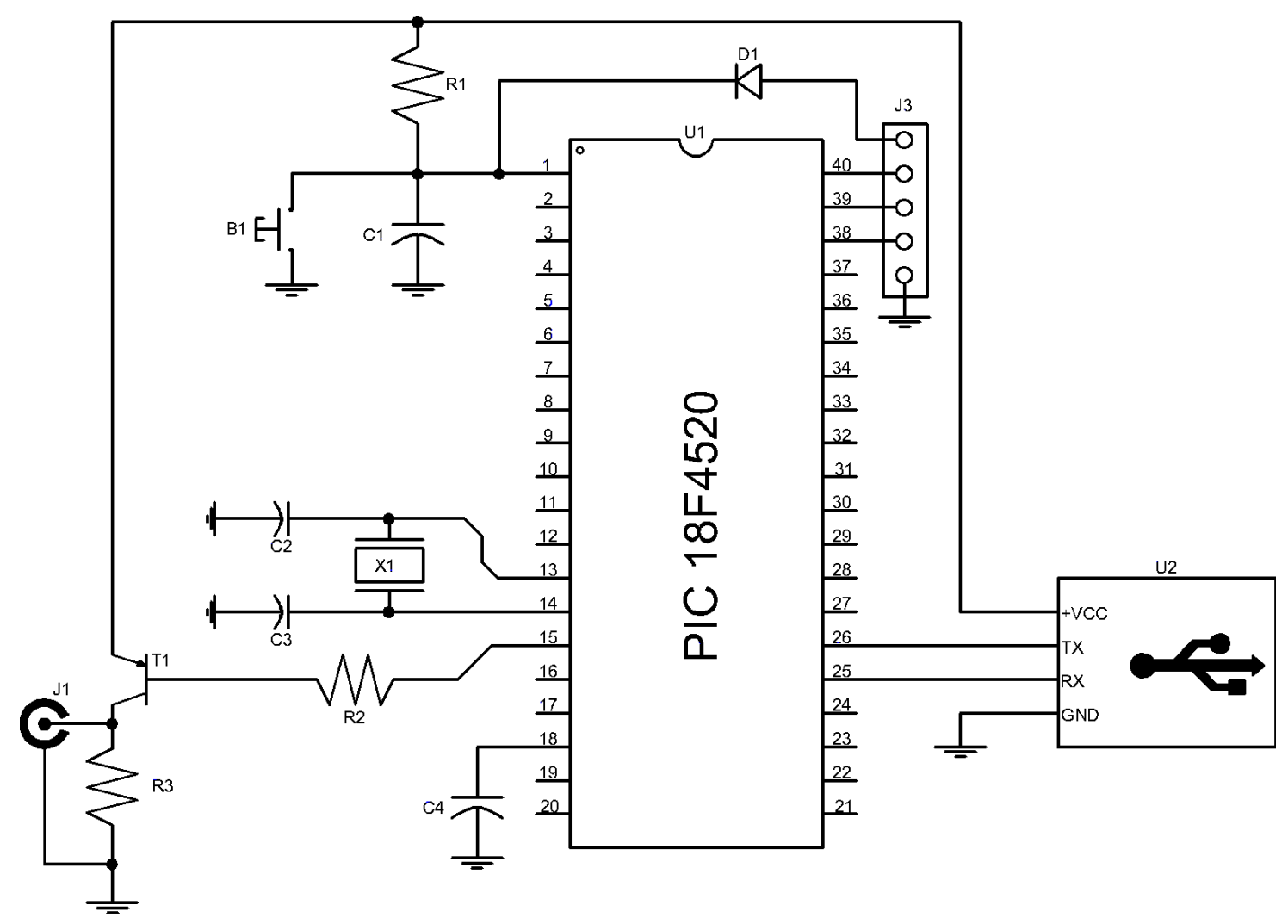

Figura 26 - Esquemático da interface PC-rádio.

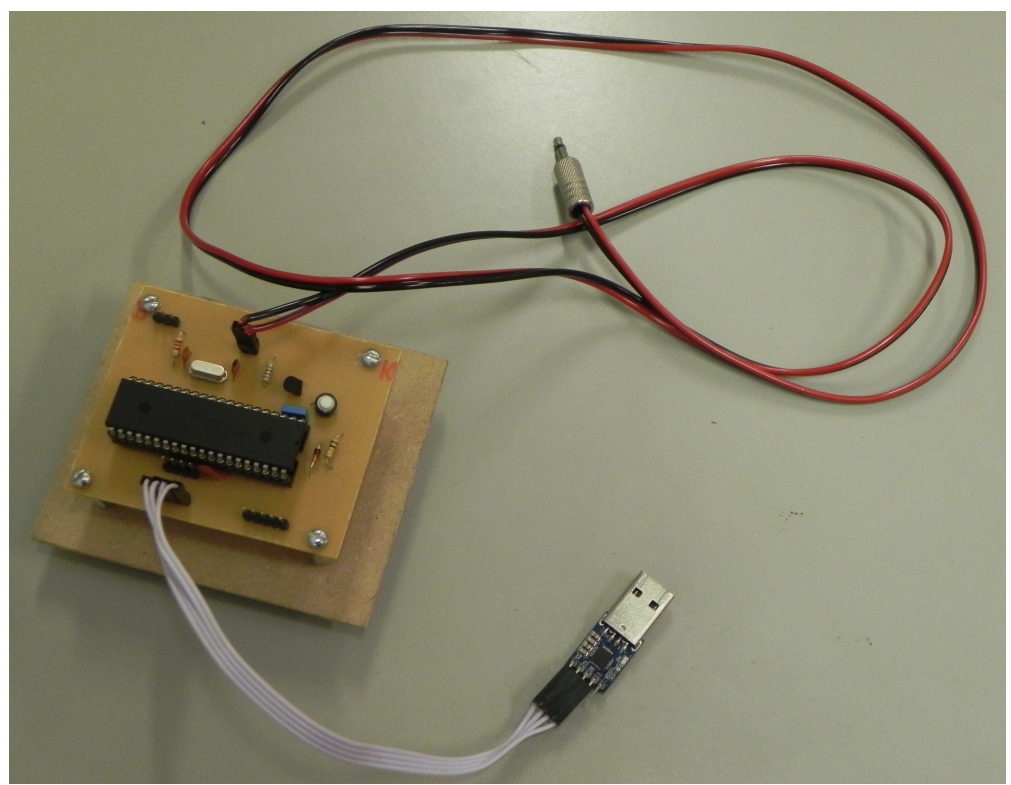

Figura 27 - Interface PC-rádio construída.

\subsubsection{Comunicação do Rádio}

A primeira etapa do projeto, consistiu-se em descobrir como é feita a comunicação entre o computador e o rádio. Em laboratório, com auxílio do osciloscópio e através do 
sinal enviado pelo PCTx ao rádio verificou-se que a informação do computador é modulada através da técnica Pulse Position Modulation (PPM), com polarização invertida, que é a mesma utilizada em servomotores analógicos, conforme Figura 28.

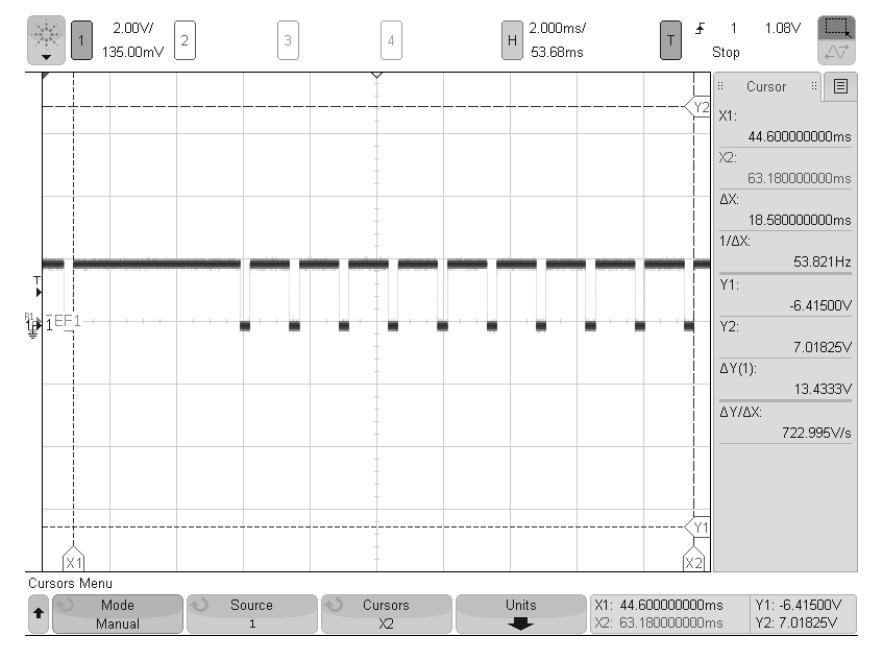

Figura 28 - Sinal PPM para 9 canais.

A codificação PPM consiste no envio da informação através de um sinal com as seguintes características:

- amplitude fixa;

- cada canal separado por um pulso fixo de $300 \mu$ s;

- o frame inicia com um pulso de sincronismo;

- cada sinal possui duração de $0,7 \mathrm{~ms}$ a $1,7 \mathrm{~ms}$, ou 1 a $2 \mathrm{~ms}$, levando em conta o pulso de separação entre canais;

- polarização normal, para sinal de pulso de separação em nível baixo, ou polarização invertida, para sinal de pulso de separação em nível alto.

O rádio utilizado para controle do quadricóptero é o modelo DX7s da Specktrum, com 7 canais, com tecnologia de transmissão DSM2/DSMX de sinal sem fio de 2,4GHz, conforme a Figura 29.

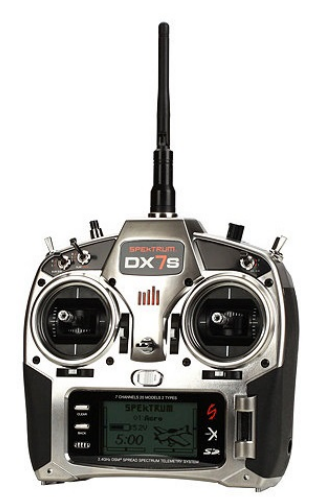

Figura 29 - Rádio DX7s da Spectrum. 
Na parte traseira dele há uma entrada fêmea, do tipo conector P2 mono, para o modo Trainer que pode é utilizado em softwares específicos para treinamento do piloto e para ensino supervisionado de operador. Esse último é realizado conectando dois rádios: um master e outro slave, através da ligação de um cabo inserido nas portas trainers. O comando da aeronave é cedido do rádio master para o slave, sendo que o primeiro pode tomar a autorização quando ele solicitar.

Assim, a placa eletrônica, desenvolvida para interfacear o computador com o rádio, emula um rádio slave, o que permite, através de uma comunicação CDC na entrada USB do computador, enviar comandos para um rádio master que está conectado com uma aeronave.

Ensaios experimentais não foram realizados com o quadricóptero devido ao desconhecimento dos parâmetros da aeronave adquirida no laboratório. Trabalhos futuros podem focar na obtenção desses, permitindo reproduzir e analisar na prática os controladores aplicados em simulação. 


\section{Conclusão}

No presente trabalho, modificou-se o modelo do robô móvel com tração diferencial através da inclusão do modelo do atuador e a mudança do torque para tensão elétrica como variável de entrada. Essa mudança permitiu melhor compreensão do robô e ajuste dos controladores para a proposta desejada de acompanhamento de trajetória.

Após a modelagem, realizou-se uma análise comparativa entre três controladores aplicados no problema de acompanhamento de trajetória de um robô móvel com tração diferencial e em um quadricóptero. A partir de simulações e ensaios experimentais apresentouse melhor desempenho do RLQ-R, em relação aos demais controladores, diante de incertezas paramétricas no modelo utilizado.

Além disso, foi desenvolvida uma interface de comunicação entre o computador e rádio de aeromodelismo, que pode ser utilizada em diversos veículos aéreos não-tripulados como: quadricópteros, helicópteros e aviões. Essa etapa permitiu compreender a mecânica, a eletrônica e a lógica de operação dos quadricópteros.

Outro destaque a ser dado é a aplicação do sistema de captura de movimento em robótica. Esses sistemas têm como vantagens o fornecimento da posição e a orientação dos veículos com alta precisão, imunidade à vibrações e robustez em relação à variação de iluminação.

Os resultados obtidos sugerem trabalhos a serem desenvolvidos no futuro. Dentre eles, a aplicação de um Regulador Robusto com salto Markoviano para lidar com falhas de comunicação na captura da posição pelas câmeras, provenientes de perdas de pacotes na intranet ou falha na identificação do objeto devido à oclusão de marcadores.

Outra proposta seria a identificação dos parâmetros dos quadricópteros adquiridos para aplicação experimental dos controles aqui simulados. 


\section{Referências}

ABEYWARDENA, D. et al. Model-aided state estimation for quadrotor micro air vehicles amidst wind disturbances. In: Intelligent Robots and Systems (IROS 2014), 2014 IEEE/RSJ International Conference on. Chicago, IL: IEEE, 2014. p. $4813-4818$.

ANEESH, D. Tracking controller of mobile robot. In: Computing, Electronics and Electrical Technologies (ICCEET), 2012 International Conference on. Kumaracoil: IEEE, 2012. p. 343-349.

AZAD, P. et al. Stereo-based markerless human motion capture for humanoid robot systems. In: Robotics and Automation, 2007 IEEE International Conference on. Roma: IEEE, 2007. p. 3951-3956. ISSN 1050-4729.

BASAR, T.; BERNHARD, P. $\mathbf{H}_{\infty}$-optimal control and related minimax design problems: a dynamic game approach. Boston: Birkhäuser, 1991. ISBN 9780817635541.

BASAR, T.; OLSDER, G. Dynamic Noncooperative Game Theory. 2. ed. London: Society for Industrial and Applied Mathematics, 1998.

BILLS, C.; CHEN, J.; SAXENA, A. Autonomous MAV flight in indoor environments using single image perspective cues. In: Robotics and Automation (ICRA), 2011 IEEE International Conference on. Shanghai: IEEE, 2011. p. 5776-5783. ISSN 1050-4729.

BILLS, C.; YOSINSKI, J. MAV Stabilization using Machine Learning and Onboard Sensors. Cornell University, 2010.

BLOCH, A.; MCCLAMROCH, N. Control of mechanical systems with classical nonholonomic constraints. In: Decision and Control, 1989., Proceedings of the 28th IEEE Conference on. Tampa, FL: IEEE, 1989. v. 1, p. 201-205.

BLOCH, A.; REYHANOGLU, M. Controllability and stabilizability properties of a nonholonomic control system. In: Decision and Control, 1990., Proceedings of the 29th IEEE Conference on. Honolulu, HI: IEEE, 1990. v. 3, p. 1312-1314.

BOUABDALLAH, S.; NOTH, A.; SIEGWART, R. PID vs LQ control techniques applied to an indoor micro quadrotor. In: Intelligent Robots and Systems, 2004. (IROS 
2004). Proceedings. 2004 IEEE/RSJ International Conference on: IEEE, 2004. v. 3, p. 2451-2456.

BOUADI, H.; BOUCHOUCHA, M.; TADJINE, M. Sliding mode control based on backstepping approach for an UAV type-quadrotor. World Academy of Science, Engineering and Technology, 2007. v. 20, p. 22-27, 2007.

BREZAK, M.; PETROVIC, I.; PERIC, N. Experimental comparison of trajectory tracking algorithms for nonholonomic mobile robots. In: Industrial Electronics, 2009. IECON '09. 35th Annual Conference of IEEE. Porto: IEEE, 2009. p. 2229-2234. ISSN 1553-572X.

BROCKETT, R. Asmpototic stability and feedback stabilization. Differential Geometric Control Theory, 1983. Birkhauser, p. 181-191, 1983.

CAMPION, G.; BASTIN, G.; DANDREA-NOVEL, B. Structural properties and classification of kinematic and dynamic models of wheeled mobile robots. Robotics and Automation, IEEE Transactions on, 1996. v. 12, n. 1, p. 47-62, Feb 1996. ISSN 1042-296X.

CASTILlo, P.; LOZANO, R.; DZUL, A. E. Modelling and Control of Mini-Flying Machines. 1. ed. London: Springer, 2005.

CHEN, B. S.; LEE, T. S.; FENG, J. H. A nonlinear $\mathcal{H}_{\infty}$ control design in robotic systems under parameter perturbation and external disturbance. International Journal of Control, 1994. v. 59, n. 2, p. 439-461, 1994.

CHWA, D. Tracking control of differential-drive wheeled mobile robots using a backstepping-like feedback linearization. Systems, Man and Cybernetics, Part A: Systems and Humans, IEEE Transactions on, 2010. v. 40, n. 6, p. 1285-1295, Nov. 2010. ISSN 1083-4427.

COELHO, P.; NUNES, U. Lie algebra application to mobile robot control: A tutorial. Robotica, 2003. Cambridge University Press, New York, NY, USA, v. 21, n. 5, p. 483-493, out. 2003. ISSN 0263-5747.

CRAIG, J. Introduction to Robotics: Mechanics and Control. 3. ed. London: Pearson/Prentice Hall, 2005. ISBN 9780201543612.

CUI, Y.; INANC, T. Multiple air robotics indoor testbed. In: Control and Decision Conference (CCDC), 2012 24th Chinese. Taiyuan: IEEE, 2012. p. 3487-3492.

DAVIS, E.; NIZETTE, B.; YU, C. Development of a low cost quadrotor platform for swarm experiments. In: 32nd Chinese Control Conference (CCC), 2013. Xi'an: IEEE, 2013. p. 7072-7077.

DONG, H.; SUN, D.; TSO, S. Tracking control of differential mobile robots using adaptive coupling scheme. In: Control, Automation, Robotics and Vision, 2002. ICARCV 2002. 7th International Conference on. Singapore: IEEE, 2002. v. 3, p. 1138-1143.

DUBE, C. Experimental validation of tip over stability of a tracked mobile manipulator. In: AFRICON, 2013. Pointe-Aux-Piments: IEEE, 2013. p. 1-6. ISSN 2153-0025. 
ESCARENO, J.; SALAZAR-CRUZ, S.; LOZANO, R. Embedded control of a four-rotor UAV. In: American Control Conference, 2006. Minneapolis, MN: IEEE, 2006. p. 6 pp.-.

FAIGL, J. et al. Surveillance planning with localization uncertainty for UAVs. In: 3rd Israeli Conference on Robotics. Ariel: Ariel University Center, 2010.

FENG, L.; KOREN, Y.; BORENSTEIN, J. A model-reference adaptive motion controller for a differential-drive mobile robot. In: Robotics and Automation, 1994. Proceedings., 1994 IEEE International Conference on. San Diego, CA: IEEE, 1994. p. 3091-3096 vol.4.

FIGUEIREDO, L. C.; JOTA, F. G. Introdução ao controle de sistemas não-holonômicos. Sba: Controle \& Automação Sociedade Brasileira de Automatica, 2004. Scielo, v. 15, p. 243 - 268, 09 2004. ISSN 0103-1759.

GARCIA, P.; LOZANO, R.; DZUL, A. Modelling and Control of Mini-Flying Machines. London: Springer, 2006. (Advances in Industrial Control). ISBN 9781846281792 .

HIGUCHI, K.; SHIMADA, T.; REKIMOTO, J. Flying sports assistant: External visual imagery representation for sports training. In: Proceedings of the 2nd Augmented Human International Conference. New York, NY, USA: ACM, 2011. (AH '11), p. 7:1-7:4. ISBN 978-1-4503-0426-9.

HOFFMANN, G. M. et al. Quadrotor helicopter flight dynamics and control: Theory and experiment. In: In Proc. of the AIAA Guidance, Navigation, and Control Conference. Hilton Head, South Carolina: American Institute of Aeronautics and Astronautics, 2007.

HOU, Z.-G. et al. Adaptive control of an electrically driven nonholonomic mobile robot via backstepping and fuzzy approach. Control Systems Technology, IEEE Transactions on, 2009. v. 17, n. 4, p. 803-815, July 2009. ISSN 1063-6536.

HU, Y.; GE, S.; SU, C.-Y. Stabilization of uncertain nonholonomic systems via time-varying sliding mode control. Automatic Control, IEEE Transactions on, 2004. v. 49, n. 5, p. 757-763, May 2004. ISSN 0018-9286.

HUANG, H. et al. Aerodynamics and control of autonomous quadrotor helicopters in aggressive maneuvering. In: Robotics and Automation, 2009. ICRA '09. IEEE International Conference on. Kobe: IEEE, 2009. p. 3277-3282. ISSN 1050-4729.

HWANG, C.-L.; WU, H.-M. Trajectory tracking of a mobile robot with frictions and uncertainties using hierarchical sliding-mode under-actuated control. Control Theory Applications, IET, 2013. v. 7, n. 7, p. 952-965, May 2013. ISSN 1751-8644.

INOUE, R. et al. Robust recursive control of a skid-steering mobile robot. In: Advanced Robotics (ICAR), 2013 16th International Conference on. Montevideo: IEEE, 2013. p. 1-6.

INOUE, R. S. Controle Robusto descentralizado de movimentos coordenados de robôs heterogêneos. Tese (Doutorado) — Escola de Engenharia de São Carlos da Universidade de São Paulo, 2011. 
JOHANSSON, R. Quadratic optimization of motion coordination and control. Automatic Control, IEEE Transactions on, 1990. v. 35, n. 11, p. 1197-1208, Nov 1990. ISSN 0018-9286.

KANAYAMA, Y. et al. A stable tracking control method for an autonomous mobile robot. In: Robotics and Automation, 1990. Proceedings., 1990 IEEE International Conference on. Cincinnati, OH: IEEE, 1990. p. 384-389 vol.1.

KANG, H. jin et al. Biped walking stabilization on soft ground based on gait analysis. In: Biomedical Robotics and Biomechatronics (BioRob), 2012 4th IEEE RAS EMBS International Conference on. Rome: IEEE, 2012. p. 669-674. ISSN 2155-1774.

KHALAJI, A.; MOOSAVIAN, S. Robust adaptive controller for a tractor-trailer mobile robot. Mechatronics, IEEE/ASME Transactions on, 2014. v. 19, n. 3, p. 943-953, June 2014. ISSN 1083-4435.

KHALIL, H. Nonlinear Systems. 2. ed. New Jersey, United States: Prentice Hall, 1996. ISBN 9780132280242.

KOLMANOVSKY, I.; MCCLAMROCH, N. Developments in nonholonomic control problems. Control Systems, IEEE, 1995. v. 15, n. 6, p. 20-36, Dec. 1995. ISSN 1066-033X.

KRISHNAN, R. Electric Motor Drives: Modeling, Analysis, and Control. New Jersey, United States: Prentice Hall, 2001. ISBN 9780130910141.

LARIBI, M. et al. Toward new minimally invasive surgical robotic system. In: Industrial Technology (ICIT), 2012 IEEE International Conference on. Athens: IEEE, 2012. p. 504-509.

A new teleoperated robotic system for minimally invasive surgery : Modeling and identification. In: Control, Decision and Information Technologies (CoDIT), 2013 International Conference on. Hammamet: IEEE, 2013. p. 659-664.

LI, J. et al. Computer-assisted hand rehabilitation assessment using an optical motion capture system. In: Image Analysis and Signal Processing (IASP), 2012 International Conference on. Hangzhou: IEEE, 2012. p. 1-5.

LUENBERGER, D. G. Linear and Nonlinear Programming. 2. ed. Boston: Springer, 2003. ISBN 9781402075933.

LUUKKONEN, T. Modelling and control of quadcopter. Independent research project in applied mathematics, Espoo, 2011. Aalto University School of Science, 2011.

MARTINS, N. et al. Trajectory tracking of a nonholonomic mobile robot with parametric and nonparametric uncertainties: A proposed neural control. In: Control and Automation, 2008 16th Mediterranean Conference on. Ajaccio: IEEE, 2008. p. 315-320. 
MAUROVIC, I.; BAOTIC, M.; PETROVIC, I. Explicit model predictive control for trajectory tracking with mobile robots. In: Advanced Intelligent Mechatronics (AIM), 2011 IEEE/ASME International Conference on. Budapest: IEEE, 2011. p. 712-717. ISSN 2159-6247.

METCALF, C. et al. Markerless motion capture and measurement of hand kinematics: Validation and application to home-based upper limb rehabilitation. Biomedical Engineering, IEEE Transactions on, 2013. IEEE, v. 60, n. 8, p. 2184-2192, Aug 2013. ISSN 0018-9294.

NG, W. S.; SHARLIN, E. Collocated interaction with flying robots. In: RO-MAN, 2011 IEEE. Atlanta, GA, USA: IEEE, 2011. p. 143-149.

ORIOLO, G.; LUCA, A. D.; VENDITTELLI, M. Wmr control via dynamic feedback linearization: design, implementation, and experimental validation. Control Systems Technology, IEEE Transactions on, 2002. v. 10, n. 6, p. 835-852, Nov 2002. ISSN 1063-6536.

PARK, B. S. et al. Adaptive neural sliding mode control of nonholonomic wheeled mobile robots with model uncertainty. Control Systems Technology, IEEE Transactions on, 2009. v. 17, n. 1, p. 207-214, Jan 2009. ISSN 1063-6536.

A simple adaptive control approach for trajectory tracking of electrically driven nonholonomic mobile robots. Control Systems Technology, IEEE Transactions on, 2010. v. 18, n. 5, p. 1199-1206, Sept 2010. ISSN 1063-6536.

RAFFO, G. V.; ORTEGA, M. G.; RUBIO, F. R. An integral predictive/nonlinear $\mathcal{H}_{\infty}$ control structure for a quadrotor helicopter. Automatica, 2010. v. 46, n. 1, p. 29-39, 2010.

RASHID, R. et al. Differential drive wheeled mobile robot (WMR) control using fuzzy logic techniques. In: Mathematical/Analytical Modelling and Computer Simulation (AMS), 2010 Fourth Asia International Conference on. Kota Kinabalu, Malaysia: IEEE, 2010. p. 51-55.

REIS, G. dos; SIQUEIRA, A.; TERRA, M. Nonlinear $\mathcal{H}_{\infty}$ Control via quasiLPV representation and game theory for wheeled mobile robots. In: Intelligent Control, 2005. Proceedings of the 2005 IEEE International Symposium on, Mediterrean Conference on Control and Automation. Limassol: IEEE, 2005. p. 686-691.

RIGATOS, G.; SIANO, P. An H-infinity feedback control approach to autonomous robot navigation. In: Industrial Electronics Society, IECON 2014 - 40th Annual Conference of the IEEE. Dallas, TX: IEEE, 2014. p. 2689-2694.

SAYED, A. H.; NASCIMENTO, V. H. Design criteria for uncertain models with structured and unstructured uncertainties. In: Robustness in Identification and Control. Los Angeles, CA: Springer London, 1999. v. 245, p. 159 - 173. ISBN 978-1-85233-179-5.

SHAN, J.; WANG, X. Experimental study on mobile robot navigation using stereo vision. In: Robotics and Biomimetics (ROBIO), 2013 IEEE International Conference on. Shenzhen: IEEE, 2013. p. 1958-1965. 
SHOJAEI, K.; SHAHRI, A. Output feedback tracking control of uncertain nonholonomic wheeled mobile robots: a dynamic surface control approach. Control Theory Applications, IET, 2012. v. 6, n. 2, p. 216-228, January 2012. ISSN 1751-8644.

TERRA, M.; CERRI, J.; ISHIHARA, J. Optimal robust linear quadratic regulator for systems subject to uncertainties. Automatic Control, IEEE Transactions on, 2014. v. 59, n. 9, p. 2586-2591, 2014.

VICON. Motion Capture System. 20 de Março 2012. Disponível em: <http://www.vicon.com/>.

Vicon DataStream SDK Developer's Manual. Vicon Motion System Limited, 2013.

ZARROUK, D.; SHARF, I.; SHOHAM, M. Conditions for worm-robot locomotion in a flexible environment: Theory and experiments. Biomedical Engineering, IEEE Transactions on, 2012. v. 59, n. 4, p. 1057-1067, April 2012. ISSN 0018-9294.

ZEMALACHE, K.; BEJI, L.; MARREF, H. Control of an under-actuated system: application a four rotors rotorcraft. In: Robotics and Biomimetics (ROBIO). 2005 IEEE International Conference on. Shatin: IEEE, 2005. p. 404-409.

ZONG, C.; CLADY, X.; CHETOUANI, M. An embedded human motion capture system for an assistive walking robot. In: Rehabilitation Robotics (ICORR), 2011 IEEE International Conference on. Zurich: IEEE, 2011. p. 1-6. ISSN 1945-7898.

ZUO, Z. Trajectory tracking control design with command-filtered compensation for a quadrotor. Control Theory Applications, IET, 2010. v. 4, n. 11, p. 2343-2355, November 2010. ISSN 1751-8644. 